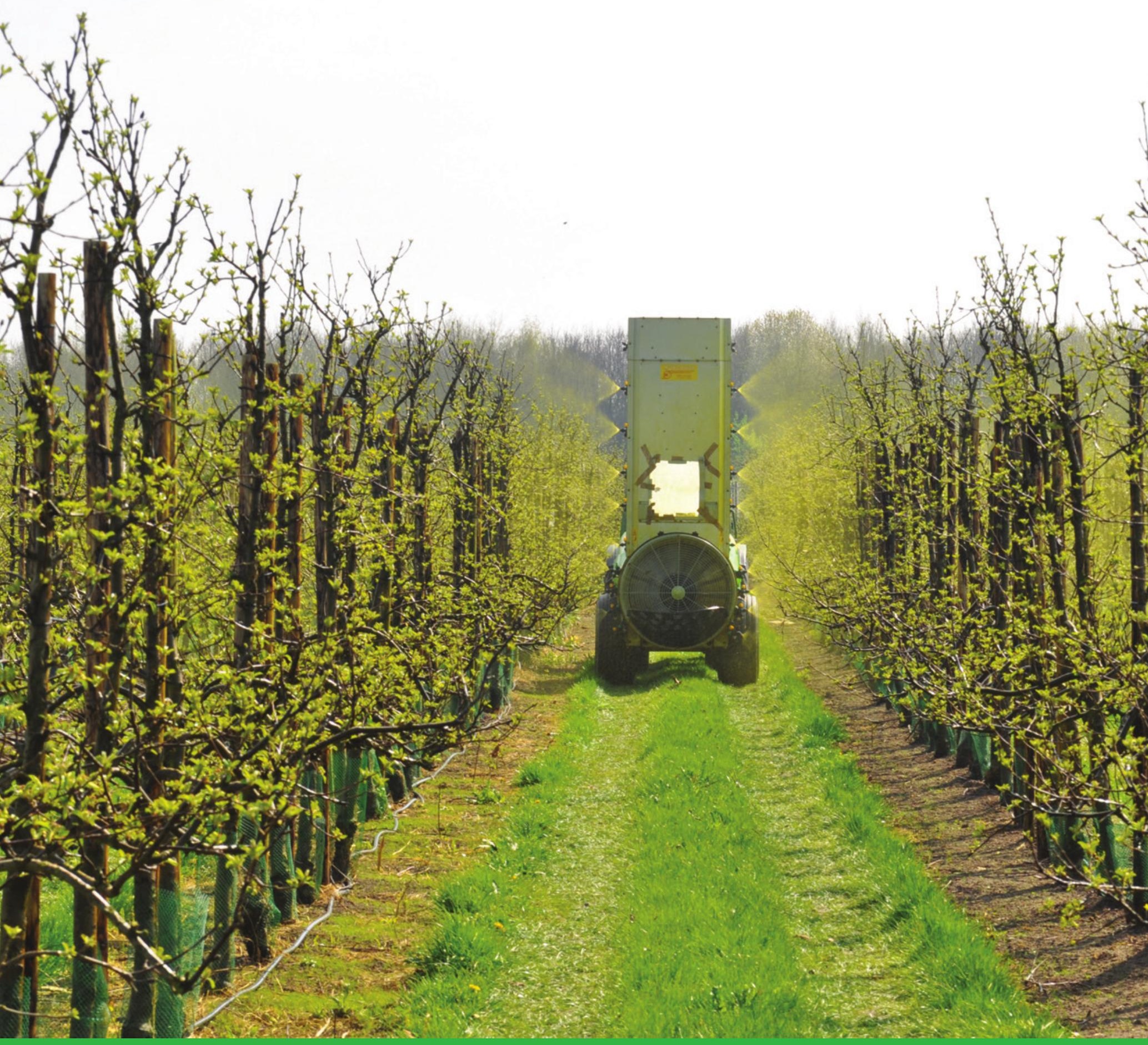

\title{
Development of a spray drift model for spray applications in fruit orchards
}





\section{Development of a spray drift model for spray applications in fruit orchards}

H.J. Holterman, J.C. van de Zande, J.F.M. Huijsmans, M. Wenneker

This study was carried out by the Wageningen Research Foundation (WR) business unit Agrosystems Research and was commissioned and financed by the Dutch Ministry of Agriculture, Nature and Food Quality (LNV) (project number BO-20-002-003).

WR is part of Wageningen University \& Research, the collaboration of Wageningen University and Wageningen Research Foundation.

Wageningen, February 2018

Report WPR-566 
Holterman, H.J., J.C. van de Zande, J.F.M. Huijsmans, M. Wenneker, 2018. Development of a spray drift model for spray applications in fruit orchards. Wageningen Research, Report WPR-566. 72 pp.; 44 fig.; 16 tab.; 18 ref.

This report can be downloaded for free at https://doi.org/10.18174/442091

An innovative model has been developed for downwind deposits of pesticides due to spray drift next to an orchard of pome fruit trees (apple, pear). The SPEXUS model (spray drift exposure for upward and sideways directed sprays) is an empirical model based on 20 years of experimental data of spray drift deposits for conventional cross-flow pesticide applications. The major factors affecting the deposits are downwind distance, wind speed, wind direction, air temperature, density of the tree canopy and size of the orchard. Modelling the canopy density of the trees as a continuous function of time of year is a new approach. Canopy density is uniquely related to the phenological growth stage (identified by the $\mathrm{BBCH}$ index). Experimentally observed features of the effects of the mentioned factors are modelled by selecting appropriate sub-models. These effects are discussed and interpreted. Modelled deposits and measured deposits were compared and gave a correlation coefficient of $86 \%$. Drift reducing techniques were implemented using experimental data on reductions of downwind spray deposits as a function of downwind distance. The SPEXUS model forms the basis for risk assessment for exposure of aquatic organisms concerning all edge-of-field water bodies next to fruit orchards in the Netherlands.

Key words: spray drift, model, pome fruit, surface water, canopy growth stage

(C) 2018 Wageningen, Stichting Wageningen Research, Wageningen Plant Research, Business Unit Agrosystems Research, P.O. Box 16, 6700 AA Wageningen, The Netherlands; T +31 (0)317 480700 ; www.wur.eu/plant-research

Chamber of Commerce no. 09098104 at Arnhem

VAT NL no. 8065.11.618.B01

Stichting Wageningen Research. All rights reserved. No part of this publication may be reproduced, stored in an automated database, or transmitted, in any form or by any means, whether electronically, mechanically, through photocopying, recording or otherwise, without the prior written consent of the Stichting Wageningen Research.

Stichting Wageningen Research is not liable for any adverse consequences resulting from the use of data from this publication.

\section{Report WPR-566}

Photo cover: H.J. Holterman 


\section{Contents}

$\begin{array}{ll}\text { Preface } & 5\end{array}$

$\begin{array}{ll}\text { Summary } & 7\end{array}$

$\begin{array}{lr}\text { Samenvatting } & 9\end{array}$

1

Introduction

11

Spray drift experiments with fruit orchards $\quad 12$

2.1 Survey of experiments 12

2.1.1 Preparing experiments for data analysis 12

2.1.2 Experimental results 13

2.1.3 Single-row experiments $\quad 15$

$\begin{array}{lll}2.2 & \text { Limitation of database content } & 17\end{array}$

$\begin{array}{lll}2.3 & \text { Pairwise correlation } & 17\end{array}$

$\begin{array}{lll}2.4 & \text { Regression analysis } & 20\end{array}$

$\begin{array}{lll}2.5 & \text { First modelling approach } & 21\end{array}$

$\begin{array}{lll}3.1 & \text { Model description } & 22\end{array}$

3.1.1 Basic set-up of the spray drift model $\quad 22$

$\begin{array}{ll}3.1 .2 \text { Wind speed and temperature } & 23\end{array}$

$\begin{array}{ll}3.1 .3 \text { Wind direction } & 25\end{array}$

3.1.4 Orchard size and canopy density $\quad 26$

$\begin{array}{ll}3.1 .5 \text { Canopy density factor } & 27\end{array}$

$\begin{array}{ll}3.1 .6 & \text { Sprayer fan speed } \\ & 29\end{array}$

3.2 Model refinements by curve-fitting $\quad 29$

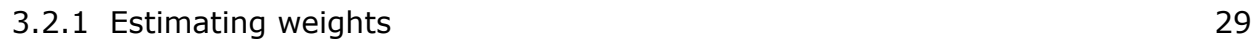

3.2.2 Curve-fitting procedure 30

$\begin{array}{ll}3.2 .3 \text { Curve-fitting results } & 31\end{array}$

3.3 Drift-reducing application techniques $\quad 34$

3.3.1 Drift reduction curves $\quad 34$

3.3.2 Smooth transition between the dormant and full-leaf crop stages 36

$\begin{array}{lll}3.4 & \text { Averaged spray drift deposits onto a water body surface } & 38\end{array}$

$4 \quad$ Examples and applications $\quad 40$

$\begin{array}{lll}4.1 & \text { Spray drift deposits vs. downwind distance } & 40\end{array}$

$\begin{array}{lll}4.2 & \text { Effect of wind speed on downwind deposits } & 41\end{array}$

4.3 Effect of wind direction on downwind deposits 43

4.4 Effect of ambient temperature on downwind deposits $\quad 43$

$\begin{array}{lll}4.5 & \text { Effect of canopy density on downwind deposits } & 44\end{array}$

$5 \quad$ Discussion $\quad 45$

$\begin{array}{llr}6 & \text { Conclusion } & 48\end{array}$

$\begin{array}{ll}\text { References } & 49\end{array}$

$\begin{array}{ll}\text { List of symbols } & 51\end{array}$ 
Annex 2 Estimating the fan speed factor

Annex 3 ВBCH and day-of-year for apple trees

Annex 4 Canopy density factor

61

Annex 5 Alternative interpretation of canopy density effects

63

Annex 6 The Levenberg-Marquardt method

65

Annex 7 The Pattern-Search method

67

Annex 8 Wind speed stratification

68

Annex 9 List of model constants

69

Annex 10 BBCH codes for pome fruit 


\section{Preface}

This report has been produced on behalf of the Dutch Ministry of Agriculture, Nature and Food Quality (LNV) under project number BO-20-002-003. The project aimed at developing pesticide exposure scenarios for aquatic organisms in edge-of-field watercourses next to fruit orchards. Often, in such crops the sprays are applied in upward and sideways direction and exposure for aquatic organisms can be relatively high. This report reflects an essential part of the project, namely the development of the SPEXUS model to describe and estimate downwind deposits of spray drift next to pome fruit orchards. Spray drift is one of the major entry routes for pesticides to reach the edge-of-field watercourses. The SPEXUS model will be implemented in the DRAINBOW exposure model for environmental risk assessments of such watercourses.

For several years, a Dutch working group worked on the evaluation of such risk assessments for aquatic organisms exposed to pesticides. We would like to thank the members who participated in this working group throughout the years for their contribution and fruitful discussions: Paulien Adriaanse, Jos Boesten, Corine van Griethuysen, Mechteld ter Horst, Ton van der Linden, Aaldrik Tiktak, Louise Wipfler. 


\section{Summary}

This report describes a new approach to model and assess the deposits of spray drift in pesticide treatments of pome fruit orchards. The model, named SPEXUS (spray drift exposure for upward and sideways directed sprays), is developed based on data from 20 years of spray drift experiments in apple tree orchards. The empirical model computes downwind spray deposits as a function of distance from the last tree row. Major factor in this computation are wind speed, wind direction, ambient temperature, canopy density of the trees and size of the orchard. Canopy density, identified by the phenological growth stage $\mathrm{BBCH}$, is modelled as a function of time of year. The continuous relationship to canopy density is new and it certainly is a step forward in developing realistic models for spray drift in orchard spraying.

The comparison of measured deposits and modelled deposits shows a correlation coefficient of $86 \%$. Paired deposits indicate that measured deposits are accurate (showing a correlation coefficient of $98 \%$ ). It was concluded that variance between measured and modelled deposits was caused by local and momentary changes in environmental factors like wind speed, wind direction and canopy density of nearby trees. The results indicate that the SPEXUS model can predict downwind deposits depending on average wind speed, average wind direction, air temperature and canopy density. However, local small-scale turbulence and geometrical inhomogeneity of the trees can cause variance in experimental deposits, which cannot be accounted for in the current model.

Experimental data show some remarkable trends particularly in their dependence on wind speed and temperature. The SPEXUS model is designed to reflect this behaviour, though further experiments may be required to verify and better understand these trends. It is recommended that the model should be validated against new experimental data not used in its development. Experimental verification under specific conditions (such as low and high wind speeds and temperatures) would be welcome and may help to strengthen the model.

The model can be used on its own, but it has been implemented in a realistic risk assessment model for aquatic organisms exposed to pesticides applied in fruit orchards for all edge-of-field water bodies in the Netherlands.

The model has been developed for orchards of apple trees in the Netherlands. In principle, the model can be adjusted for other fruit crops and other climate zones by using an appropriate BBCH-to-DOY relationship. 


\section{Samenvatting}

Dit rapport beschrijft een nieuwe benadering in het modelleren en beoordelen van drift van gewasbeschermingsmiddelen toegepast bij bespuitingen in fruitboomgaarden. Het ontwikkelde model, genaamd SPEXUS (spray drift exposure for upward and sideways directed sprays), is gebaseerd op experimentele gegevens van 20 jaar van drift studies in appelboomgaarden. Het empirische model berekent de benedenwindse driftdeposities als functie van de afstand vanaf de laatste bomenrij. De belangrijkste factoren zijn windsnelheid, windrichting, omgevingstemperatuur, bladerdichtheid van de bomen en grootte van het perceel. Bladerdichtheid hangt samen met het fenologische groeistadium en wordt gekarakteriseerd door de $\mathrm{BBCH}$-index. Bladerdichtheid is een functie van het tijdsverloop gedurende het jaar. De continue relatie met bladerdichtheid is nieuw en een duidelijke stap voorwaarts in de ontwikkeling van realistische modellen voor drift in de fruitteelt.

De vergelijking van experimenteel gemeten deposities en modelresultaten levert een correlatiecoëfficiënt van $86 \%$. Paarsgewijze deposities zijn nauwkeurig en geven een correlatiecoëfficiënt van $98 \%$. Hieruit werd geconcludeerd dat de verschillen tussen meetresultaten en modelresultaten veroorzaakt werden door lokale en tijdelijke wisselingen in de omgevingsfactoren windsnelheid, windrichting en bladerdichtheid van nabije bomen. The resultaten tonen aan dat het SPEXUS model de benedenwindse driftdepositie goed kan beschrijven voor gemiddelde windsnelheid, windrichting, temperatuur en bladerdichtheid. Echter, lokale variaties als turbulentie en structurele verschillen tussen bomen veroorzaken variatie in driftdeposities die momenteel niet gemodelleerd kunnen worden.

Experimentele resultaten laten enkele opmerkelijke trends zien, met name in relatie tot windsnelheid en temperatuur. Het SPEXUS model is zodanig ontwikkeld dat het deze trends kan beschrijven.

Weliswaar kunnen aanvullende metingen nodig zijn om dit te verifiëren en beter te kunnen begrijpen. Het wordt aanbevolen het model te valideren aan de hand van metingen die niet gebruikt zijn in de ontwikkeling van het model. Met name metingen onder specifieke omstandigheden (zoals lage en hoge windsnelheden en temperaturen) zijn zeer welkom en kunnen helpen het model te versterken.

Het model kan op zichzelf gebruikt worden, maar het is ook al geïmplementeerd in een realistisch model voor risicobeoordeling bij de blootstelling aan bestrijdingsmiddelen van waterorganismen in waterlopen naast fruitboomgaarden in heel Nederland.

Het model is ontwikkeld voor appelboomgaarden in Nederland. In principe kan het model aangepast worden voor andere fruitgewassen en andere klimaatomstandigheden, door geschikte relaties tussen $\mathrm{BBCH}$ en dag van het jaar toe te passen. 


\section{Introduction}

In crop protection in the Netherlands, the use of chemicals to withstand pests is inevitable. Although ongoing adjustments in application technology keep improving the efficiency in application of pesticide sprays, the loss of chemicals to non-target areas still cannot be prevented completely. Particularly the exposure of edge-of-field watercourses to deposits of spray drift is of major concern. For spray applications in fruit crops, downwind deposits of spray drift are significantly higher than those for field crops, mainly caused by the sideways horizontally-directed application of sprays using common orchard sprayers (Van de Zande et al. 2000). A suitable model to predict the downwind off-target spray deposition next to fruit orchards is of great importance for risk assessments. Yet until now such a model was still lacking. This report deals with the development of the SPEXUS model (spray drift exposure model for upward and sideways directed sprays), an empirical model to estimate downwind deposits of spray drift next to pome fruit orchards. The report offers a comprehensive description of the model published earlier as a journal paper (Holterman et al. 2017).

The model is based on 20 years of experimental results on off-target deposits of spray drift. These experiments were carried out during various times of year, covering all growth stages of the fruit trees. This made it possible to develop a spray drift model that is a continuous function of tree canopy throughout the year. Canopy density and growth stage are described by the phenological BBCH scale $(\mathrm{BBCH} 2001)$ and linked to the day-of-year through expert's observation during the experiments. Other relevant parameters were weather conditions like wind speed, wind direction and ambient temperature.

Chapter 2 deals with the experiments used in the model development. The essential parameters are identified and described. Observed dependence of downwind deposits on these parameters is investigated as well.

In Chapter 3 the SPEXUS model development is described, including the sub-models for each relevant input parameter that can follow the experimentally observed behaviour adequately. The final model consists of many constants; the fine-tuning process to quantify these constants is described. Other aspects, such as the effect of drift reducing application techniques on downwind deposits, are dealt with as well.

Chapter 4 gives example computations and discusses the effects of several input parameters on downwind deposits of spray drift.

Discussion and conclusion of the new model are given in Chapters 5 and 6, respectively. 


\section{Spray drift experiments with fruit orchards}

\subsection{Survey of experiments}

Deposits of spray drift downwind from apple tree orchards have been measured for about 20 years. The major goal of these experiments was to assess various application techniques for spray drift reduction relative to a given standard technique, a commonly used cross-flow fan technique. As a consequence, for this standard application technique a large number of experimental data have been gathered under varying conditions. The standard spray application technique involved a Munckhof cross-flow fan sprayer with common settings in Dutch fruit growing (e.g. Albuz ATR lilac hollow cone nozzles at $700 \mathrm{kPa}$ spray pressure, spraying volume $175-200 \mathrm{~L} / \mathrm{ha}$ ). The fan is set to high speed for the full-leaf situation (May 1 and onwards) and to low speed for the dormant situation (before May 1 ). The spray was directed always towards the trees (indicated by the red arrows in Figure 1). This means that in treating the outer side of the first tree row, the sprayer applied its spray only in one direction. In between tree rows, spray was applied in both directions. This is considered the reference technique in this study. Although the specific experimental layout changed, particularly regarding the number of rows treated and the downwind distances where deposits were sampled, essentially the set-up was the same since 1992. For instance, downwind deposits were determined using a fluorescent tracer dye dissolved in water, the collectors were synthetic filter materials placed on the ground, the filters were washed in the laboratory and the fluorescence of the extracted solution was measured and the deposits were computed from the tracer's concentration. The collectors were placed in two rows on the ground, about $1.5 \mathrm{~m}$ apart, thus giving paired measured deposits for each distance (Figure 1). For the standard application technique, 158 experiments with paired deposits were available from experiments between 1992 and 2011 (Van de Zande et al. 2017). These were treated as 316 experiments, giving a total of 5456 values of spray drift deposition. Paired deposits could have been averaged and treated as one value. However, to gain insight in the variance of a single collector sample, is was decided to treat all samples as individual values.

The orchards consisted of spindle shaped dwarf apple trees; a few different locations were used. Some orchard locations were used for several years. Clearly the trees grew older and each year the trees were pruned. This means that each year the orchard used was not exactly the same as the year before. While this may enhance variance, it will make the results more robust as these are based on essentially different orchards. Actual tree height ranged from $2.25 \mathrm{~m}$ to about $3.0 \mathrm{~m}$. Height changed during the growing season due to the development of new shoots. However, the top part of the trees was relatively open and an average tree height of $2.25 \mathrm{~m}$ was assumed throughout as an equivalent canopy height in the computation of wind speed profiles. The distance between the tree rows was $3.0 \mathrm{~m}$ and distance between trees in a row was $1.0-1.25 \mathrm{~m}$.

\subsubsection{Preparing experiments for data analysis}

Clearly, in 20 years the experimental set-up changed slightly to account for changes of interest or to address certain aspects better. This means that the raw database of experiments needed some preparation to be able to compare data and to do an overall analysis on the results.

For instance, during the years wind speeds were measured at different heights both downwind and above the orchard. Using a logarithmic profile and accounting for orchard height, all wind speeds were adjusted to those at $4 \mathrm{~m}$ above ground level within the orchard area (using the method described in Annex 8). Thus, with an average tree height of $2.25 \mathrm{~m}$, the database now contains wind speeds either measured or estimated at $1.75 \mathrm{~m}$ above the trees.

In some of the earlier experiments, meteorological measurements were incomplete. One or more of the following factors could be lacking: wind speeds, wind direction, temperature or relative humidity. In those cases, meteorological data from the nearest weather station were used at the date and time 
of the experiment. Wind speeds from such a station are measured at $10 \mathrm{~m}$ height. Again, estimates were derived from those values for an in-orchard wind speed at a height of $4 \mathrm{~m}$. Wind speed and direction were averaged over the time required to carry out an experiment (i.e. applying the spray to the given number of tree rows).

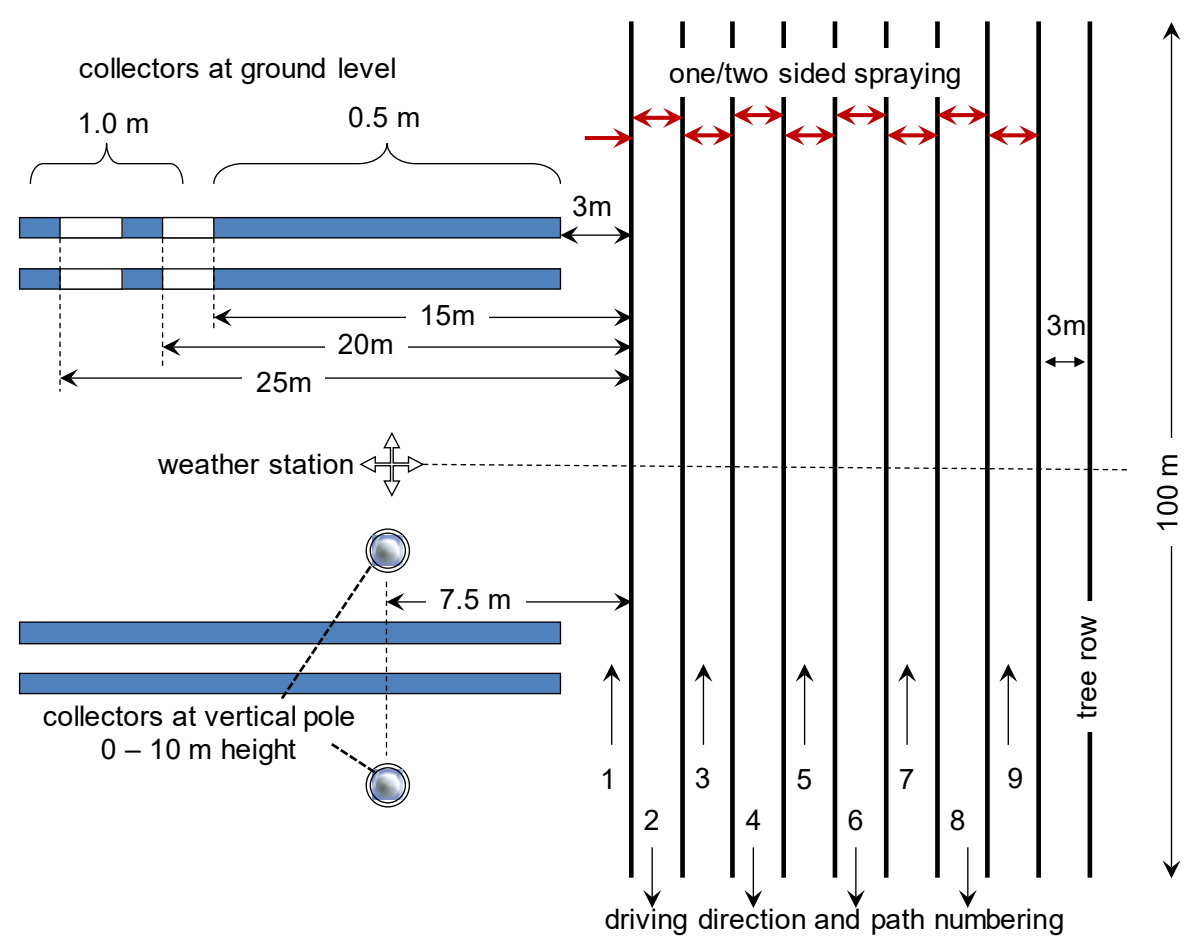

Figure 1 Schematic layout of the experiments measuring downwind spray deposits (Stallinga et al. 2013). Red arrows indicate the direction of spray applied towards the trees.

\subsubsection{Experimental results}

Some experimental results are shown in this section. Figure 2 shows all measured deposits of spray drift as a function of downwind distance. Clearly, deposits of spray drift decrease with increasing distance. Still there is a wide variance in the observed deposits, primarily caused by different environmental conditions (weather conditions, canopy density). Using adequate subsets of the full dataset may help to clarify the effect of individual quantities. For instance, the effect of canopy density becomes clear when looking at drift deposits at a limited distance range. Figure 3 shows spray deposits at a distance $4-6 \mathrm{~m}$ downwind as a function of day-of-year. There still is a wide variance, but on average a clear trend can be seen. Up to about day 110, deposits tend to increase. After that, deposits decrease and in autumn deposits seem to increase again slightly. These trends are supported by the developing canopy density acting as a filter intercepting part of the drifting spray cloud.

Figure 4 shows drift deposits at the same distance $(4-6 \mathrm{~m})$ as a function of average wind speed. Deposits appear to increase with increasing wind speed up to about $3 \mathrm{~m} / \mathrm{s}$. Remarkably, with a further increase in wind speed, deposits seem to decrease. Possibly the drift cloud is blown farther downwind resulting in lower deposits relatively close to the orchard.

Similarly, Figure 5 shows downwind spray deposits $(4-6 \mathrm{~m})$ as a function of air temperature. When temperature rises from about $5^{\circ} \mathrm{C}$ up to about $15^{\circ} \mathrm{C}$, deposits tend to increase. However, at higher temperatures, deposits appear to decrease. Possibly, at low temperatures, a rise in temperature implies an increase in evaporation rate. This may cause a decrease in average droplet size in the spray cloud, leading to a higher number of droplets in the airborne spray cloud leaving the orchard downwind, thus increasing the downwind spray deposits. At higher temperatures, evaporating droplets may become so small that the spray cloud can travel long distances and the deposits of spray drift 
close to the orchard decrease. Often, higher temperatures are linked to an increased turbulence, which may cause a similar effect of the tendency of the spray cloud to deposit farther downwind.

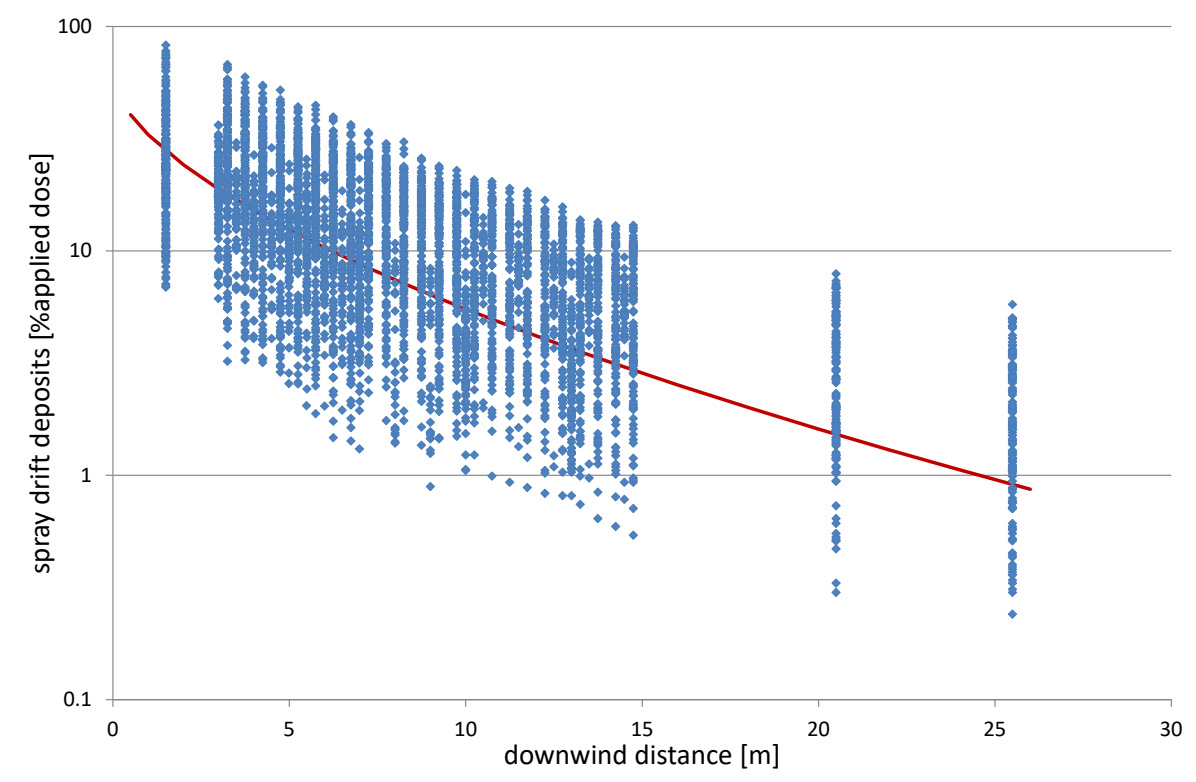

Figure 2 Measured spray drift deposits as a function of downwind distance from the last tree row, for all experiments. Solid curve: example of modified exponential behaviour as will be presented in Ch.3.

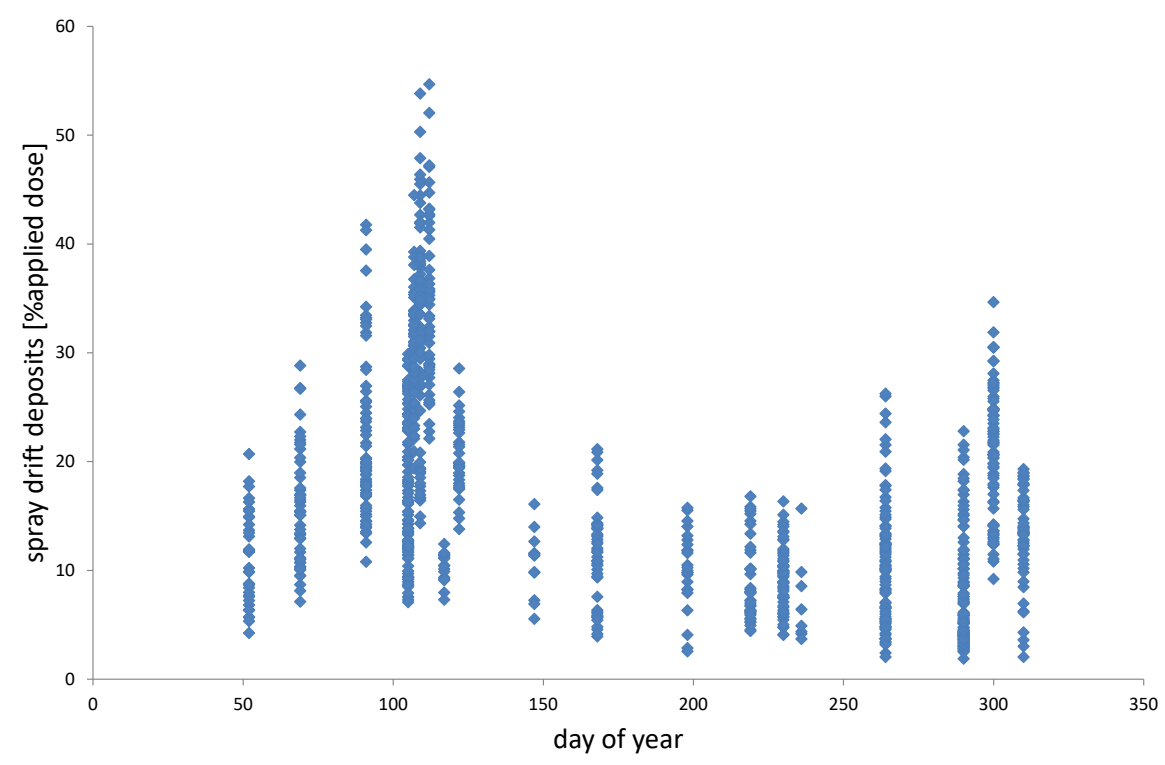

Figure 3 Measured spray drift deposits at a distance 4- $6 \mathrm{~m}$ downwind from the last tree row as a function of day of year, for all experiments. 


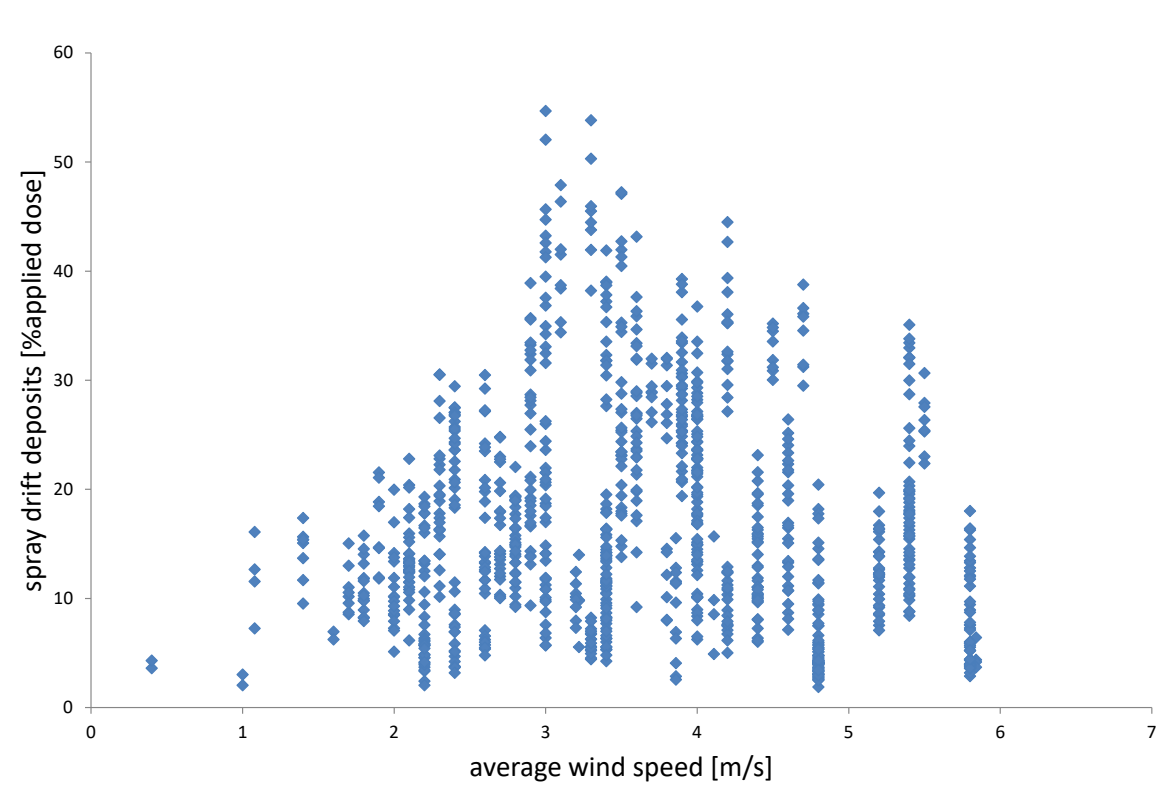

Figure 4 Measured spray drift deposits at a distance 4- $6 m$ downwind from the last tree row as a function of average wind speed, for all experiments.

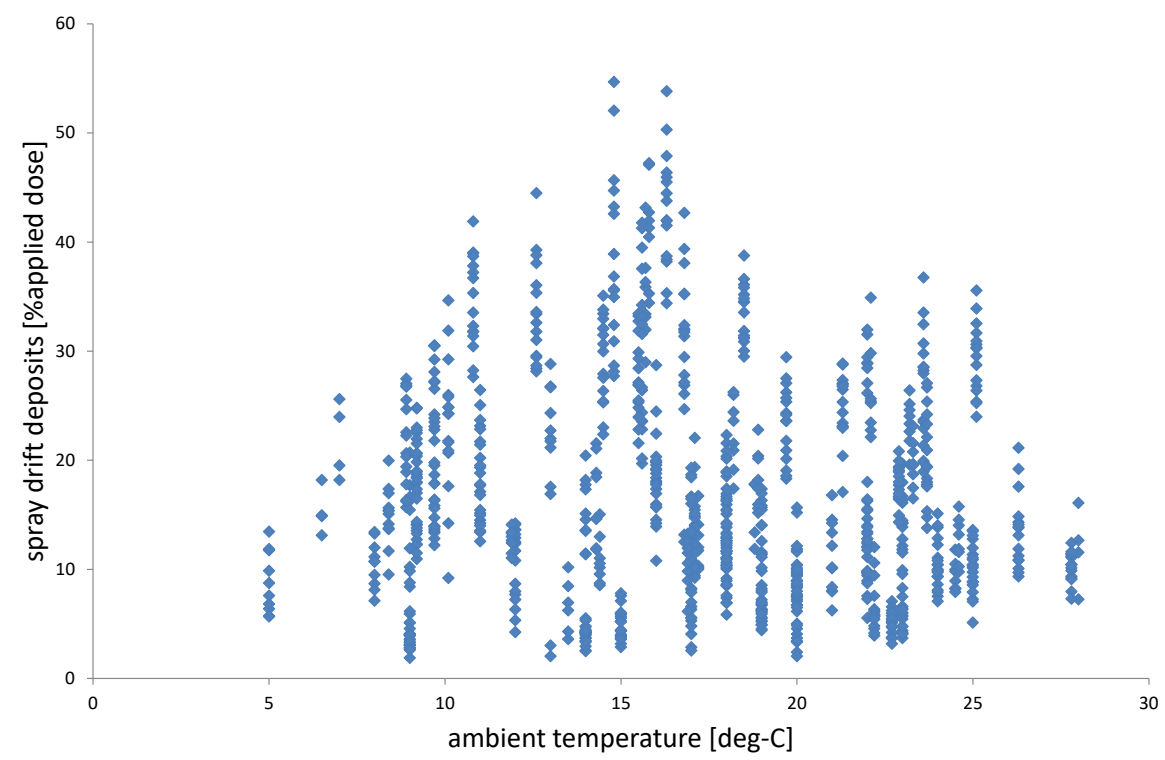

Figure 5 Measured spray drift deposits at $4-6 \mathrm{~m}$ downwind from the last tree row as a function of ambient temperature, for all experiments.

\subsubsection{Single-row experiments}

In a series of experiments in 2002, individual rows of apple trees were sprayed and the downwind deposition of spray drift was measured (Michielsen et al. 2007, Wenneker et al. 2007). In this way the contribution of spraying each row of trees to the total spray drift was investigated. The experiments were carried out in early (dormant) and late (full canopy) growth stage of the trees. See Annex 1 for further details.

Figure 6 shows the cumulated spray deposits downwind from an orchard with dormant trees, as a function of the number of rows treated $(N)$ and assessed at five distances from the last row of trees ( 3 to $13 \mathrm{~m}$ ). Solid lines indicate the experimental data. These data were fitted by a sub-model described in Section 3.1.4 and Annex 1 and are indicated by the dashed lines in the graph. Similarly, Figure 7 shows cumulated deposits next to an orchard with trees in full leaf. 
The half-numbered values on the $\mathrm{x}$ axis may seem awkward but are caused by the sequential application of spray in different paths. When the sprayer has travelled path 1 (also see Figure 1 ), the first tree row is sprayed from the outer side only. Therefore, after finishing path 1 the number of treated rows is 0.5 . At the end of path 2 , tree row 1 is treated from both sides, whereas tree row 2 is treated only from one side. Therefore, in that case the number of treated rows is 1.5 . In each subsequent path spray is applied to both sides, thus increasing the cumulative number of treated rows by 1 . Consequently, the cumulated number of treated rows takes the values $0.5,1.5,2.5, .$. as is shown in Figure 6. Of course, the last path of the sprayer is outside the last tree row and spray is applied one-sided again, thus completing the number of treated rows to equal the number of tree rows.

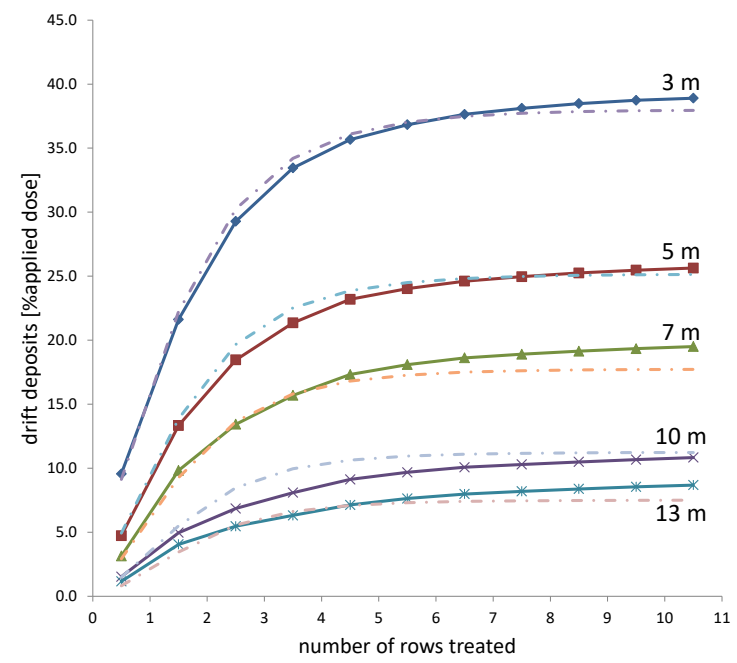

Figure 6 Cumulated deposits of spray drift next to an orchard with bare (dormant) apple trees as a function of the number of rows treated; derived from single-row experiments (solid lines); for various downwind distances downwind from the last row of trees. Dashed lines: modelled curves.

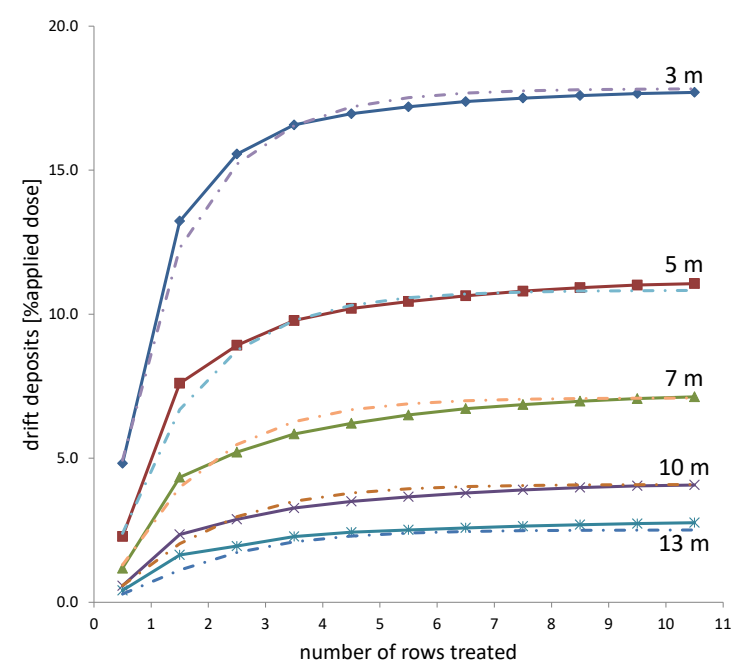

Figure $7 \quad$ Cumulated deposits of spray drift next to a full canopy orchard as a function of the number of rows treated; derived from single-row experiments (solid lines); for various downwind distances downwind from the last row of trees. Dashed lines: modelled curves.

Figure 8 shows how these deposits for single row treatments are combined to give downwind spray deposits depending on the total number of treated rows. When the number of treated rows is 10 , the drift curve approaches a stable situation. Note that with an inter-row distance of $3.0 \mathrm{~m}$, row number 10 is located $30 \mathrm{~m}$ upwind. The experimental results indicated that spray applied $30 \mathrm{~m}$ upwind still appeared to contribute to deposits of spray drift downwind from the orchard. 


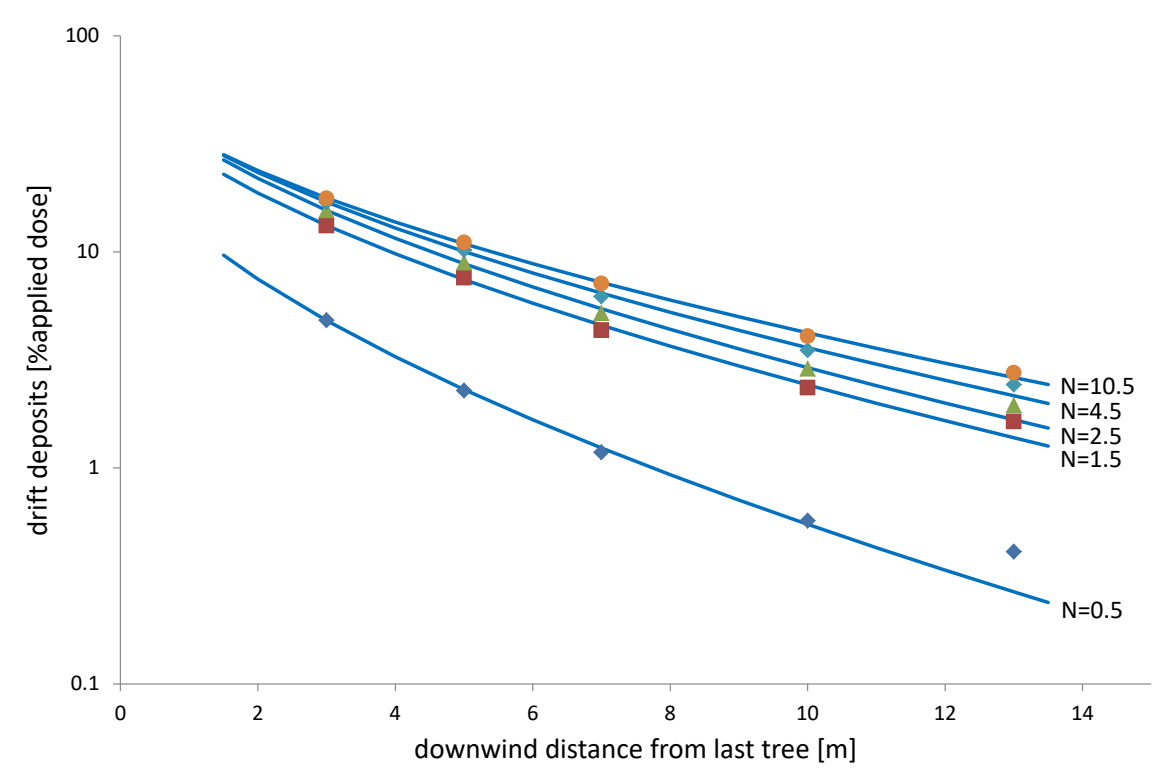

Figure 8 Downwind deposits of spray drift as a function of distance, for an increasing number of rows $(N)$ treated. Symbols: measured deposits, solid lines: fitted curves.

\subsection{Limitation of database content}

Before starting the curve-fitting process, the data set was checked to remove outliers and other 'abnormal' data. In good agricultural practice (GAP), spray applications do not take place when wind speed is above $5 \mathrm{~m} / \mathrm{s}$. Therefore, measurements with average wind speeds above $6 \mathrm{~m} / \mathrm{s}$ were excluded (to allow an arbitrary margin above the GAP wind speed limit). One of the experiments was carried out with a wind direction of more than $50^{\circ}$ with respect to the cross-wind direction. To avoid a too large effect of such a single experiment on the model development, this experiment was excluded as well. Other runs excluded consisted of experiments with extremely low or high deposits, probably resulting from a significant change in wind direction in the course of the experiment. In the end, the database used in the curve-fitting process consisted of 4954 deposits (out of 5456 in total) forming 280 drift curves (out of 316). This equalled 2477 paired deposits in 140 experiments. The median value and range of all primary factors are listed in Table 1. See p.51 for the List of symbols used. Since the model will be fitted using these quantities and their ranges given in the table below, in fact the validity of the model will be limited to those ranges.

Table 1 Primary variables, their mean value and range in the experiments used for curve-fitting.

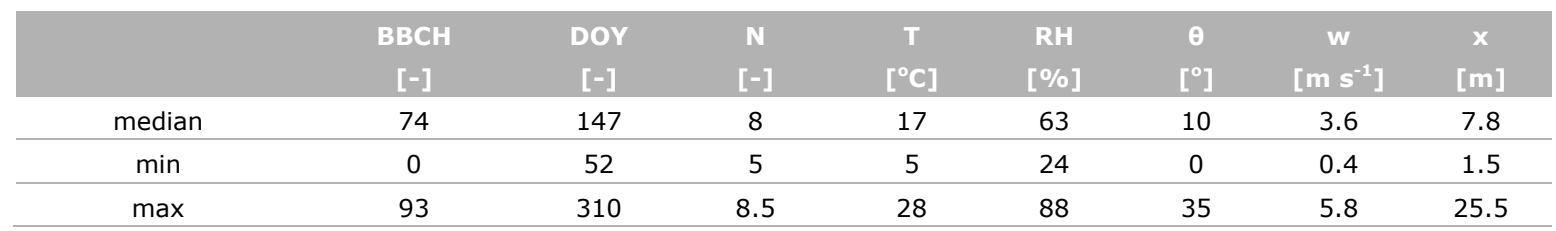

\subsection{Pairwise correlation}

In all experiments two parallel lines of collectors were placed on the ground downwind of the orchard and perpendicular to the tree row direction to have an indication of the accuracy of deposits. The distance between these lines was about $1.5 \mathrm{~m}$. Clearly, all external conditions can be considered the same for the paired lines of collectors. Possible differences in paired deposits may be due to stochastic 
differences in wind direction and wind speed, differences in the structure and density of the trees nearest to the collectors (particularly for collectors close to the edge of the orchard), or handling and processing of the sampled collectors. Therefore, a pairwise comparison of all individual collectors can give a good indication of the accuracy of the experimental method as a whole. As the current spray drift model is a function of (average) external factors and cannot focus on the small-scale differences mentioned above, the pairwise correlation is the upper limit for the correlation between model results and experimental results. The current model cannot do better, but ideally should approach the pairwise correlation as close as possible. Figure 9 shows the drift deposits in the first row compared to those in the second row. The correlation coefficient is $98 \%$.

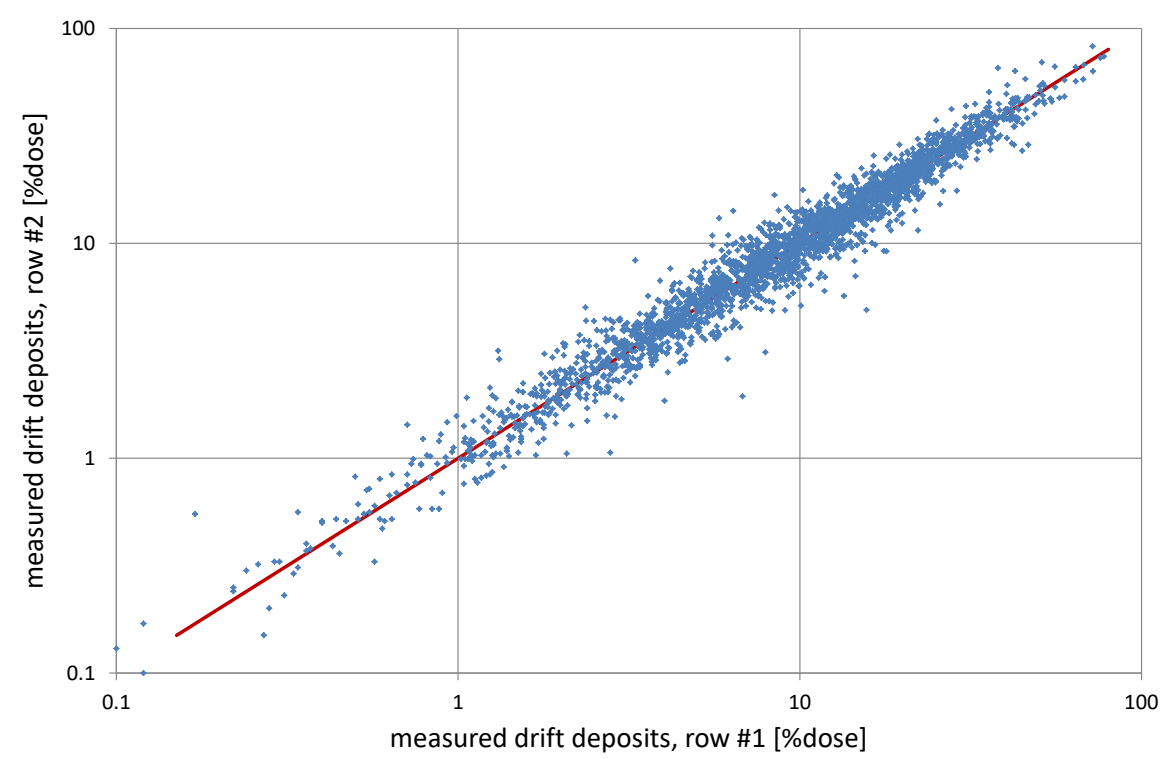

Figure 9 Pairwise comparison of experimental drift data (dots); solid line: ideal correlation $(y=x)$.

The ratio of the paired spray deposits is shown as a function of their averaged value in Figure 10. Obviously, the median (P50) is exactly 1 . The $10^{\text {th }}$ and $90^{\text {th }}$ percentiles are about 0.80 and 1.25 , respectively. As expected, the lines indicate that for smaller deposits the variance in ratios is slightly higher than that for larger deposits, yet the differences in variances are small.

For each data pair $y_{1}$ and $y_{2}$, the relative pairwise difference (RD) is defined by:

$$
R D=\frac{y_{2}-y_{1}}{y_{2}+y_{1}}
$$

For positive values of $y_{1}$ and $y_{2}, R D$ is within the range -1 to +1 . The cumulative frequency distribution of all RD values is shown in Figure 11. It shows that almost $80 \%$ of all RD values is within the range $0.1 /+0.1$. This means that most paired values do not differ more than $10 \%$ from their averaged value, confirming that paired values are usually very close to each other. The cumulative frequency distribution is close to a normal distribution and symmetric, indicating that the differences between paired values are stochastic. Additionally, all pairs were divided into 10 groups of approximately equal number of pairs (ca. 270 pairs), where each group corresponds to a different range of average deposits. For each group the root of mean squared differences (RMS) of the RD values was computed, as shown in Figure 12. The RMS value is a good measure of the standard deviation of RD values. As expected, the variation in paired values decreases with increasing deposits, but for all groups RMS is roughly 0.1 . The dashed line indicates an inverse square-root behaviour as found in estimating errors in spray deposits (Section 3.2.1) and will be discussed there. 


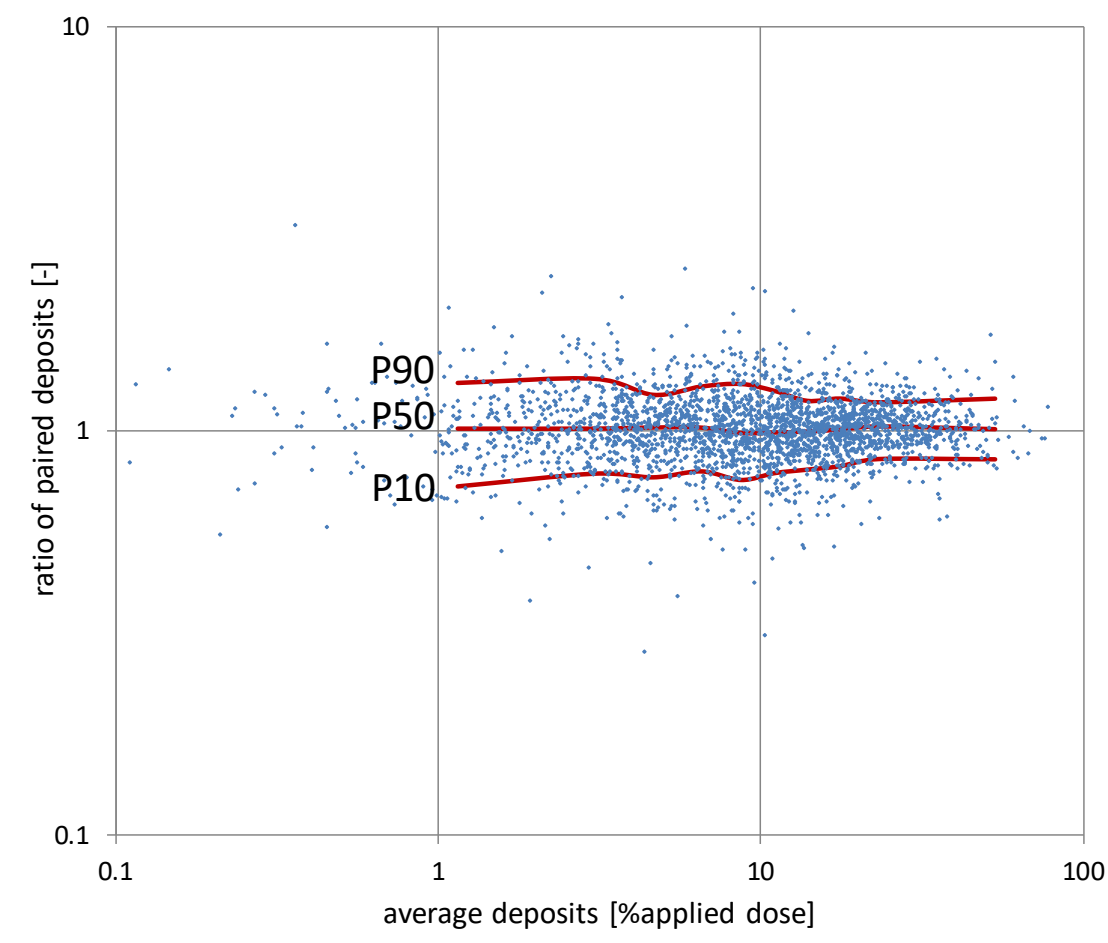

Figure 10 Ratio of paired deposits vs their averages. Solid lines indicate $10^{\text {th }}, 50^{\text {th }}$ and $90^{\text {th }}$ percentile lines.

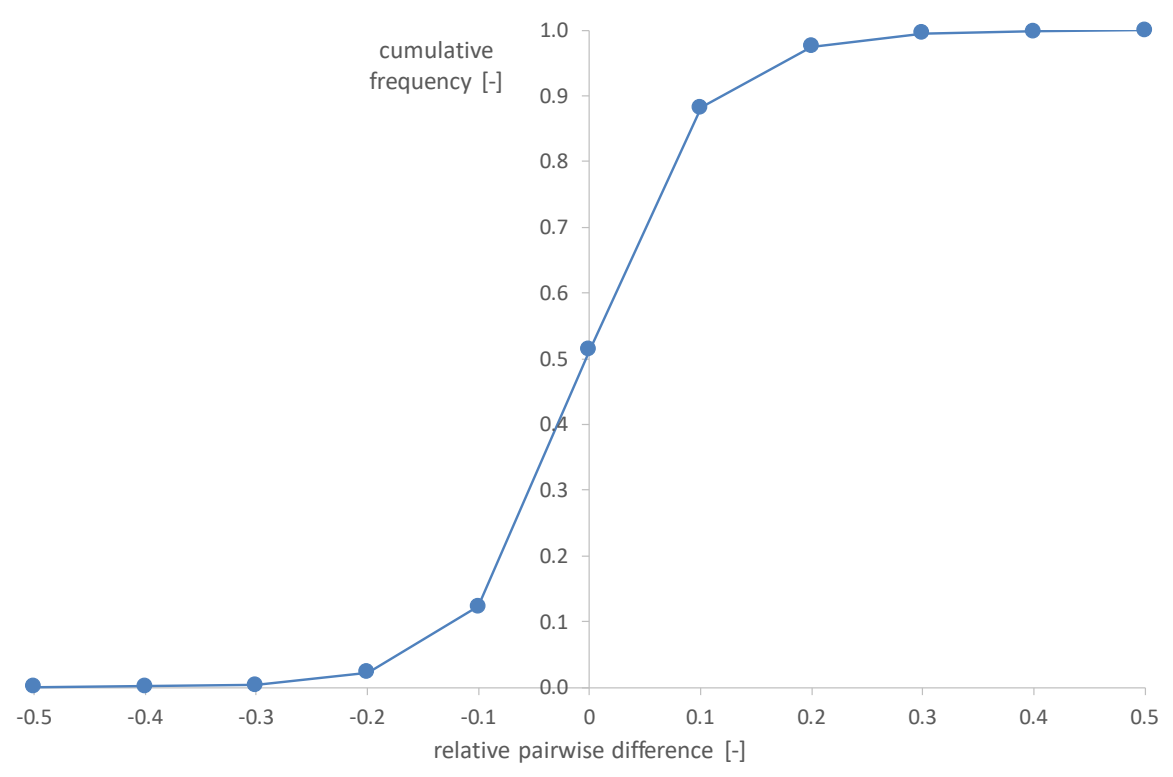

Figure 11 Cumulative frequency distribution of relative pairwise differences. 


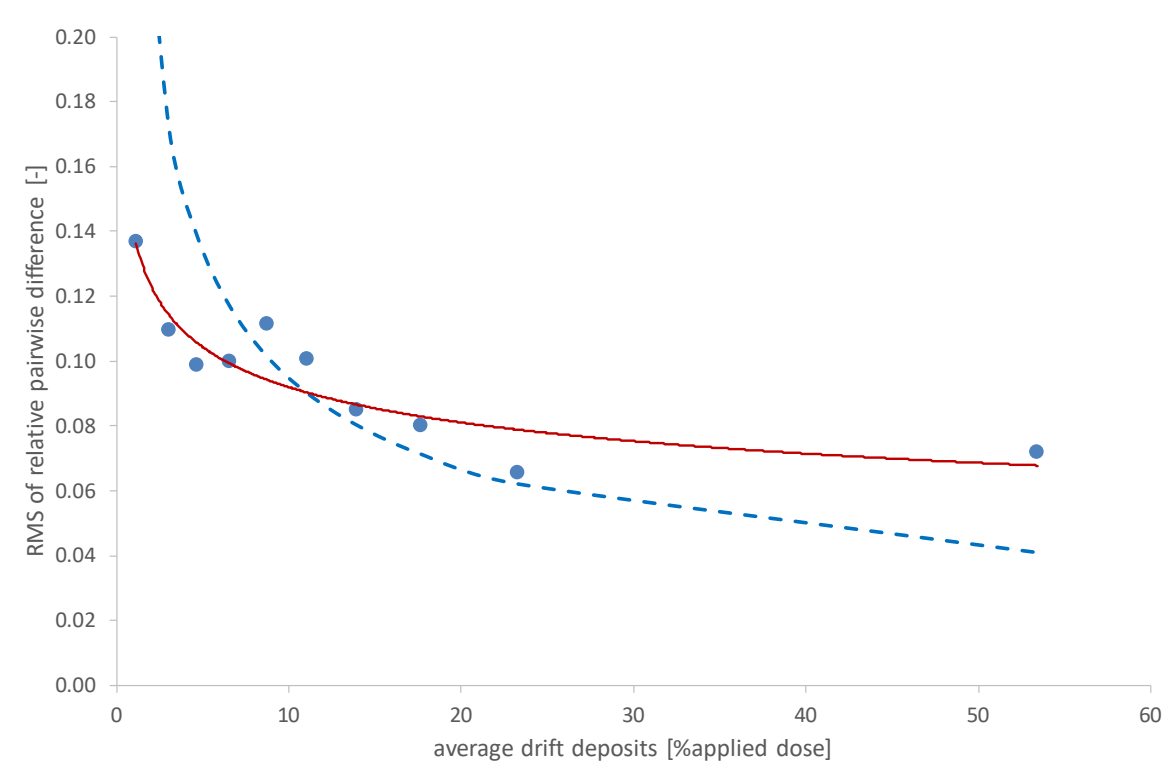

Figure 12 RMS of relative paired differences as a function of average deposits. Solis line: fitted power-law curve. Dashed line: inverse square-root trend line (Section 3.2.1).

\subsection{Regression analysis}

The full data set comprised of 316 deposition curves or 5456 deposits values. Input parameters were day-of-year (DOY) of the measurement, corresponding growth stage, fan speed setting of the sprayer (high or low), number of tree rows treated, ambient temperature, relative humidity, wind direction with respect to the orientation of the tree rows, wind speed at $4 \mathrm{~m}$ height, distance of deposits downwind from last tree row. The growth stage is identified by the phenological $\mathrm{BBCH}$ index, see Annex 10 for the BBCH codes for pome fruit (BBCH 2001).

Vertical temperature gradient was estimated from two temperatures measured at $0.5 \mathrm{~m}$ and $4.0 \mathrm{~m}$ height. However, in early years temperature was not measured at two heights, so the list of temperature gradients was incomplete.

The data set was analysed using Genstat statistical software (VSN International; version 18; 2015). Using the procedure RUNCERTAINTY (Jansen et al. 2005) it could be shown that distance is by far the most important parameter, which seems obvious. Other parameters, ordered by their importance, are DOY, $\mathrm{BBCH}$, number of tree rows, wind direction, wind speed and temperature. Relative humidity appeared of no significance. Table 2 indicates how each pair of input parameter is correlated. For instance, BBCH and DOY are highly correlated (0.92), so only one of them could be used as an independent input parameter. For convenience DOY is selected, since BBCH is a non-linear quantity which is more complex to use as a variable in a model. Similarly, temperature and relative humidity are inversely correlated (-0.75). From the statistical analysis mentioned before, temperature is the preferred quantity to use as an input parameter. Fan speed does not appear in this analysis, since it has only two values: high and low. 
Table 2 Bilateral correlation coefficients between the primary variables.

\begin{tabular}{|c|c|c|c|c|c|c|c|c|}
\hline & $\begin{array}{c}\mathrm{BBCH} \\
{[-]}\end{array}$ & $\begin{array}{l}\text { DOY } \\
{[-]}\end{array}$ & $\begin{array}{c}N \\
{[-]}\end{array}$ & $\begin{array}{c}\mathrm{T} \\
{\left[{ }^{\circ} \mathrm{C}\right]}\end{array}$ & $\begin{array}{c}\text { RH } \\
{[\%]}\end{array}$ & $\begin{array}{c}\theta \\
{\left[{ }^{\circ}\right]}\end{array}$ & $\begin{array}{c}w \\
{\left[\mathrm{~m} \mathrm{~s}^{-1}\right]}\end{array}$ & $\begin{array}{c}x \\
{[\mathrm{~m}]}\end{array}$ \\
\hline $\mathrm{BBCH}$ & 1.00 & 0.92 & 0.20 & -0.05 & 0.18 & 0.20 & -0.38 & 0.05 \\
\hline $\mathrm{N}$ & & & 1.00 & 0.17 & -0.25 & 0.17 & -0.24 & 0.24 \\
\hline $\mathrm{T}$ & & & & 1.00 & -0.75 & 0.20 & 0.01 & 0.04 \\
\hline$\theta$ & & & & & & 1.00 & -0.27 & 0.06 \\
\hline$w$ & & & & & & & 1.00 & -0.17 \\
\hline$x$ & & & & & & & & 1.00 \\
\hline
\end{tabular}

\subsection{First modelling approach}

Clearly, downwind distance $\mathrm{x}$ is the most important factor for spray deposits. In many cases a relatively simple exponential function suffices to describe the relation with distance:

$$
y=a e^{-b x}
$$

where $\mathrm{y}$ is the deposit (\%applied dose, related to mass per unit area) and $\mathrm{x}$ is downwind distance (m) from the last row of trees; parameters $a$ and $b$ result from fitting the curve to the data. Thus, for each of the 316 experimental curves, a value for $a$ and $b$ was obtained, which in principle may be functions of all relevant factors except distance. Now regression analysis was carried out for the data-set of parameter $a$, as well as for the data-set of parameter $b$, relating them to the primary variables of Table 1. Ideally, this would yield empirical functions describing parameters $a$ and $b$ as functions of all factors but distance.

However, this procedure did not return satisfactory results: the modelled deposits and measured deposits correlated only poorly. Several reasons can be given for this outcome. Firstly, the given procedure is in fact a two-stage fitting process: the parameters a and $b$ are results from a first curvefitting process of all individual experiments. In a second stage empirical functions of the primary factors are fitted to these parameters, in fact interpreting them as quasi-experimental input data. Within each stage some accuracy is lost. Secondly, in trying to find descriptive models for the parameters $a$ and $b$ these parameters are treated independently, although these parameters clearly must be positively correlated: a slight overestimation of parameter a must be compensated by a slightly larger $b$. Therefore, determining descriptive functions for $a$ and $b$ independently will lead to $a$ loss of overall performance of the model. Thirdly, but equally important: so far it appeared impossible to obtain an accurate functional description of parameter $b$ in terms of the primary factors that correlated well with the set of fitted values from the first stage.

Because of these drawbacks and the slightly disappointing results, this two-stage modelling approach was abandoned. A direct approach was followed instead, yet considerably more difficult and laborious. This approach is described in Chapter 3. 


\section{Spray drift model for downwind deposits}

\subsection{Model description}

\subsubsection{Basic set-up of the spray drift model}

Downwind spray deposition is modelled by the following exponential decay function of distance $\mathrm{x}$ :

$$
y=q_{1} e^{-q_{2} x^{c}}
$$

This function differs from a simple exponential function (section 2.5) by introducing the parameter c which modifies the dependence of $y$ on the distance. For $c<1$, effectively the decrease of the logarithm of $y$ with distance slows down gradually, similar to a double-exponential function as used elsewhere (Groot et al. 2012, Van de Zande et al. 2012). Yet, Eq.(3) only has 3 parameters, while a doubleexponential function requires 4 parameters. The model of Eq.(3) will be denoted as 'slackened exponential' to denote the decreasing rate of decrease of $\log (y)$ with increasing distance. See Figure 13 for an example plot of this drift equation.

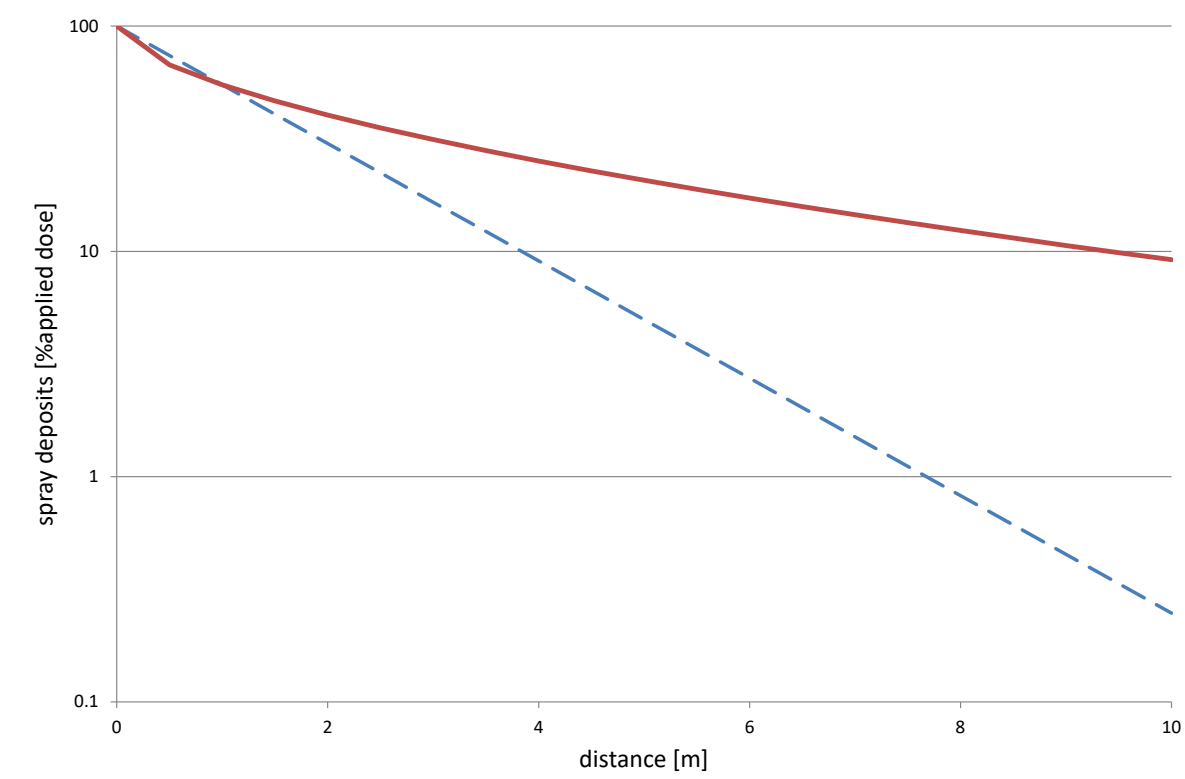

Figure 13 Example of spray drift curve computed by Eq.(3) (solid red curve; $q_{1}=100 \%$, $q_{2}=0.60 \mathrm{~m}^{-1}, \mathrm{c}=0.60$ ). The dashed curve indicates the deposits when $\mathrm{c}=1$ (while $q_{1}$ and $q_{2}$ remain the same).

The coefficients $q_{1}, q_{2}$ and $c$ are independent of distance $x$, yet these may be functions of external parameters such as wind speed, wind direction, temperature, orchard size and canopy density. The coefficients $q_{1}$ and $q_{2}$ depend on various external factors. The following relationship is assumed for $q_{1}$ and $\mathrm{q}_{2}$ to allow separation of variables:

$$
q_{j}=q_{j 0} F_{w j} F_{T j} F_{N j} F_{f j}
$$

where index $j=1,2 . F_{w}$ reflects adjustments for wind speed, $F_{T}$ for temperature, $F_{N}$ for orchard size and canopy density, and $F_{f}$ for the setting of the sprayer fan speed. The factor $q_{j 0}$ is a constant. Orchard size and canopy density are closely related quantities, basically affecting the filtering property 
of the trees for passing clouds of spray. Therefore these quantities are combined into the factors $F_{\mathrm{Nj}}$. The coefficients $q_{1}, q_{2}$ must have positive values to give a useful representation of downwind spray deposits (Eq.(3), Figure 13). This implies that all factors in Eq.(4) must take positive values as well in any circumstances. An appropriate choice of the mathematical description of the factors may suffice, yet in some cases certain constraints may be required to impose, for example in the case of $F_{\mathrm{T}}$ as will be shown in Section 3.1.2.

A further relevant factor is wind direction. Wind direction does not necessarily affect downwind spray deposits per se, but merely affects the direction in which the airborne spray cloud moves. Therefore, wind direction was treated separately as discussed in Section 3.1.3.

The parameter $\mathrm{c}$ is estimated from the single-row experiments (Annex 1). Although these experiments seem to indicate that $\mathrm{c}$ is best kept constant (at a value of 0.6 ), a slight adjustment for $\mathrm{N}$ appeared to improve the spray drift model, see Section 3.1.4.

The implementation of the above-mentioned factors in the SPEXUS model will be discussed in the next sections.

\subsubsection{Wind speed and temperature}

It is assumed that wind speed $w$ affects both $q_{1}$ and $q_{2}$ by a factor $F_{w 1}$ and $F_{w 2}$, respectively. The graph of Figure 4 suggests that at least a second-order dependence on wind speed is required. Therefore, a second-degree polynomial dependence of $\log \left(F_{w}\right)$ on wind speed was assumed. Taking $\log \left(F_{w}\right)$ rather than $F_{w}$ itself assures that $F_{w}>0$ for all possible values of the wind speed (or the constants to be used), which is an implicit requirement in using Eq.(4) (as mentioned in Section 3.1.1). This leads to the following empirical relation for $F_{w}$ :

$$
F_{w j}=e^{-a_{1 j}\left(w-w_{0}\right)-a_{2 j}\left(w-w_{0}\right)^{2}}
$$

for $j=1,2$; where $a_{1 j}$ and $a_{2 j}$ are constants and $w_{0}(=3 \mathrm{~m} / \mathrm{s})$ is a reference wind speed, which is arbitrary but preferably should equal the time averaged wind speed roughly. Note that $F_{w j}=1$ for $w=w_{0}$, so for wind speeds not too far from average the factor $F_{w j}$ is relatively close to 1 . In this way, implicitly $F_{\mathrm{w} 1}$ and $F_{\mathrm{w} 2}$ act as a modification factors for wind speeds deviating from their (approximate) average.

Figure 14 shows $F_{w 1}$ and $F_{w 2}$ as a function of wind speed in the final model. For wind speeds $>6 \mathrm{~m} / \mathrm{s}$, the value of $F_{w 2}$ was kept constant at its value for $6 \mathrm{~m} / \mathrm{s}$, preventing it to increase for higher wind speeds. As wind speeds in the experiments are all below $6 \mathrm{~m} / \mathrm{s}$ (Table 1), there is no evidence whatsoever how $F_{w_{2}}$ should continue for higher wind speeds. Keeping $F_{w 2}$ constant for higher wind speeds assures that the model shows no 'unexpected' behaviour outside the validity range of the model. Examples of downwind spray deposits as a function of wind speed will be given in Section 4.2. 


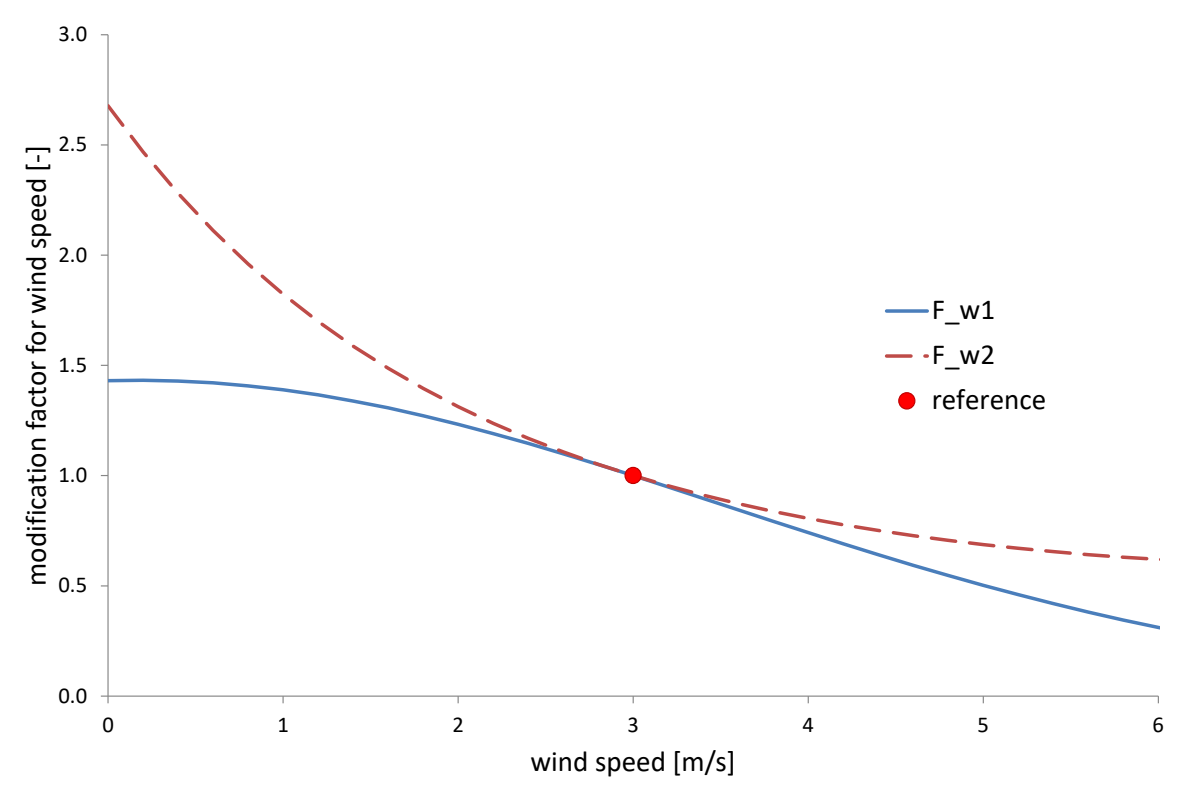

Figure 14 Modification factors $F_{w 1}$ and $F_{w 2}$ for wind speed. Red dot: reference point: $F_{w 1}=F_{w 2}=1$ at $w=3.0 \mathrm{~m} / \mathrm{s}$.

Similarly, the graph of Figure 5 suggests that at least a second-order dependence on temperature is expected. Therefore, a second-degree polynomial dependence of $F_{\mathrm{T}}$ on temperature was assumed:

$$
F_{T j}=1+b_{1 j}\left(T-T_{0}\right)+b_{2 j}\left(T-T_{0}\right)^{2}
$$

For $j=1,2$; where $b_{1 j}$ and $b_{2 j}$ are constants and $T_{0}\left(=15^{\circ} \mathrm{C}\right)$ is a reference temperature. Selecting a reference temperature is arbitrary from a mathematical point of view, yet it is convenient to select a value close to the time averaged temperature of the experimental dataset. Note that Eq.(5) is exponential while Eq.(6) is linear (in $\mathrm{T}$ and $\mathrm{T}^{2}$ ). For $\mathrm{F}_{\mathrm{Tj}}$ an exponential equation would be preferred too (to assure $\mathrm{F}_{\mathrm{Tj}}>0$ for all temperatures, see Section 3.1.1), but the linear equation appeared to perform better in the curve-fitting process. However, the draw-back is that $\mathrm{F}_{\mathrm{Tj}}$ may become $\leq 0$ for certain temperatures. If this occurs, $\mathrm{F}_{\mathrm{Tj}}$ must be adjusted appropriately. The constraining measures described in the next paragraph appear to be sufficient and adequate to result in $\mathrm{F}_{\mathrm{Tj}}>0$ in the final model for all temperatures.

The experimental range for the primary quantities is given in Table 1 (Section 2.2). E.g. for values of air temperature outside the experimental range, validity of the model is not assured. Roughly, the experimental temperatures range from 5 up to $30^{\circ} \mathrm{C}$. Consequently, there is no evidence how $\mathrm{F}_{\mathrm{T}}$ should behave outside this temperature range and any appropriate assumption may suffice. Therefore, in case the model has to deal with temperatures $\mathrm{T}<5^{\circ} \mathrm{C}$, the factor $\mathrm{F}_{\mathrm{Tj}}$ at $\mathrm{T}=5^{\circ} \mathrm{C}$ is assumed (using Eq.(6)). Similarly, for $\mathrm{T}>30^{\circ} \mathrm{C}, \mathrm{F}_{\mathrm{Tj}}$ at the boundary of $30^{\circ} \mathrm{C}$ is used instead. It turns out that these boundary values of $\mathrm{F}_{\mathrm{Tj}}$ are $>0$ (see Figure 15).

Like $\mathrm{F}_{\mathrm{wj}}$, the factors $\mathrm{F}_{\mathrm{Tj}}$ can be seen as modification factors for temperatures deviating from their (approximate) average. 


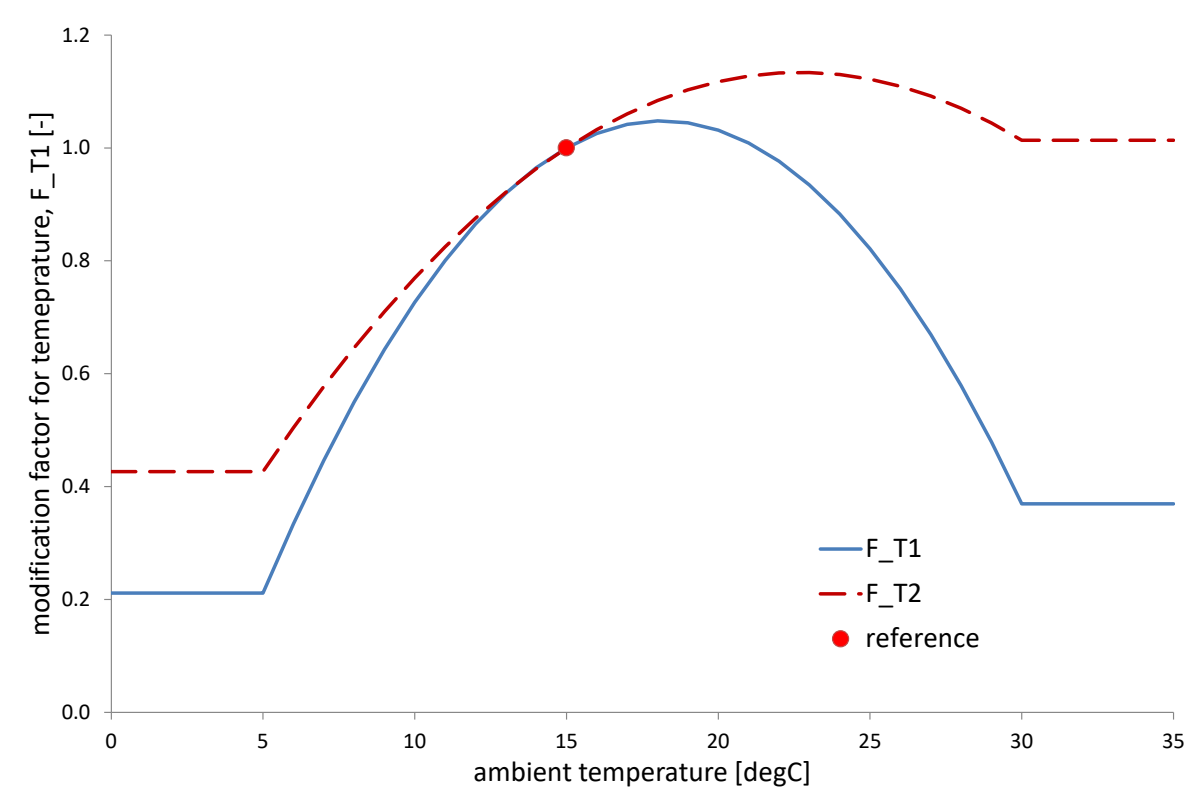

Figure 15 Modification factors $F_{T 1}$ and $F_{T 2}$ for ambient temperature. Red dot: reference point: $F_{T 1}=F_{T 2}=1$ at $T=15^{\circ} \mathrm{C}$. Straight horizontal endings indicate the constraints imposed outside the range $5-30^{\circ} \mathrm{C}$.

\subsubsection{Wind direction}

Assume wind direction is given by an angle $\theta$ with respect to cross wind. Thus, for the spray cloud to reach a (perpendicular) distance $x$ off the edge of the orchard, it must travel the following distance in the flow direction of the wind (see Figure 16):

$$
s=x / \cos \theta
$$

The actual distance $x$ has increased by a factor $F_{\text {dir }}=1 / \cos \theta$ to give the travelled distance $s$. Note that $F_{\text {dir }}=1$ for a cross wind and $F_{\text {dir }}>1$ for all other wind directions. For $\theta>90^{\circ}$ and $\theta<-90^{\circ}$ the factor $F_{\text {dir }}$ has no meaning, since in those cases the edge of the orchard is on the upwind side and off-target drift deposits are zero for such edges by conventional agreement. Essentially, in all cases where a distance $x$ is involved in the model, it should be replaced by $x \cdot F_{\text {dir. }}$ In Section 3.1.4 the effect of orchard size on downwind deposits of spray drift is discussed. Essentially, orchard size is identified by the source length (the 'fetch') of the spray cloud in the upwind direction. For an orchard of size L (Figure 16), the effective fetch is given by:

$$
L_{e f f}=L F_{d i r}
$$

The fetch $L$ can be replaced by $N D_{\text {row, }}$ where $N$ is the number of tree rows and $D_{\text {row }}$ is the distance between rows (typically $D_{\text {row }}=3.0 \mathrm{~m}$, Section 2.1 ). Edge effects near the front and rear end of the orchard are disregarded (like the line $C D$ and $A B$ in Figure 16). These edge effects will be discussed in Chapter 5. 


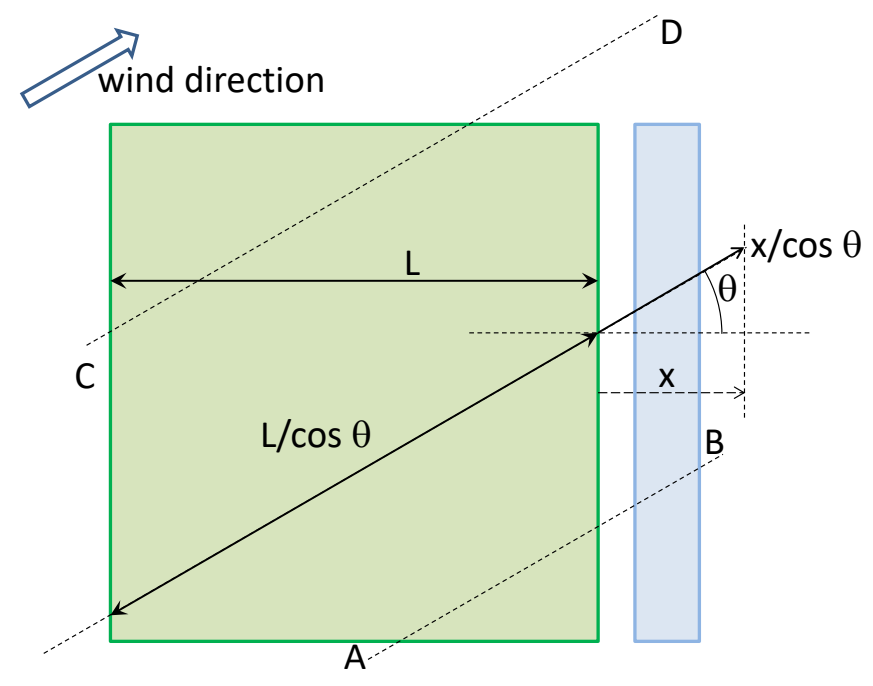

Figure 16 Effect of wind direction on effective distance of downwind deposition of spray drift and on effective fetch.

\subsubsection{Orchard size and canopy density}

In the single-row experiments downwind deposits were measured when spraying rows 1 to 11 separately. These experiments were done in orchards both with dormant (bare) trees and with trees in leaves (Section 2.1.3). From adding these deposits for subsequent rows sprayed, the effect of an increasing orchard size can be investigated. Fitting the accumulated curves of downwind deposits using Eq.(3) gives parameters $q_{1}, q_{2}$ and $c$ as functions of orchard size, represented by the number of rows $\mathrm{N}$. Consistent representations of these parameters as functions of $\mathrm{N}$ must stabilize (i.e. approach a constant value) when orchard size increases (i.e. $\mathrm{N}$ increases). The following empirical relations show the normalized factors $F_{\mathrm{N} 1}$ and $F_{\mathrm{N} 2}$ for $\mathrm{q}_{1}$ and $\mathrm{q}_{2}$, respectively, having such a stabilizing effect (see Annex 1):

$$
\begin{aligned}
& F_{N 1}=r_{10}\left(1-p_{11 D} r_{11} e^{-p_{12 D} r_{12} N F_{d i r}}\right) \\
& F_{N 2}=r_{20}\left(1+p_{21 D} r_{21} e^{-p_{22 D} r_{22} N F_{d i r}}\right)
\end{aligned}
$$

Note that, compared to the equations given in Annex 1, the number of rows $\mathrm{N}$ is modified by the factor $F_{\text {dir }}$ to account for increased fetch depending on wind direction (see Section 3.1.3). Parameters $p_{i j D}$ are constants obtained for orchards with dormant trees; $r_{i j}$ are positive scaling factors depending on canopy density. Canopy density is quantified using a 'canopy density factor' $\beta$, which is defined such that $\beta=0$ for bare trees and $\beta>0$ when leaves develop. Section 3.1.5 deals with this canopy density factor. According to Annex 1 , the factors $r_{10}, r_{21}$ and $r_{22}$ are decreasing functions of $\beta$ and are modelled by:

$$
r_{i j}(\beta)=\frac{1}{1+u_{i j} \cdot \beta}
$$

Similarly, the factors $r_{11}, r_{12}$ and $r_{20}$ are increasing functions of $\beta$ and are modelled by:

$$
r_{i j}(\beta)=1+u_{i j} \cdot \beta
$$

The parameters $u_{i j}$ are the rate constants, determined from the results of the single-row experiments.

In early spring the trees are bare, thus $\beta \approx 0$, and consequently all $r_{i j}$ are equal to 1 . Additionally, if the orchard is sufficiently large, then Eqs. (9) and (10) reduce to $F_{\mathrm{N} 1}=1$ and $F_{\mathrm{N} 2}=1$. This means that $F_{\mathrm{N} 1}$ and $\mathrm{F}_{\mathrm{N} 2}$ can be considered 'normalized' modification factors with respect to large orchards in early spring. 
An alternative approach to interpret the effects of orchard size and canopy density on downwind spray deposits is presented in Annex 5. Although the physical approach given there is a clear simplification, it appears to support the empirical approach of the present section.

As all factors in Eqs.(9) and (10) take positive values, with increasing $N$ the factor $F_{\mathrm{N} 1}$ increases while $F_{\mathrm{N} 2}$ decreases, both to their asymptotic limits. This is in accordance with Figure A1.2 and Figure A1.3

(Annex 1) corresponding to $\mathrm{F}_{\mathrm{N} 1}$ and $\mathrm{F}_{\mathrm{N} 2}$, respectively. The alternative approach in Annex 5 also supports the relation between $\mathrm{F}_{\mathrm{N} 1}$ and $\mathrm{N}$. This behaviour of $\mathrm{F}_{\mathrm{N} 1}$ and $\mathrm{F}_{\mathrm{N} 2}$ is easily understood. $A$ larger orchard will produce a larger amount of spray drift. Therefore $q_{1}$ (through its factor $F_{N 1}$ ) increases with increasing orchard size. At the same time, contributions to the spray cloud originating from rows treated further upwind will consist of smaller droplets. Such smaller drops have a lower sedimentation velocity and may travel further downwind. This is accompanied by a decreasing value of $\mathrm{q}_{2}$ (through its factor $\mathrm{F}_{\mathrm{N2} 2}$ ).

In the processing of the single-row experiments the parameter $\mathrm{c}$ in Eq.(3) was kept constant at a value of 0.6 (Annex 1). During the curve-fitting process of the full set of spray drift experiments it turned out that a moderate decrease of $\mathrm{c}$ with increasing $\mathrm{N}$ would improve the performance of the model. Ideally, c should be $\leq 1$ for all possible values of $\mathrm{N}$ (to maintain the types of drift curves shown in Figure 1). Several empirical equations were tried; the following equation gives satisfactory results:

$$
c=a \cdot \frac{b+N^{m}}{1+N^{m}}
$$

Where $a$ and $m$ are optimized in the curve-fitting process $(a>0, m>0)$ and $b$ is a preselected constant $(b=3.0)$. With this equation, $c=2 a$ when $N=1$; parameter $c$ decreases asymptotically to $c=a$ for increasing values of $\mathrm{N}$.

The largest value of parameter $\mathrm{c}$ (i.e. $\mathrm{c}_{\max }$ ) occurs for the lowest number of treated rows, $\mathrm{N}=0.5$. In this hypothetical treatment only the outer row is sprayed one-sided from the outside, while none of the other tree rows are treated. Curve-fitting gave $a \approx 0.50$ and $m \approx 0.63$ (see Annex 9). With these values, $C_{\max } \approx 1.12$, which is just above 1 . For $N \geq 1, c \leq 1$ as desired. Clearly, the case of $N=0.5$ (spraying only one half of a tree row while the rest of the orchard is untreated) is possible but it is a scenario that has no practical importance. Therefore, $c_{\max }$ being slightly above 1 was not considered a significant problem.

\subsubsection{Canopy density factor}

The tree canopy acts as a filter that may catch part of the passing spray cloud. The current spray drift model does not require a full understanding of how this filtering actually takes place. However, the canopy density affects parameters such as $F_{N}$ mentioned in the previous section and therefore needs quantification. The canopy density factor $\beta$ is introduced to quantify this effect of the tree canopy in the spray drift model. By definition, $\beta=0$ for dormant trees, while $\beta>0$ when the canopy develops. In principle, the canopy density factor may be linked to quantities like leaf area index (LAI) or leaf area density (LAD). Since $\beta$ (through its parameters described below) is determined empirically as part of the curve-fitting process for all deposition data, establishing the actual relationship between $\beta$ and LAI or LAD is not required.

Essentially, the canopy density factor $\beta$ is a function of growth stage (BBCH). However, it turned out to be more practical to use the $\mathrm{BBCH}$ to day-of-year (DOY) relationship (Figure 17, Annex 3 ) to describe $\beta$ as a function of DOY. Basically, $\beta$ is a cyclic function of DOY, with a period of 1 year. Annex 4 describes the construction of a suitable cyclic function by several modifications of a sinusoid function; the current section only mentions the final equations. The canopy density factor $\beta$ is modelled by:

$$
\beta=a_{3}\left(1-e^{-\left(a_{0} \sin \pi u\right)^{a_{4}}}\right)
$$

where the parameter $u$ is a non-linear modification function of the fraction of year $z(=D O Y / 365)$, to imply skewing towards the second half of the year:

$$
u(z)=z \cdot\left(1+a_{1}(z-1)+a_{2}\left(z^{2}-1\right)\right)
$$


The function $u(z)$ is a general $3^{\text {rd }}$ grade polynomial between $z=0$ and $z=1$ with boundary conditions $\mathrm{u}(0)=0$ and $\mathrm{u}(1)=1$. Practical use requires $\mathrm{u}(\mathrm{z})$ to be an increasing function of $\mathrm{z}$ (i.e. the derivative $d u / d z \geq 0$ for all $z$ between 0 and 1 ). This condition restricts the possible range of values of $a_{1}$ and $a_{2}$. Figure 18 gives the resulting $\beta$ from the curve-fitting process as a function of $z$. Note that $\beta$ is a fiveparameter function $\left(a_{0} . . a_{3}, m\right)$; the relatively large number of parameters involved expresses the importance of canopy density in the current spray drift model. On the other hand, it can be easily seen that using five parameters is a minimum to control a shape like that shown in Figure 18 . This shape has at least five distinct features: position and steepness of the two slopes and height of $\beta$ at the central part. Consequently, at least five parameters are required for independent control of these features.

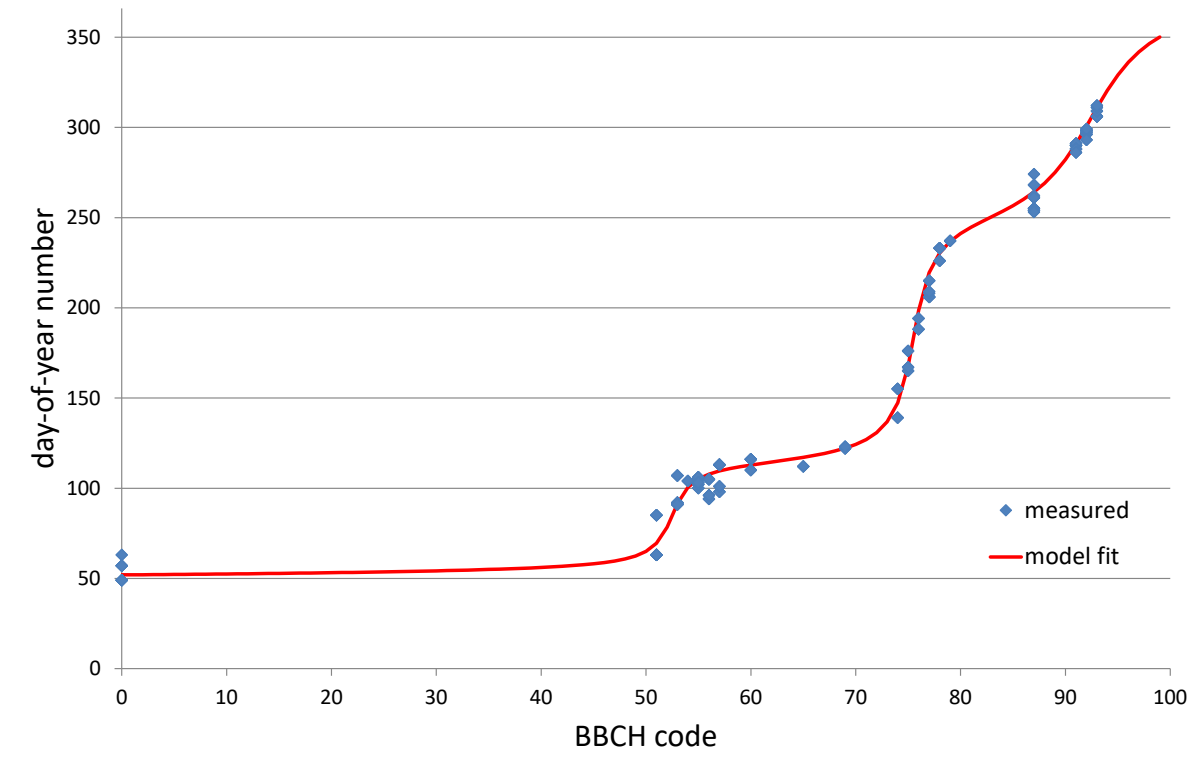

Figure 17 Observed phenological growth stages (BBCH) at various days-of-year (dots); solid line represents fitted curve of DOY as a function of $\mathrm{BBCH}$ (see Annex 3).

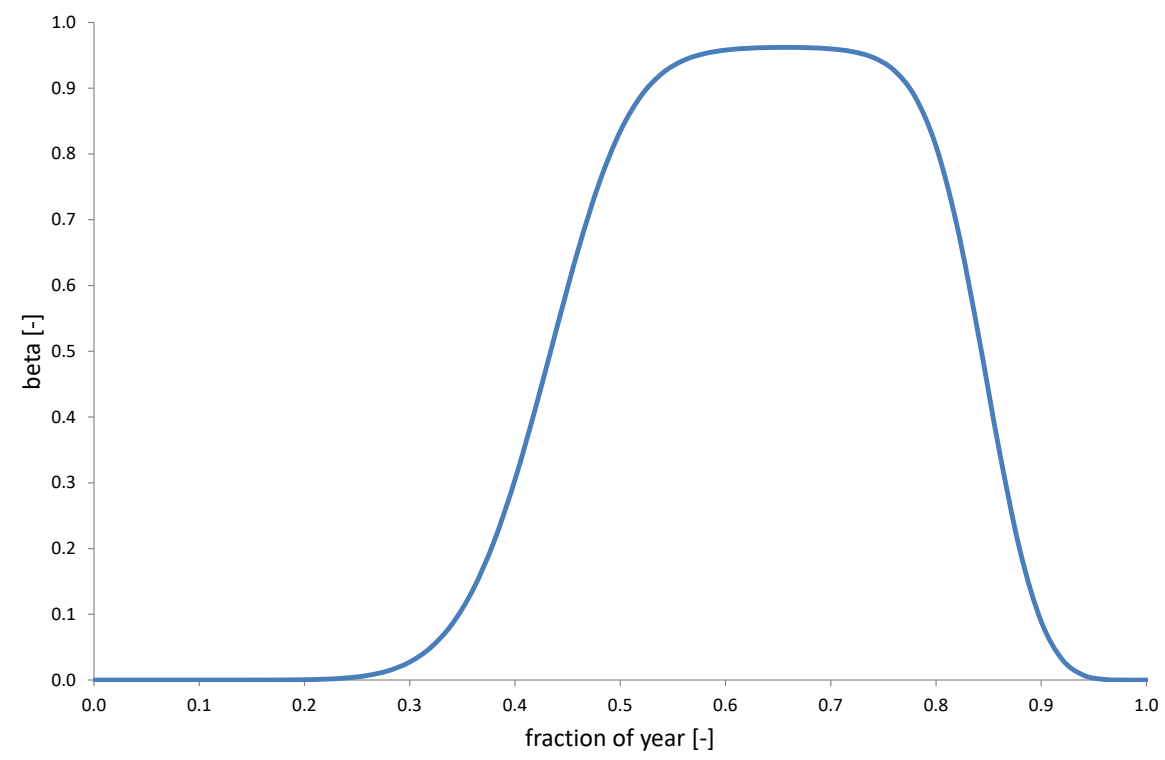

Figure 18 Canopy density factor as a function of fraction of year (z), from curve-fit optimizations. 


\subsubsection{Sprayer fan speed}

Eq. (4) contains a factor $F_{f j}$ to account for the effect of fan speed. A conventional orchard sprayer uses an air fan to blow droplets towards the trees. With dormant trees less air is required than when trees are in leaves. Usually, only two fan speeds are selected: a 'low' fan speed for dormant trees and a 'high' fan speed for trees in leaves. The fan speed factors $F_{f j}$ are considered modifications with respect to the orchard with dormant trees. That is, by definition $F_{f j}=1$ for low fan speed. Annex 2 describes the experimental quantification of the fan speed factor, which appears to be about the same for both $\mathrm{q}_{1}$ and $\mathrm{q}_{2}$, while it is $<1$ for high fan speed:

$$
F_{f 1}=F_{f 2}=f_{f s}
$$

The limited set of experiments in Annex 2 indicated that $\mathrm{f}_{\mathrm{fs}} \approx 0.52$. However, refined curve-fitting of the spray drift model yielded $\mathrm{f}_{\mathrm{fs}}=0.72$ as the optimal value.

The common practice to use a low fan speed in dormant trees while using a high fan speed otherwise, is conveniently converted into a $\mathrm{BBCH}$ range: typically, for $\mathrm{BBCH}$ between 70 and 95 , the fan speed is set to 'high' (corresponding to DOY 124 - 335; May 4 - Dec 1 ). This corresponds to $z \approx 0.34$ and $z \approx 0.92$, respectively, indeed representing low values of $\beta$ (Figure 18 ).

\subsection{Model refinements by curve-fitting}

The SPEXUS model described above contains many constants that should be fine-tuned to optimize the model compared to the experiments. The constants were adjusted in order to minimize the sum of squares of differences between measured deposits $\left(y_{i}\right)$ and computed deposits $\left(f_{i}\right)$. For the optimized model, the correlation coefficient of $f_{i}$ and $y_{i}$ was determined, as well as the slope $(A)$ of the average linear trend line $f=A^{*} y$. For a good model fit the correlation coefficient should be close to 1 , while the slope $A$ should be close to 1 as well. As often is the case for data values covering several orders of magnitude, it turned out that better results were obtained by fitting $\ln \left(y_{i}\right)$ rather than $y_{i}$ itself. Individual deposits were weighted accordingly, using a weight factor $w_{i}$ based on estimated accuracy of each deposit $y_{i}$; see the next section. Thus, the sum of squares to be minimized was:

$$
S=\frac{1}{n-n_{\text {par }}} \sum w_{i}^{2}\left(\ln \left(y_{i}\right)-\ln \left(f_{i}\right)\right)^{2}
$$

where $\mathrm{n}$ is the number of measurements in the summation and $\mathrm{n}_{\mathrm{par}}$ is the number of parameters to be adjusted. Note that $\mathrm{n}$ may be less than the total number of available deposits, since measurements were excluded from the summation when $y_{i}=0$ or $f_{i} \leq 0$ (clearly, for such values taking the logarithm is not possible). In principle, the model set-up described in Section 3.1 assures that $f_{i}>0$ in all cases. However, in the course of optimization some parameters may be tried that may cause (few) $f_{i}$ to become $\leq 0$. This has to be accounted for in determining $\mathrm{S}$ using Eq.(17).

\subsubsection{Estimating weights}

Usually, the weight used in sum-of-squares methods is the reciprocal of the standard error s. In this case, using $\ln (y)$ rather than $y$ itself, the standard error of $\ln (y)$ must be used instead. Equivalent to the differential of $\ln (y)$, i.e. $d(\ln (y))=d y / y$, the standard error of $\ln (y)$ equals the ratio of standard error of $y$ and $y$ itself:

$$
S_{\ln (y)}=\frac{s_{y}}{y}
$$

provided that $s_{y} \ll y$. 
The next question to solve now is how the standard error $\mathrm{s}_{\mathrm{y}}$ can be estimated without having access to exactly repeated experiments. Ideally, a relation between $s_{y}$ and $y$ is sought. For this, a method based on variation of droplet numbers can be used. Note that deposits consist of a large number of droplets deposited onto the collector. Assume $\mathrm{N}_{\mathrm{d}}$ droplets are deposited, giving a total deposit of $\mathrm{y}$. Although these droplets may differ in size and the drop size spectrum of the deposit probably differs from the original drop size spectrum near the spray nozzles, deposits of individual drops can be described using binomial statistics. The coefficient of variation (CV) of y appears to be proportional to that of $N_{d}$ (Holterman 2000):

$$
C V_{\mathrm{y}}=\Phi C V_{\mathrm{Nd}}
$$

where $\Phi$ is an enhancement factor depending on the relative width of the drop size spectrum. For a monodisperse spray $\Phi=1$, for all other sprays $\Phi>1$. Typically, $\Phi \sim 2$ for many downwind deposits. From binomial statistics, the variance in the number of drops equals $\operatorname{Var}\left(N_{d}\right)=N_{d}$. This yields $C V_{N d}=1 / \sqrt{ } N_{d}$, and Eq.(19) can be written as

$$
s_{\mathrm{y}}=\Phi y / \sqrt{N_{d}}=\Phi \sqrt{y V}
$$

where $V$ is the average volume per droplet, $V=y / N_{d}$. This equation shows that the standard error of $y$ is proportional to $\sqrt{y}$. Using this result in Eq.(18) gives:

$$
S_{\ln (y)}=\Phi \sqrt{V / y}
$$

showing that $S_{\ln (y)}$ is proportional to the inverse square root $1 / \sqrt{ } y$, assuming that average droplet volume $V$ does not change too much. Since $w_{i}=1 / S_{\ln (y)}$, the weights to be used in Eq.(17) are given by:

$$
w_{\mathrm{i}} \sim \sqrt{y_{i}}
$$

disregarding the proportionality constant. This result can be interpreted as follows. While fitting $\ln (y)$ rather than $y$ itself, the importance of lower deposits is enhanced considerably. The weight function of Eq.(22) tends to balance this by returning weight to larger deposits, as it accounts for the fact that large deposits are more accurate (i.e have lower CV) due to a larger number of drops involved.

In Section 2.3 paired spray deposits were investigated. The relative pairwise difference RD was introduced (Eq.(1)). It is easily shown that RD is roughly proportional to $s_{y} / y$. This means that it can be expected that RD is proportional to $1 / \sqrt{ } y$. This inverse square-root trend is presented as a dashed line in Figure 12. The figure shows that the standard error in experimental RD values decreases slower than the inverse square-root behaviour suggests. See the Discussion section.

\subsubsection{Curve-fitting procedure}

Fine-tuning the model to the experimental data can be done in many ways. Several procedures have been tried. The most successful process is described here. A two-phase iterative procedure was chosen. In the first phase the Levenberg-Marquardt (LM) method was applied (Press et al. 2007) for fast convergence. The LM method is a modification of the Gauss-Newton method to improve iteration stability by damping the successive steps (through the so-called Marquardt parameter $\lambda$ ). The method is described in detail in Annex 6.

The iterative process was started with small $\lambda$ where the system approached the Gauss-Newton method and improvements were relatively large. That is, in early iteration steps the sum of squares, Eq.(17) decreased rapidly. After a number of iterations, the improvements decreased gradually and the iterative process tended to become unstable. Increasing the Marquardt parameter $\lambda$ helped to stabilize the system and further progress was possible. This process of gradually increasing $\lambda$ to stabilize the iterations had to be repeated several times. Ultimately, the iteration was stopped when a further increase of $\lambda$ did no longer result in significant improvements. 
At that point, phase two was started using the Pattern Search (PS) method (Hooke and Jeeves 1961). This relatively simple method converges more slowly although convergence to a (local) optimum is assured. Starting at a given set of parameters, each parameter is changed slightly and the new situation is evaluated by the sum of squares $\mathrm{S}$. The method looks for neighbouring cases where $\mathrm{S}$ decreases and repeats the search process from that point. The PS method is explained in detail in Annex 7. For the PS method the 'star-wise' variant was used.

\subsubsection{Curve-fitting results}

After the optimal curve-fit was reached, the correlation coefficient between measured and simulated deposits was 0.86 . Figure 19 shows measured deposits vs. simulated deposits, together with lines indicating the $10^{\text {th }}, 50^{\text {th }}$ and $90^{\text {th }}$ percentiles. These lines indicate that small computed deposits ( $<1 \%$ applied dose) tend to slightly underestimate the observed deposits. For deposits $>1 \%$ applied dose the line P50 is close to the ideal line $y=x$, indicating that on average the model fits close to the observed deposits. The lines P10 and P90 are almost parallel to the line P50, indicating that the accuracy of the model is not biased for certain levels of deposits (e.g. high or low deposits). Figure 20 shows the ratio of observed and predicted deposits as a function of predicted values. Ideally, the dots should be normally distributed across the horizontal line $y=1$. Indeed the median curve P50 is close to the ratio level $y=1$. Note that the variation is much wider than that for paired deposits as shown in Figure 10, which shows that the differences between measured and modelled deposits cannot be explained by the uncertainties in the measurements. In Figure 21 a frequency distribution is shown of the logarithm $\ln (\mathrm{y} / \mathrm{f})$ of the ratio of measured and computed deposits. For $\ln (\mathrm{y} / \mathrm{f})<0$ measured deposits are less than the corresponding predicted deposits, while for $\ln (y / f)>0$ it is the other way round. The dashed curve is a best fitting normal distribution with mean -0.09 and standard deviation $(\sigma)$ 0.39. It shows that the frequency distribution is almost normal, indicating that the differences between measured and computed deposits are likely to be of a stochastic nature. Assuming a confidence interval bounded by $2 \sigma=0.78$, the ratio of $y$ and $f$ is within the range $e^{-2 \sigma}=0.45$ and $\mathrm{e}^{+2 \sigma}=2.20$, respectively. That is, individual samples of downwind deposits of spray drift can be modelled within a factor 2.2. This range may seem rather wide, however, it reflects the possible variation in a single deposit, based on averaged conditions as input; see Discussion chapter for further interpretation.

At first glance it seems more logical to plot simulated deposits (predicted) as a function of measured deposits (observed). This however will lead to a statistical artefact, when for instance trend lines are computed (Piñeiro et al. 2008).

The curve-fitting process may lead to a local optimum rather than the absolute optimum. The usual way to check this is to repeat the curve-fitting process with a different set of initial values for the parameters to be optimized. Repeated curve-fittings led to approximately the same set of optimal parameters, which confirms that the found solution is probably the absolute optimum. The final values of the parameters to be fitted are listed in Annex 9. 


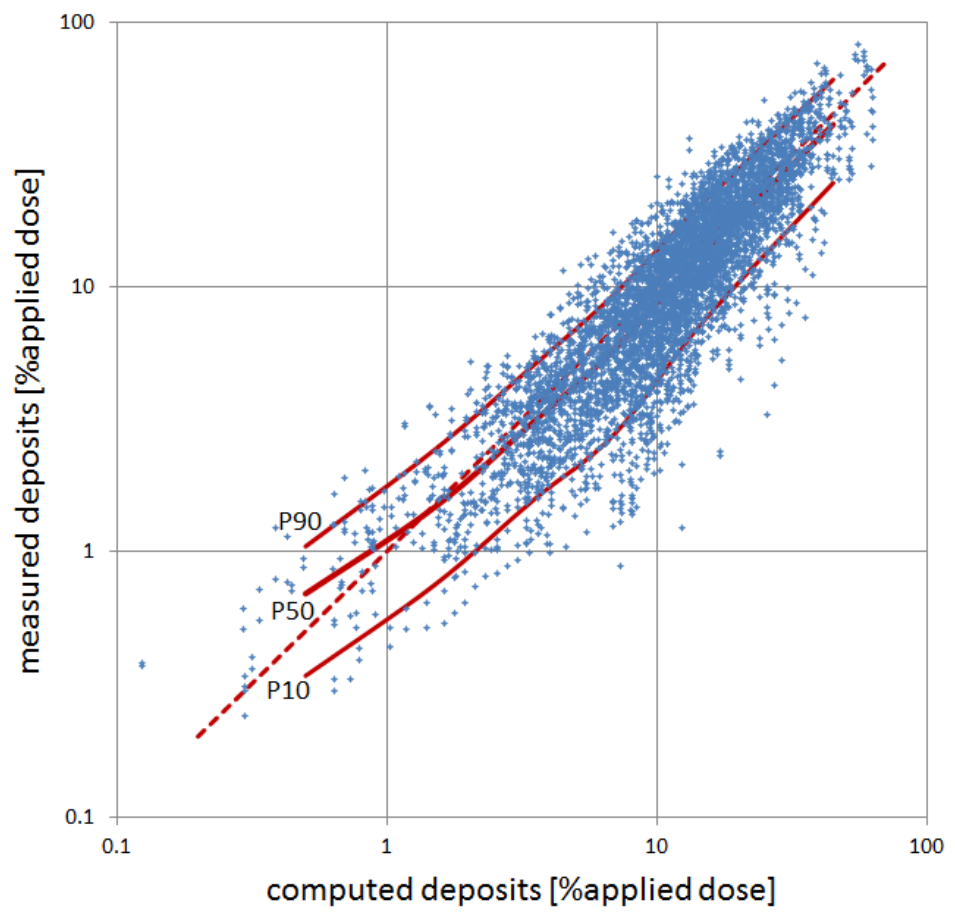

Figure 19 Correlation between measured and computed deposits. Red dashed line: ideal correlation $(y=x)$. Red solid lines represent lines of $10^{\text {th }}, 50^{\text {th }}$ and $90^{\text {th }}$ percentiles.

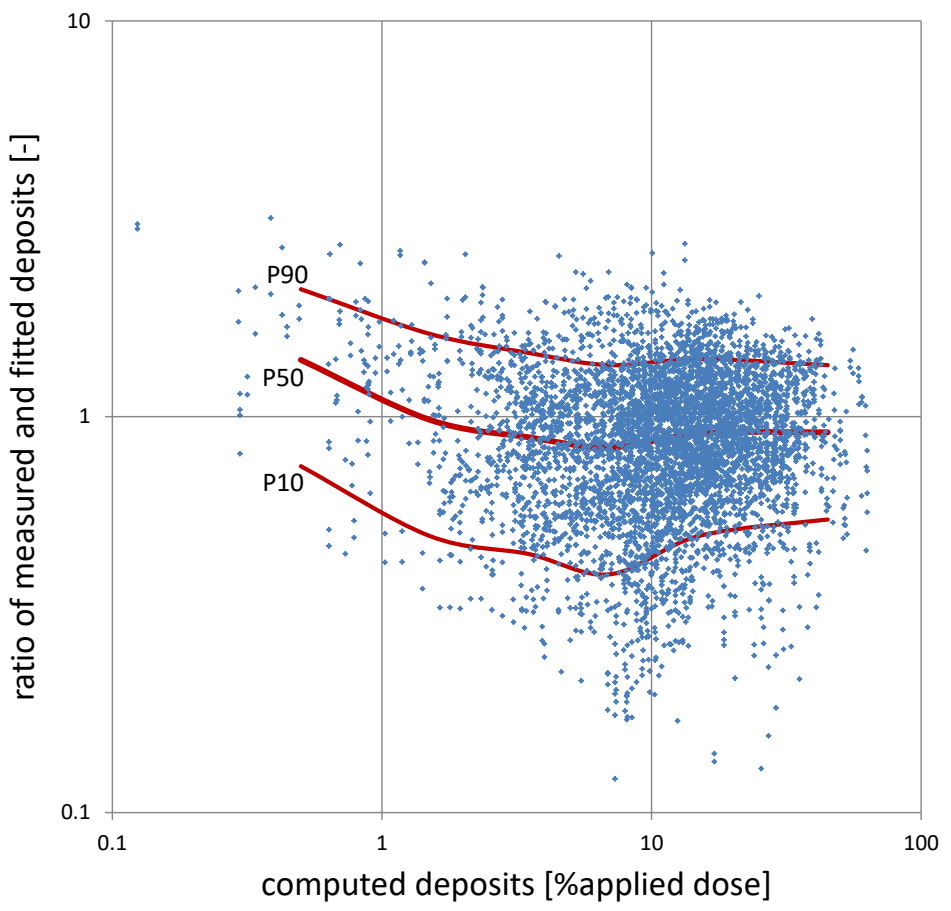

Figure 20 Ratio of measured and computed deposits as a function of computed deposits. Red solid lines represent lines of $10^{\text {th }}, 50^{\text {th }}$ and $90^{\text {th }}$ percentiles. 


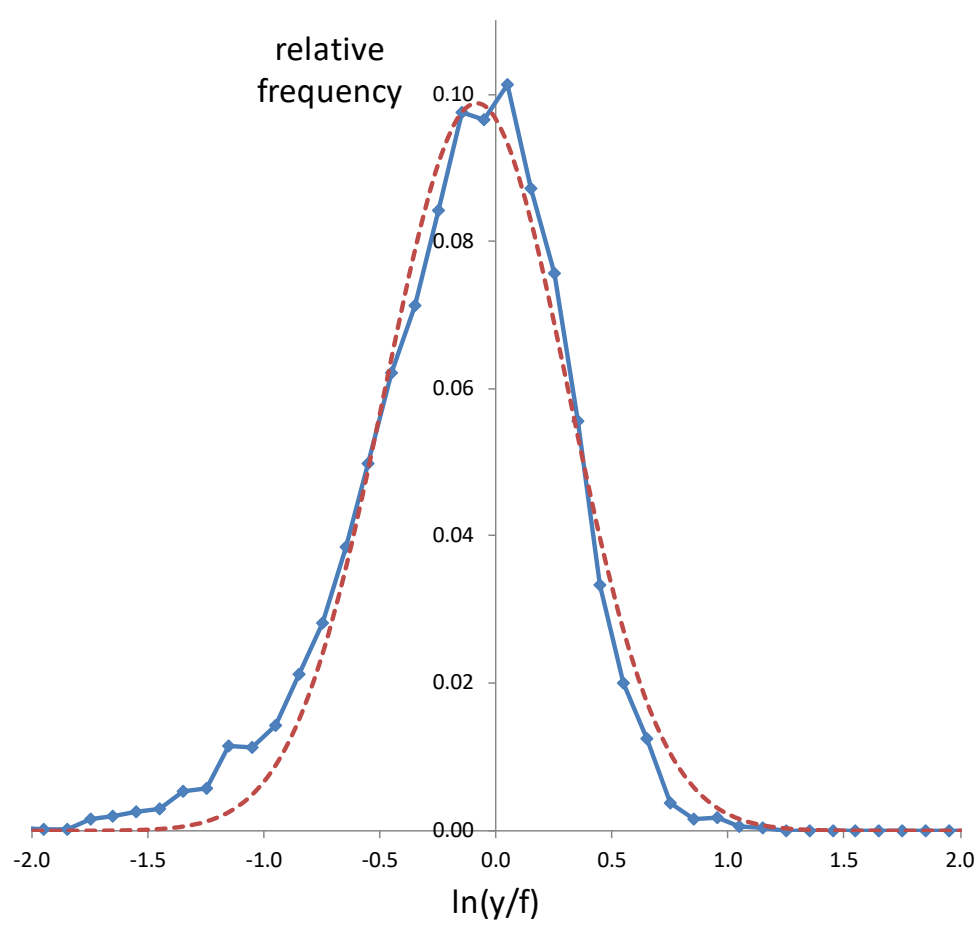

Figure 21 Frequency distribution of log ratios of measured and computed deposits. Dashed curve: best fitting normal distribution.

The occurrence of scattered data cannot be avoided in spray drift experiments. As an example, Figure 22 shows the downwind spray deposits of eight replicates (four separate experiments of paired deposits) carried out on one day. The solid curves indicate the modelled deposits. These curves are very close to each other since the environmental conditions varied only slightly during the day. The experimental data, however, are scattered and this cannot be related to specific environmental conditions.

Another feature in some cases is the reduced spray deposits nearby the orchard. In Figure 22 the deposits at $1.5 \mathrm{~m}$ downwind are well below the modelled deposits at that position, while the modelled deposits from $3-15 \mathrm{~m}$ fit closely to the measured deposits. The reduced spray deposits at this nearby distance are reflecting a 'shadow effect' of the orchard itself with respect to the spray cloud passing from above the trees. Also, when treating the outer tree row from the outside, the sprayer travels at about this distance from the tree row $(1.5 \mathrm{~m})$ and the sampling collectors are for a short while below the tractor, which may result in reduced deposits on the collectors at that distance. Formally, the edge of the orchard is located at one row spacing from the last tree row, that is at $3 \mathrm{~m}$ from the last row. This implies that the collectors at $1.5 \mathrm{~m}$ are located within the orchard area and, strictly speaking, not considered 'off target'. Therefore, it was not considered worthwhile to adjust the model to better predict samples at $1.5 \mathrm{~m}$ downwind. 


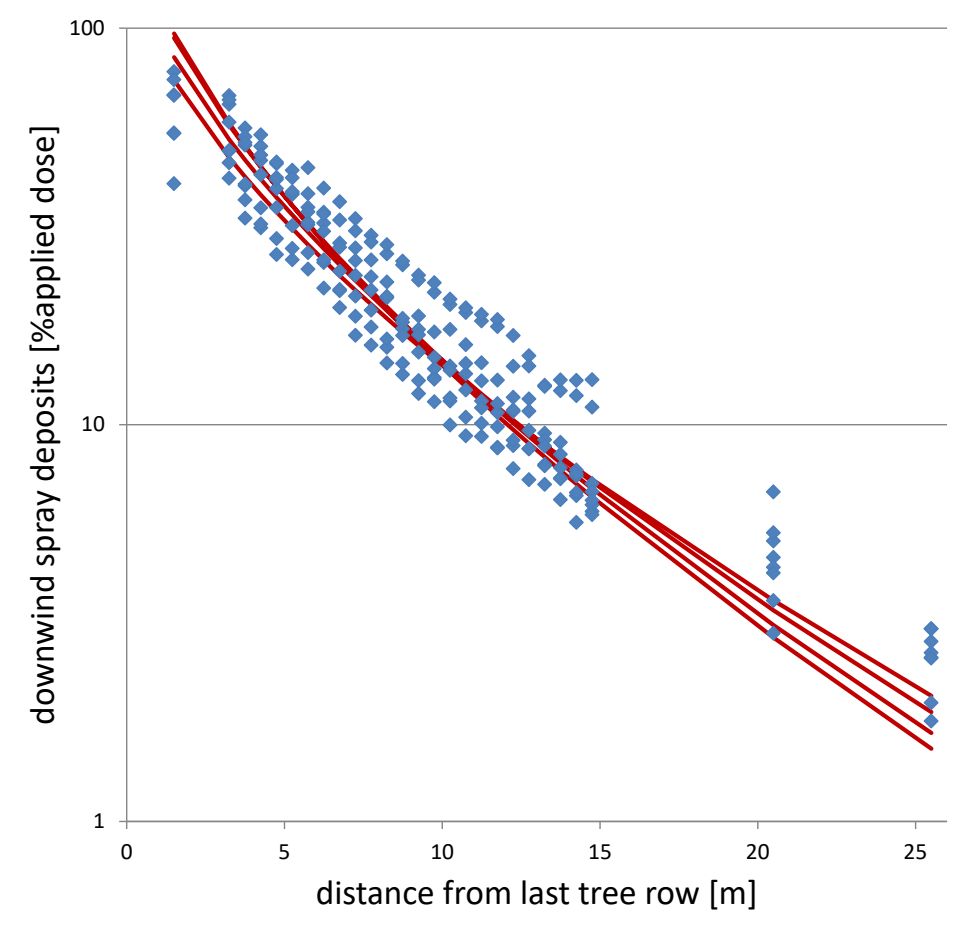

Figure 22 Four experiments (each with paired deposits) on one day, with modelled curves. $B B C H 57, D O Y 109, T \sim 16^{\circ} \mathrm{C}, w \sim 3-4 \mathrm{~m} / \mathrm{s}$.

\subsection{Drift-reducing application techniques}

The SPEXUS model was primarily built on data obtained from experiments using a conventional application technique. Several application techniques have been classified into drift reduction classes, according to their potential to reduce drift deposits under standardized conditions (Van de Zande et al. 2017). This Section describes how drift mitigation techniques were incorporated formally into the spray drift model.

\subsubsection{Drift reduction curves}

Drift mitigation by technical adjustments may lead to considerable reductions in downwind deposits of spray drift with respect to the reference application technique (Section 2.1). In principle, drift reductions are a function of downwind distance. Relatively close to the field edge, drift reductions are usually low, while farther downwind the reductions increase and approach a certain constant level. For classification of drift mitigation techniques, drift reductions are assessed for orchards with trees in full leaf at the distance where the water surface of a standardized ditch is located, i.e. $4.5-5.5 \mathrm{~m}$ downwind from the last tree row, the 'evaluation zone'. An application technique showing a drift reduction of at least $50 \%$ but less than $75 \%$ at the evaluation zone is classified as DRT50 (drift reducing technique 50\%). Similarly, drift reduction classes DRT75, DRT90, DRT95, DRT97.5 and DRT99 have been defined, see Table 3. 
Table 3 Classification of drift reducing techniques for spray application. Drift reductions are evaluated at downwind distance 4.5 - $5.5 \mathrm{~m}$ from the last tree row with respect to a reference application technique, considering trees in full leaf.

\begin{tabular}{cc} 
Classification & Drift reduction [\%] \\
none & $50-74$ \\
\hline DRT50 & $75-89$ \\
\hline DRT75 & $90-94$ \\
\hline DRT90 & $95-97.4$ \\
\hline DRT95 & $97.5-98.9$ \\
\hline DRT97.5 & $\geq 99.0$
\end{tabular}

Figure 23 shows measured drift reductions as a function of downwind distance for application techniques representative for the different DRT classes in a full-leaf orchard. The solid lines are curves fitted to the experimental data. Clearly, drift reduction percentages increase with distance and approach a limit. Note that for DRT75 and DRT90 drift reductions still increase beyond the evaluation zone. For the other classes the drift reduction at the evaluation zone is approximately at its limiting value. Since in all practical situations there is a minimal crop-free zone of $3 \mathrm{~m}$, edge-of-field watercourses will not be closer than that distance. Therefore, the drift reduction curves need not to be determined down to zero distance.

Similarly, Figure 24 shows drift reductions measured and fitted for dormant trees. A DRT50 application technique, which by definition gives at least $50 \%$ drift reduction in the full-leaf stage, does not reach that reduction level in the dormant stage where the bare trees cannot intercept much of the spray cloud. For dormant trees, the DRT50 technique reduces drift only by about $20 \%$ at the evaluation zone. Similarly, the other DRT classes show lower reductions in dormant stage than in full-leaf stage.

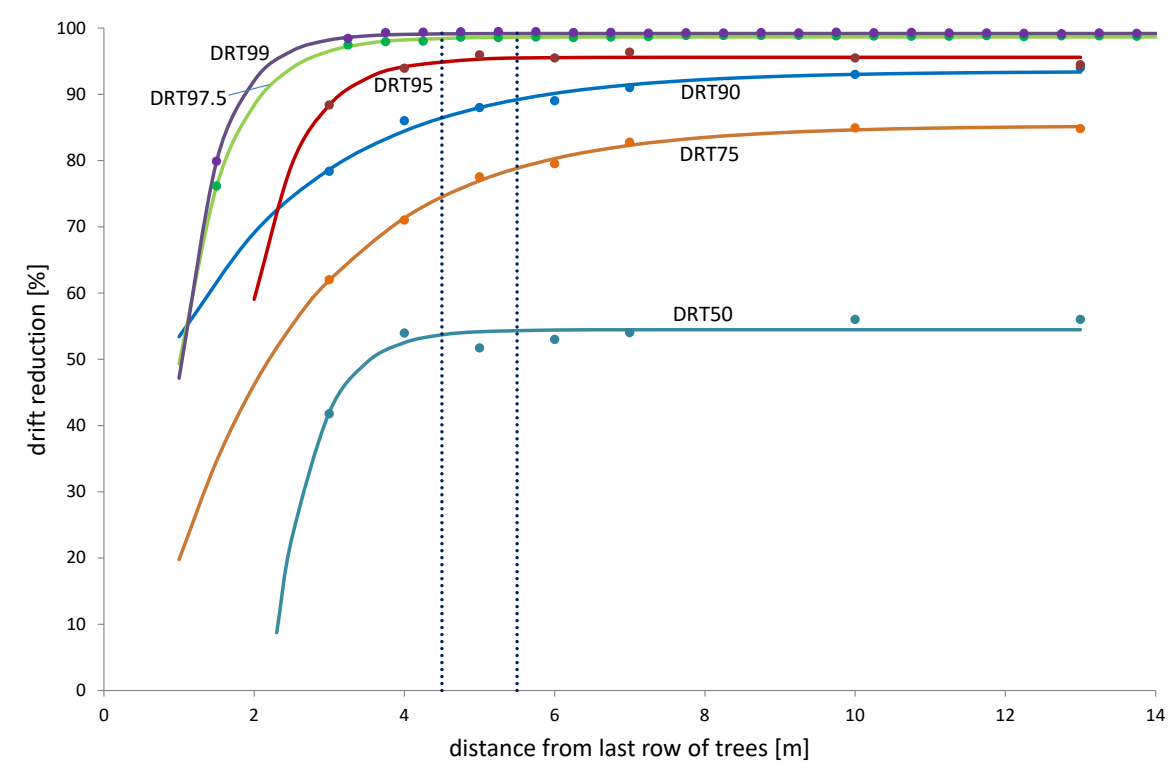

Figure 23 Drift reduction as a function of downwind distance for several DRT-classes, as a percentage of the deposits obtained for conventional application technique; for orchards in full leaf. Dots: measured reductions (Van de Zande et al. 2017); curves: fitted reductions. Dotted lines indicate the evaluation zone $(4.5-5.5 \mathrm{~m})$. 


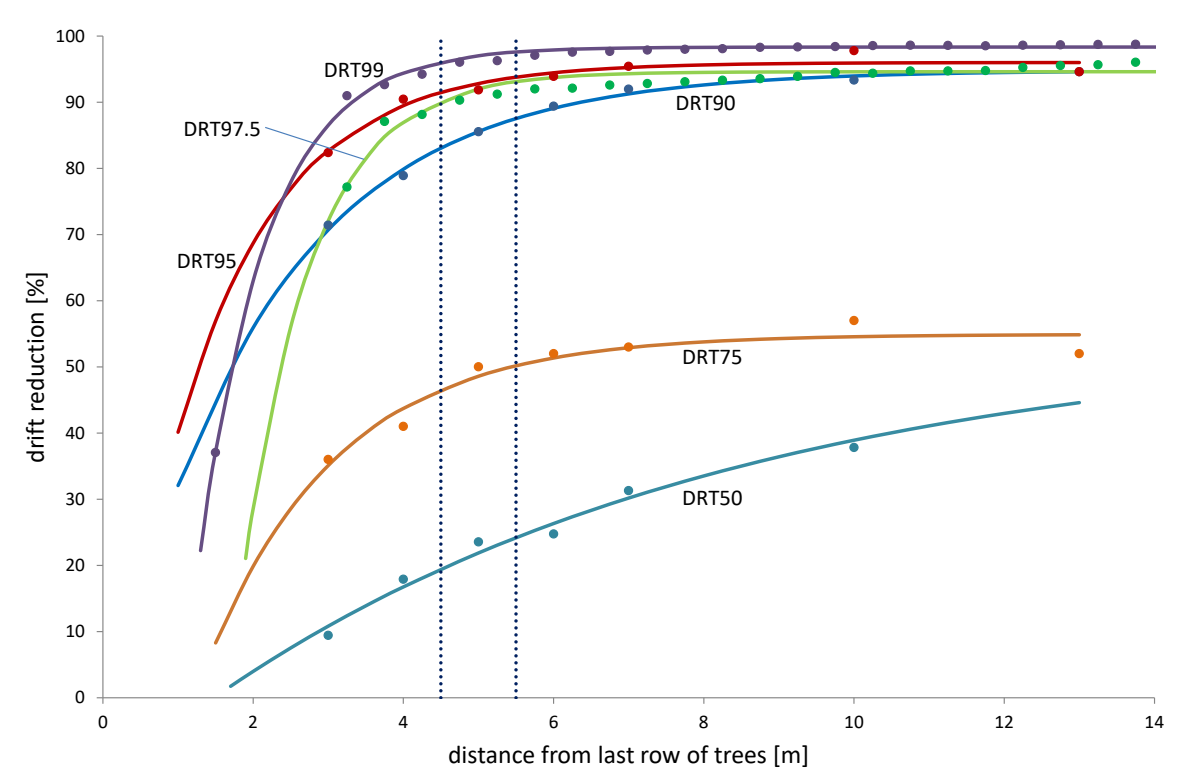

Figure 24 Drift reduction as a function of downwind distance for several DRT-classes, as a percentage of the deposits obtained for conventional application technique; for orchards in dormant stage. Dots: measured reductions (Van de Zande et al. 2017); curves: fitted reductions. Dotted lines indicate the evaluation zone $(4.5-5.5 \mathrm{~m})$.

\subsubsection{Smooth transition between the dormant and full-leaf crop stages}

The spray drift model described in the previous sections uses continuous growth stages. When using a drift reducing application technique, this continuous feature will be lost as drift reductions are quantified only for trees either in full-leaf stage or in dormant stage (Section 3.3.1). Currently, there are no drift reductions measured for intermediate growth stages. Clearly, in early spring the reduction curves for dormant trees are applicable, while in summer the full-leaf reduction curves can be used. Somewhere in between one has to decide which growth stage is more appropriate. An arbitrary choice is to use the transition days for low to high fan speed, which are given by BBCH range $70-95$. The first day of $\mathrm{BBCH} 70$ is DOY 124; the last day of $\mathrm{BBCH} 95$ is DOY 335 (Section 3.1.6). Any choice, however, will lead to inconsistent behaviour in computed drift deposits near those transition days. As an example Figure 25 shows the drift deposits on an edge-of field watercourse with water surface approximately 4-6 m downwind from the last tree row; a cross wind of $3.0 \mathrm{~m} / \mathrm{s}$ is assumed; temperature is $15^{\circ} \mathrm{C}$. The top curve shows drift deposits as a function of day-of-year for the conventional application technique ('REF'). At about DOY 100 the canopy starts developing and the interception of spray by the trees increases. Consequently, spray drift deposits on the surface of the watercourse decrease, reaching a minimum in summer with a fully developed tree canopy. The small jumps (at DOY 124 and 335) are caused by the change of low to high fan speed (and back again) of the spraying equipment. The increased fan speed forces the spray cloud to deposit farther downwind, thus causing a decrease on the nearby watercourse. Fan speed has a twofold setting (high, low) which the farmer carries out; so a sudden change in deposits can be expected.

Similarly, the dashed line represents deposits for the DRT50 technique. The jumps in spray deposits at the mentioned days are now very large. The major cause of the jump is the change of dormant to fullleaf reduction model. Clearly the canopy does not change overnight from dormant to full-leaf, so the observed large jump is highly unnatural. In the following paragraphs a smoothing algorithm is introduced to compute canopy dependent drift reductions by interpolation between the curves for dormant and full-leaf growth stages. The solid green curve in Figure 25 shows the result; a smoothed deposits curve showing only the small jump caused by the change in fan speed. Additionally, Figure 26 shows the corresponding drift reductions as a function of day-of-year for these two approaches. For other DRT techniques similar effects can be observed. 


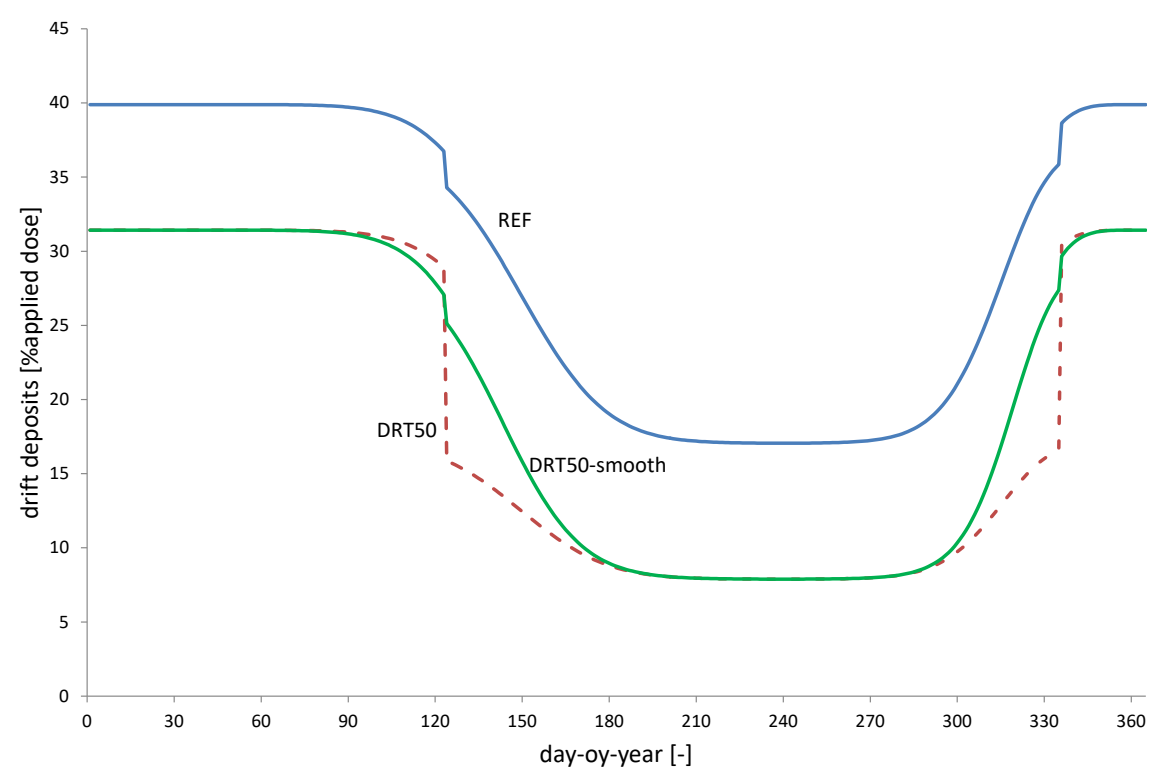

Figure 25 Drift deposits on an edge-of-field watercourse. Comparison of reference application technique and DRT50 technique; effect of transition smoothing based on tree growth stage. Wind speed $3.0 \mathrm{~m} / \mathrm{s}$; temperature $15^{\circ} \mathrm{C}$.

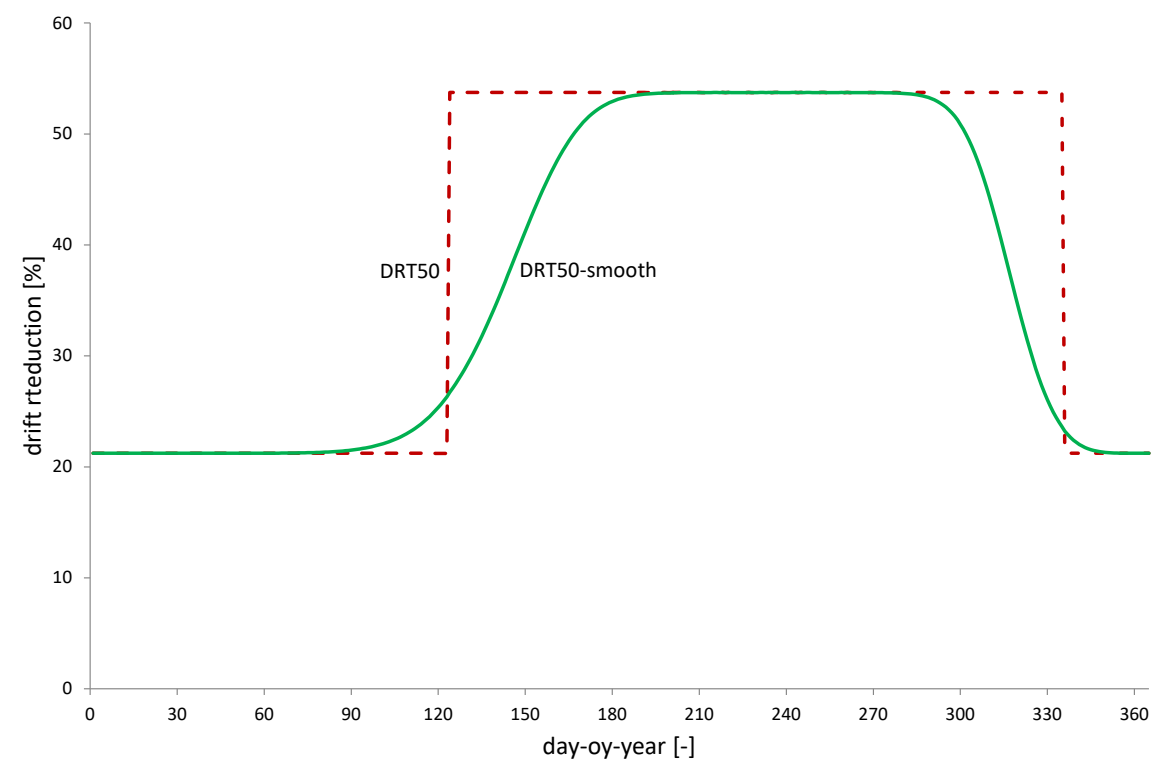

Figure 26 Drift reduction on an edge-of-field watercourse as a function of day-of-year when using a DRT50 application technique. Dashed curve: sharp transition at the change of dormant to full-leaf reduction curves. Solid smoothed line: drift reduction changes gradually when canopy density changes.

Since the tree canopy acts as a filter intercepting sprays, downwind deposits of spray drift strongly depend on canopy density. As shown in Section 3.3.1 the drift reduction curves depend on canopy density as well. Therefore it seems appropriate for intermediate growth stages to adjust drift reduction based on canopy density. The canopy density factor introduced in Section 3.1.5 offers a convenient alternative for the actual canopy density. A linear interpolation algorithm is used but with a quadratic dependence on canopy density:

$$
R_{a c t}=R_{F}+\left(R_{D}-R_{F}\right) \cdot\left(1-\frac{\beta}{\beta_{m}}\right)^{2}
$$


where $R_{a c t}$ is the actual interpolated drift reduction factor, $R_{F}$ is drift reduction for trees full in leaf, $R_{D}$ is drift reduction for dormant trees, $\beta$ is the canopy density factor and $\beta_{m}$ is its maximum for a fullgrown canopy. For $\beta=0$ and $\beta=\beta_{m}$ reductions $R_{D}$ and $R_{F}$ are obtained, respectively. The procedure is as follows. When spray application takes place using a drift reducing technique, both $R_{F}$ and $R_{D}$ are computed as if the canopy was fully grown and fully dormant, respectively. Next the canopy density factor $\beta$ is computed for the application date, and finally the interpolated drift reduction can be computed using Eq.(23).

A quadratic dependence on $\beta$ is used in Eq.(23) rather than a more simple linear relationship, to make the interpolation less sensitive to changes in $\beta$ when $\beta$ is close to $\beta_{\mathrm{m}}$. Several experiments in the period October to late November (when $\beta$ decreases but still is close to $\beta_{m}$ ) appear to support a reduced sensitivity to $\beta$. Figure 27 show an example of $\mathrm{R}_{\text {act }}$ as a function of $\beta / \beta_{m}$; the reduced slope of the curve at the right hand side indicates reduced sensitivity for larger $\beta$.

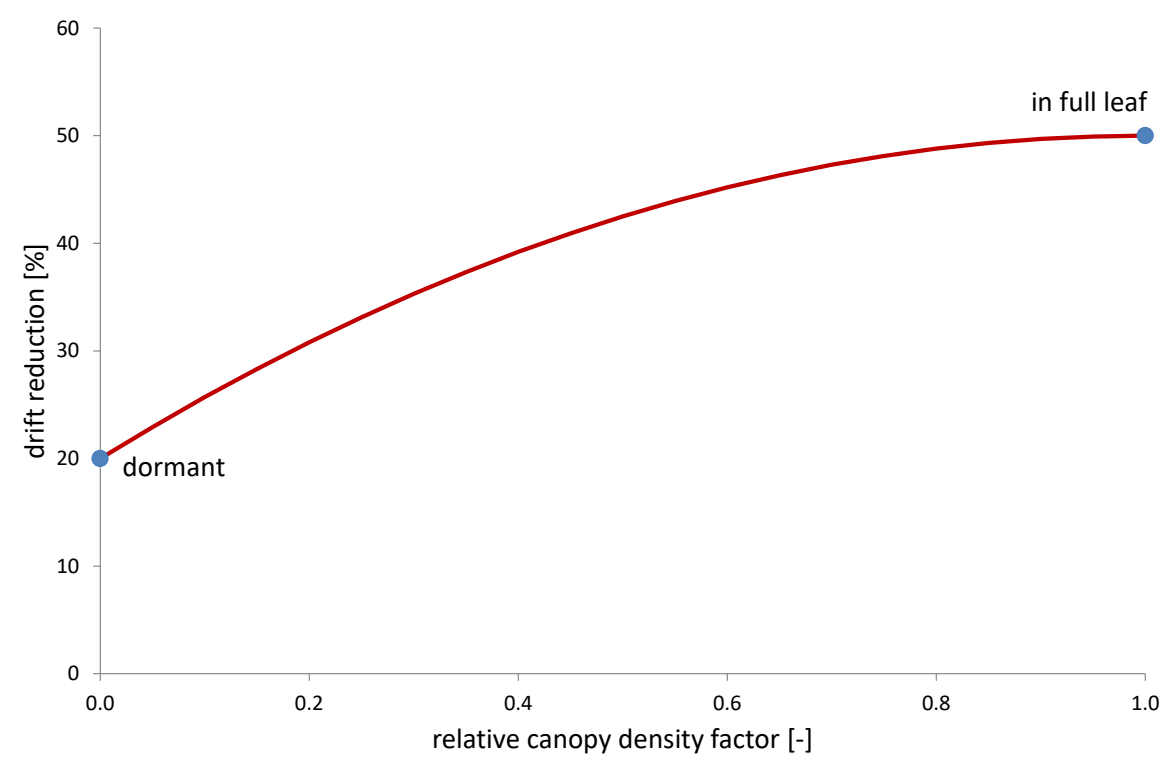

Figure 27 Example of transition function for drift reduction as a function of the canopy density factor $\beta$. The parabolic relation assures a decreasing sensitivity to changes in $\beta$ for increasing $\beta$.

\subsection{Averaged spray drift deposits onto a water body surface}

The model presented in the previous chapters computes the downwind deposits of spray drift $f(x)$ at a single location $x$. Often, the location of interest covers a certain finite distance range, such as the surface of an edge-of-field water body. In that case, the following procedure is applicable.

If wind direction is arbitrary, the drifting spray cloud will approach a downwind water body at an angle $\theta$, see Section 3.1.3 and Figure 28. Since drift deposits usually are expressed as a percentage of the (in-field) applied dose rate $D$ (unit: $\mathrm{g} / \mathrm{m}^{2}$ ), in fact deposits have the unit of (relative) mass per area as well. Now, the mass load $\Delta \mathrm{m}$ (unit: $\mathrm{g}$ ) on area $\Delta S$ equals the integral of the drift function $f(x)$ over the range $\mathrm{x}_{3} . . \mathrm{X}_{4}$, multiplied by the effective width $\Delta \mathrm{B}$ and the absolute dose $\mathrm{D}$ :

$$
\Delta m=\Delta B D \int_{x_{3}}^{x_{4}} f(x) d x
$$


The size of the deposition area is:

$$
\Delta S=\Delta B\left(x_{4}-x_{3}\right)
$$

Now the average deposits are (in \%dose rate):

$$
Y_{a}=\frac{\Delta m}{\Delta S} \cdot \frac{1}{D}=\frac{\Delta B D \int_{x_{3}}^{x_{4}} f(x) d x}{D \Delta B\left(x_{4}-x_{3}\right)}=\frac{\int_{x_{3}}^{x_{4}} f(x) d x}{\left(x_{4}-x_{3}\right)}
$$

which in fact is the length-averaged drift value across the water body surface in the direction of the wind. As a consequence of the Mean Value Theorem from mathematics, there must be some location $x_{a}$ between $x_{3}$ and $x_{4}$ (not necessarily the center position) for which $Y_{a}=f\left(x_{a}\right)$, see also Figure 29.

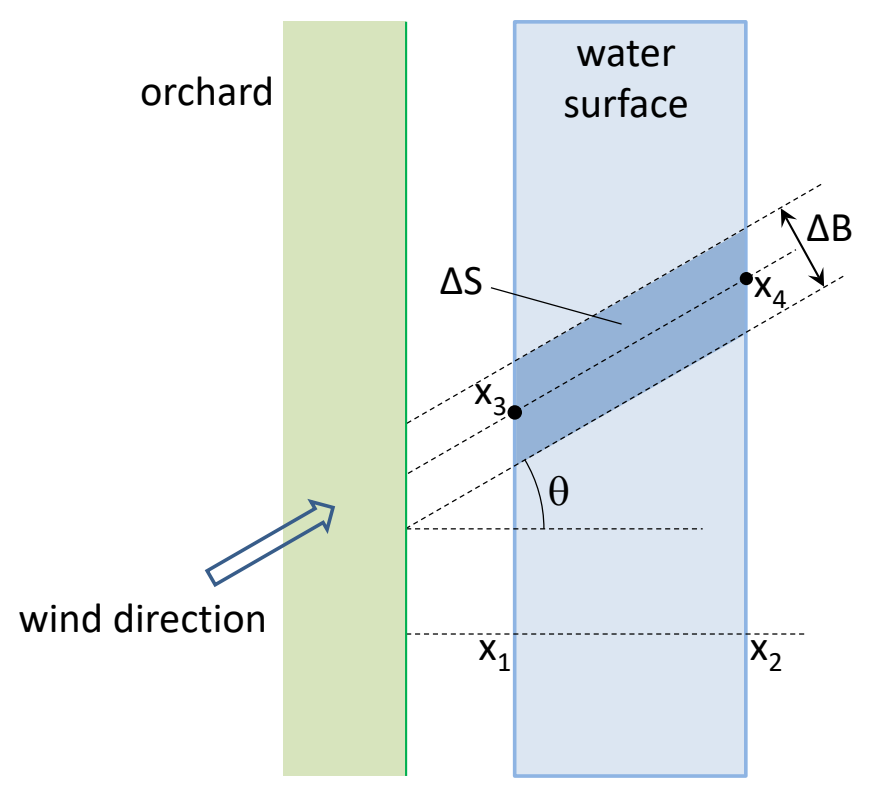

Figure 28 Visual aid for the computation of spray deposits onto a water body surface at arbitrary wind direction.

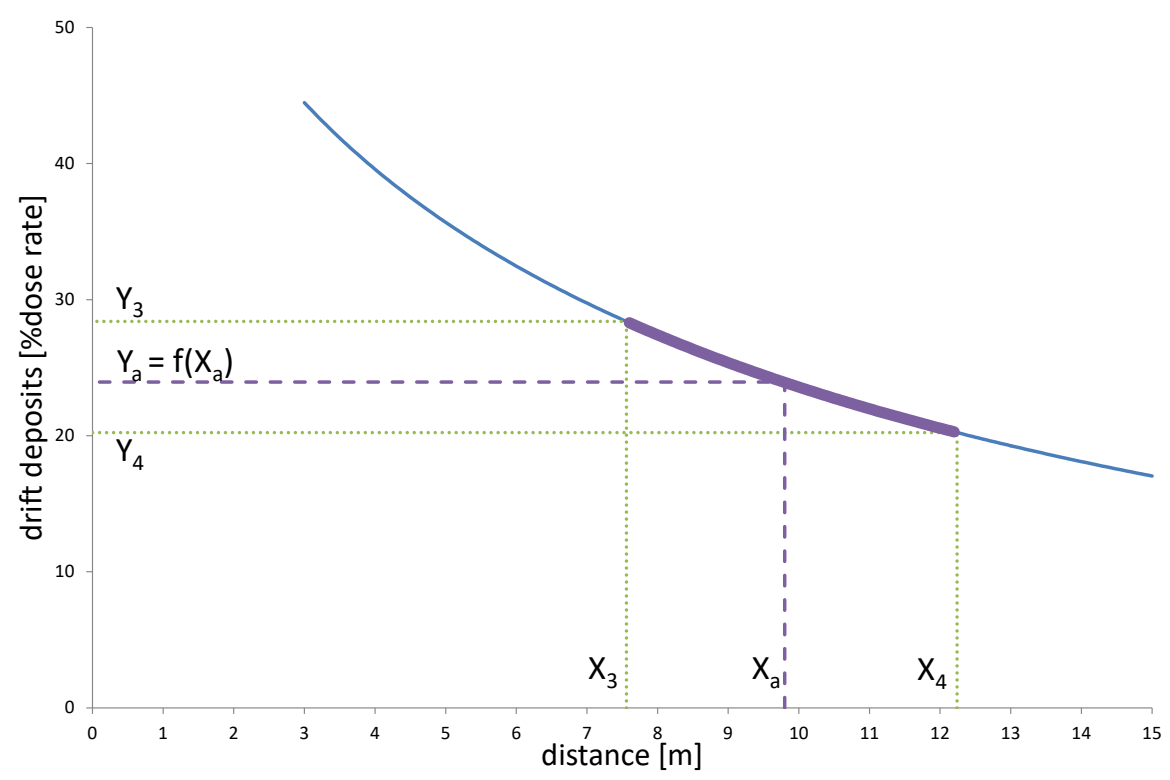

Figure 29 Example of drift deposition as a function of distance; water body surface ranges from $x_{3}$ to $x_{4}$ in the direction of the wind; the averaged deposit $Y_{a}$ on the water surface equals the drift value $f\left(x_{a}\right)$ at some location $x_{a}$ in between $x_{3}$ and $x_{4} . N B x_{a}$ is close to but not necessarily the average of $x_{3}$ and $x_{4}$. 


\section{$4 \quad$ Examples and applications}

A few examples may illustrate the use of the SPEXUS model. Example calculations were conducted for a square orchard of 1 ha, corresponding to 33 rows of trees and a path width of $3.0 \mathrm{~m}$ between the rows. Wind direction was perpendicular to the tree row direction, unless stated otherwise. Most cases implied a growth stage of $\mathrm{BBCH} 70$, corresponding to early May and a relatively open canopy. The indicated wind speeds were considered at $4 \mathrm{~m}$ height in the centre of the orchard, i.e. $1.75 \mathrm{~m}$ above the trees (Section 2.1.1). A conventional spray application technique was assumed with a high fan speed.

\subsection{Spray drift deposits vs. downwind distance}

The first example is the most straightforward: downwind deposits of spray drift as a function of distance. Figure 30 shows the drift curves for three wind speeds, all at the same temperature and $\mathrm{BBCH}$. The log-normal lines are curved due to the parameter c in Eq.(3). For low wind speeds, spray deposits occur close to the orchard and decrease rapidly for increasing distance. At higher wind speeds, the spray cloud is carried a longer distance, thus increasing the deposits farther downwind. Consequently, the deposits just outside the orchard, in the shadow of the last tree row, should decrease. The drift curve for wind speed of $5 \mathrm{~m} / \mathrm{s}$ illustrates these features (Figure 30).

Figure 31 shows drift curves vs distance for three air temperatures. The curve for $\mathrm{T}=15^{\circ} \mathrm{C}$ is the same as that for $w=3 \mathrm{~m} / \mathrm{s}$ in Figure 30 . The three curves are relatively close and differences are relatively small. Yet, there seems to be a trend that farther downwind the deposits decrease when temperature rises. The effects of temperature on downwind spray deposits are complex. Discussions on these effects is given in Section 4.4 and the Discussion section (Chapter 5).

Although it is hard to compare effects of wind speed and temperature directly, since these are different quantities, the figures indicate that for realistic changes in wind speed and temperature, the drift curves appear to be more sensitive to wind speed.

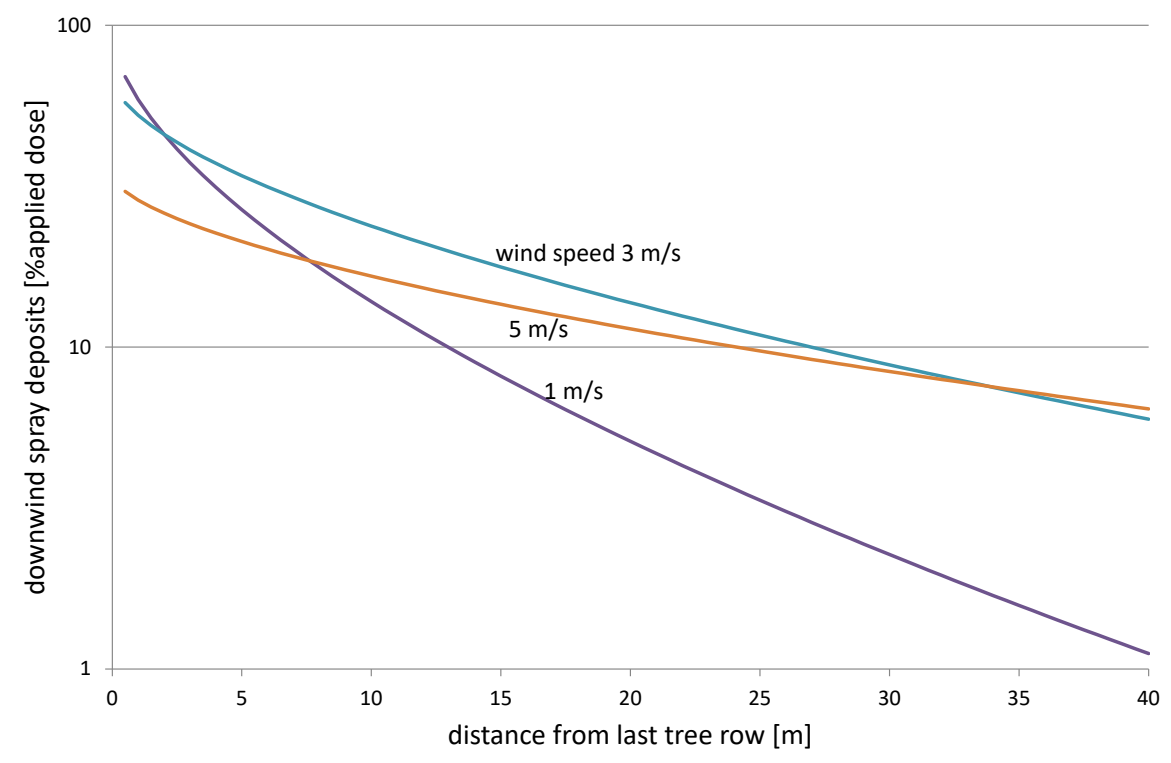

Figure 30 Downwind spray deposits as a function of distance from the last tree row, for three wind speeds (temperature $15^{\circ} \mathrm{C}, \mathrm{BBCH} 70$, conventional spray application, high fan speed). 


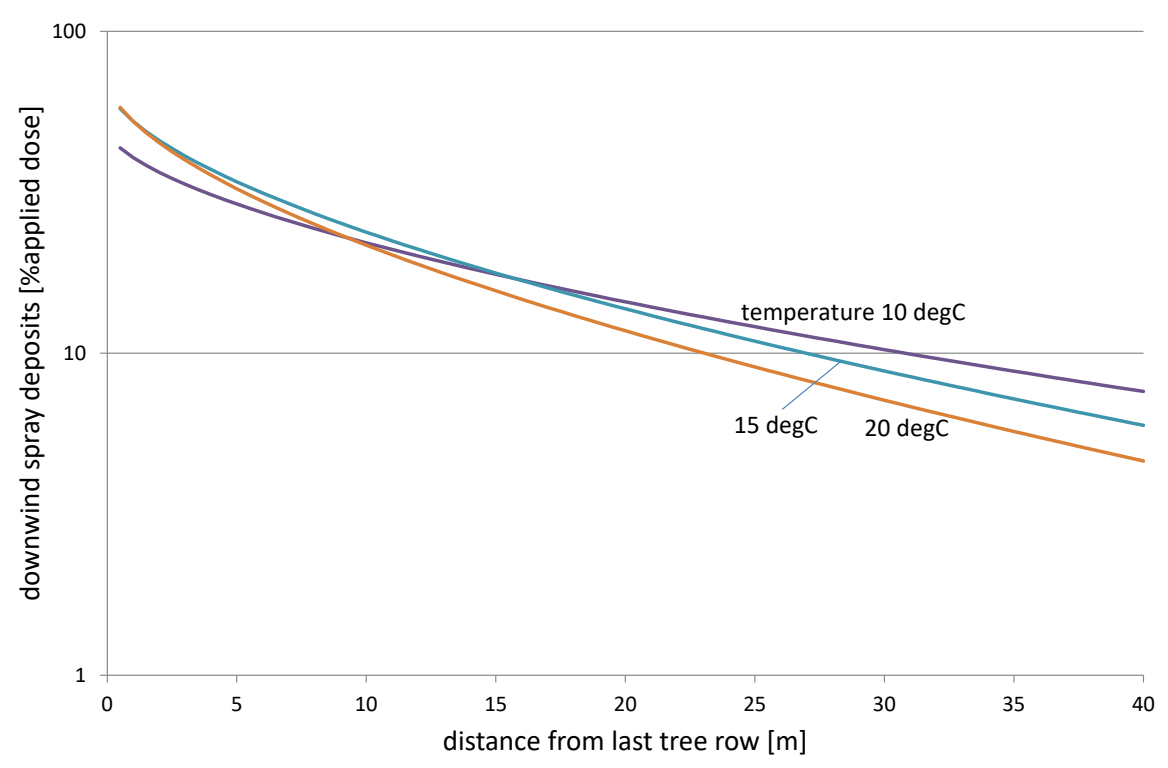

Figure 31 Downwind spray deposits as a function of distance from the last tree row, for three temperatures (wind speed $3 \mathrm{~m} / \mathrm{s}, \mathrm{BBCH} 70$ ).

\subsection{Effect of wind speed on downwind deposits}

Figure 30 in the previous section showed that wind speed significantly affects the curve for drift deposits. When considering a field situation, the location of interest (e.g. the water surface) is fixed, while the wind speed varies. Therefore it is useful to investigate the drift deposits at a fixed location as a function of wind speed. A typical edge-of-field watercourse may be located at a distance $4-6 \mathrm{~m}$ from the last tree row. For such a watercourse, Figure 32 shows deposits of spray drift in a cross wind, as a function of wind speed. The curves for three air temperatures are shown; $\mathrm{BBCH}$ is 70 . The highest drift deposits occur at a wind speed between 2 and $3 \mathrm{~m} / \mathrm{s}$, depending on temperature. For low wind speeds ( $<2 \mathrm{~m} / \mathrm{s}$ ) deposits are low since the spray cloud is not carried much downwind. Apparently, at higher wind speeds ( $>4 \mathrm{~m} / \mathrm{s}$ ) the spray cloud is carried farther downwind, to the other side of the assumed watercourse. This is supported by experimental observations as shown in Figure 4.

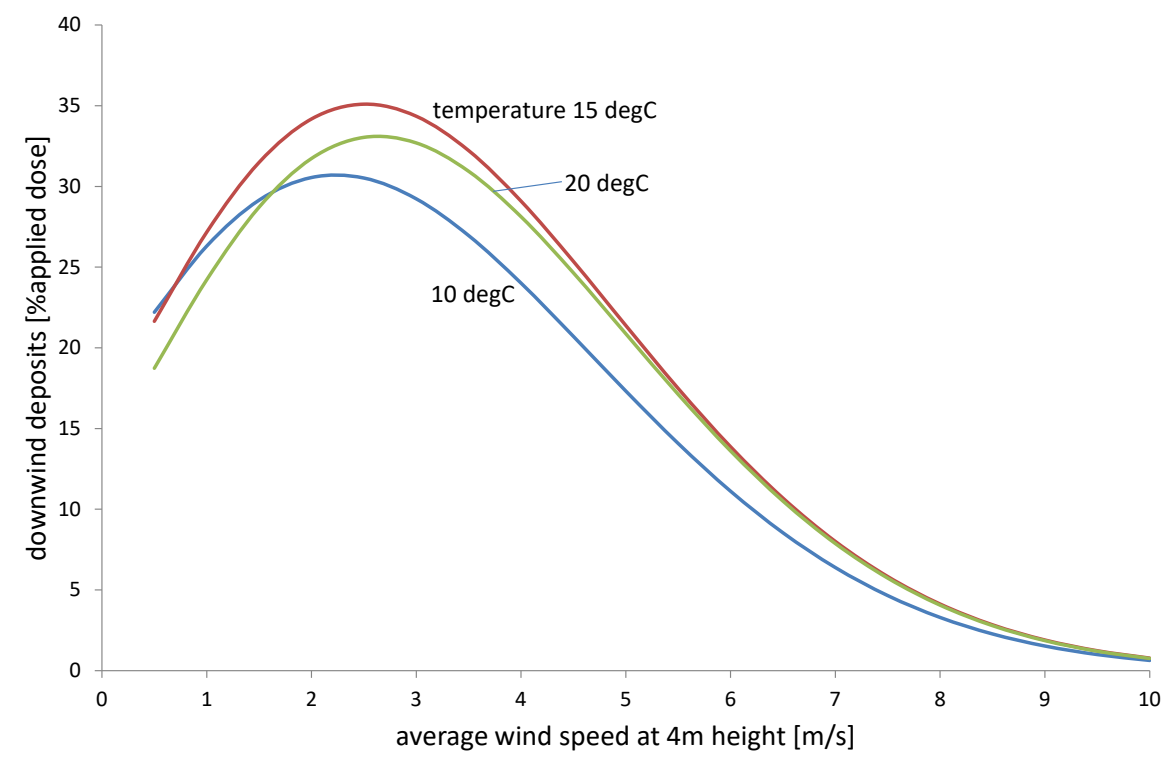

Figure 32 Downwind spray deposits at $4-6 m$ downwind from the last tree row, as a function of wind speed, for three ambient temperatures; $\mathrm{BBCH} 70$. 
Figure 33 shows deposits on three different ranges of downwind distance. The wind speed where the highest deposits are observed is higher when the distance range of interest is located farther downwind. Apparently, for each downwind distance there is a wind speed that returns the highest deposits of spray drift at that location. This is shown in Figure 34. For instance, at $10 \mathrm{~m}$ downwind the deposits reach a maximum when wind speed is $3 \mathrm{~m} / \mathrm{s}$. When wind speed is $<3 \mathrm{~m} / \mathrm{s}$ the spray cloud tends to deposit nearer to the orchard $(<10 \mathrm{~m})$, while at wind speeds $>3 \mathrm{~m} / \mathrm{s}$ the cloud tends to deposits farther downwind $(>10 \mathrm{~m}$ ). Although the graph is not extended beyond $20 \mathrm{~m}$, the shape of the curve in Figure 34 suggests that at wind speeds of about $5 \mathrm{~m} / \mathrm{s}$ (the maximum wind speed allowed in GAP) the depositing spray cloud can easily cover several tens of meters. Note that Figure 34 only links downwind distance and wind speed for highest deposits at that location. The actual height of such maximum deposits decrease with distance, as indicated by Figure 33.

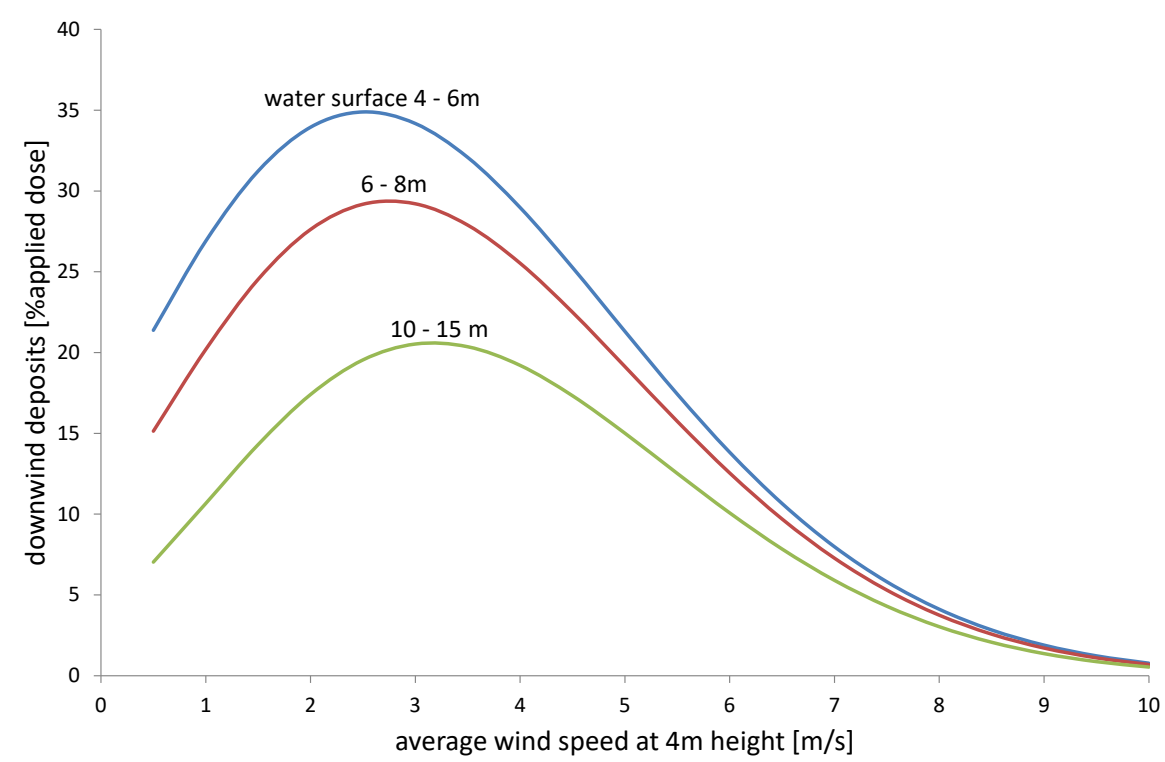

Figure 33 Downwind spray deposits onto three watercourses at different distances from the last tree row, as a function of wind speed.

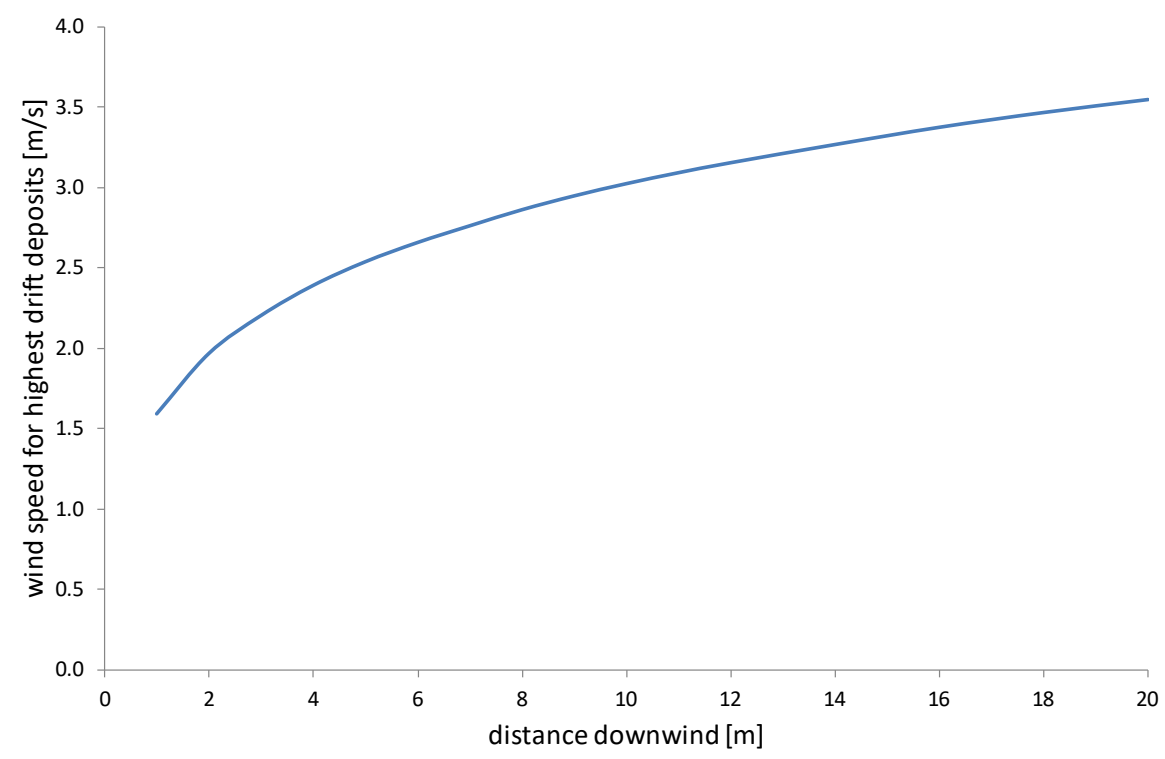

Figure 34 Wind speed for which at a given downwind distance the highest spray drift deposits occur. (Temperature $15^{\circ} \mathrm{C}, \mathrm{BBCH} 70$, conventional spray application). 


\subsection{Effect of wind direction on downwind deposits}

As mentioned in Section 3.1.3, for wind directions not perpendicular to the field edge, the water surface of an edge-of-field watercourse is located effectively farther downwind. This implies that the drifting spray cloud has to travel a longer distance to the water surface and corresponding drift deposits must decrease. If the wind direction is parallel to the field edge, the effective distance to the watercourse is infinite ( $\mathrm{s}=\infty$, Eq. (7)) and deposits must be zero. For wind directions $>90^{\circ}$ or $<-90^{\circ}$ the wind is blowing towards the field and the field edge is an upwind edge where no drift deposits can occur. Figure 35 shows simulation results for spray drift deposits on a ditch located $4-6 \mathrm{~m}$ downwind as a function of wind direction, with temperature $15^{\circ} \mathrm{C}, \mathrm{BBCH} 70$, and conventional application technique. The graph shows that with wind directions between $-30^{\circ}$ and $30^{\circ}$, as often occur in experiments with an intended cross wind situation, the drift deposits are close to their maximum value at exactly $0^{\circ}$. For wind directions deviating more than $30^{\circ}$ from a cross wind the deposits on the ditch decrease rapidly to zero (when wind becomes parallel to the field edge).

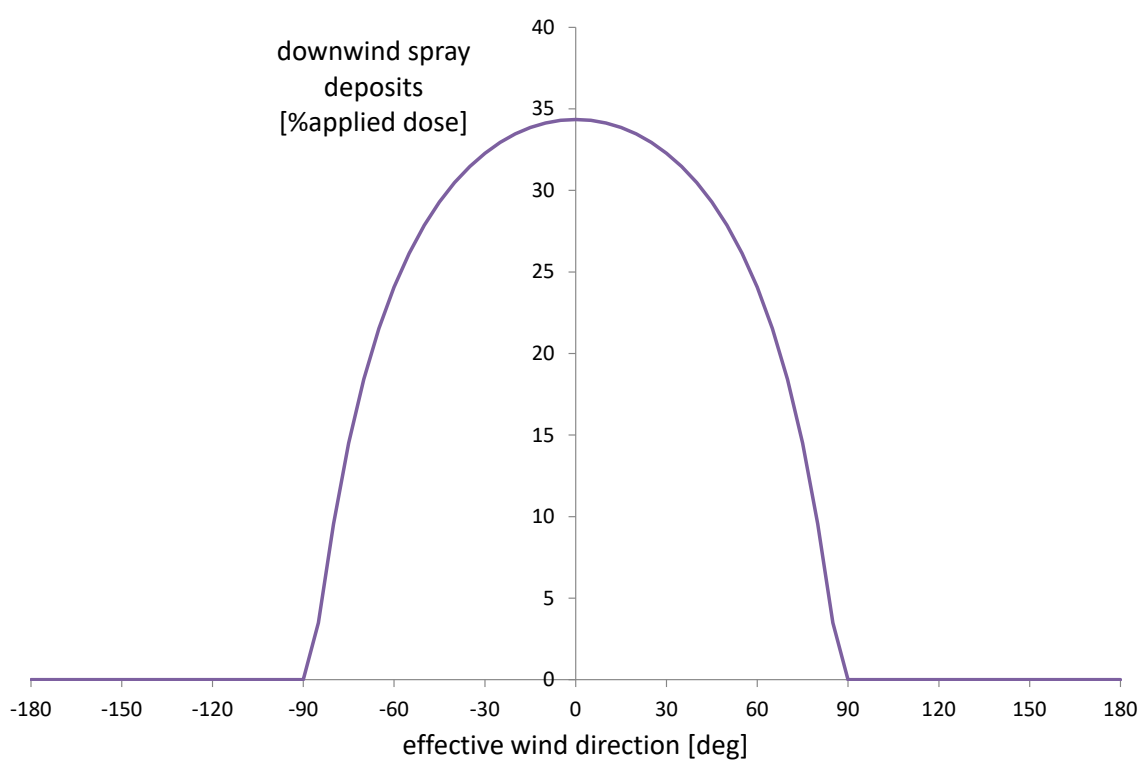

Figure 35 Downwind spray deposits at $4-6 m$ downwind from the last tree row, as a function of wind direction. (Wind speed $3 \mathrm{~m} / \mathrm{s}$; temperature $15^{\circ} \mathrm{C} ; \mathrm{BBCH} 70$ ). Wind direction 0 refers to a cross wind.

\subsection{Effect of ambient temperature on downwind deposits}

The effect of air temperature on spray deposits at $4-6 \mathrm{~m}$ downwind from the last tree row is shown in Figure 36 for three wind speeds. The experimental range of observed temperatures is given in Table 1 (Section 2.2): $5-28^{\circ} \mathrm{C}$. In Section 3.1.2 it was suggested to use fixed values of $\mathrm{F}_{\mathrm{T}}$ for $\mathrm{T}<5^{\circ} \mathrm{C}$ and $\mathrm{T}>30^{\circ} \mathrm{C}$ (see also Figure 15). Consequently, computed spray deposits will become constant as well outside the given range of temperatures, as can be seen in Figure 36.

Remarkably, both at low and high temperatures spray deposits are lower than at moderate temperatures. This, however, is supported by the experimental observations as shown in Figure 5 . The curves in Figure 36 show that the highest downwind deposits occur at moderate temperatures, but the exact temperature at the top of the curves depends on other parameters as well, such as wind speed.

Similar to wind speed, the temperature giving rise to the highest deposits depends on the downwind distance as well. E.g. Figure 31 shows that near the orchard $(<4 \mathrm{~m})$, higher temperatures $(15$ and $20^{\circ} \mathrm{C}$ ) appear to give higher deposits, while farther downwind lower temperatures $\left(10^{\circ} \mathrm{C}\right)$ appear to give higher deposits. There is no clear explanation for that yet. However, the curves in Figure 31 are relatively close and the modelled differences may not be significant. 


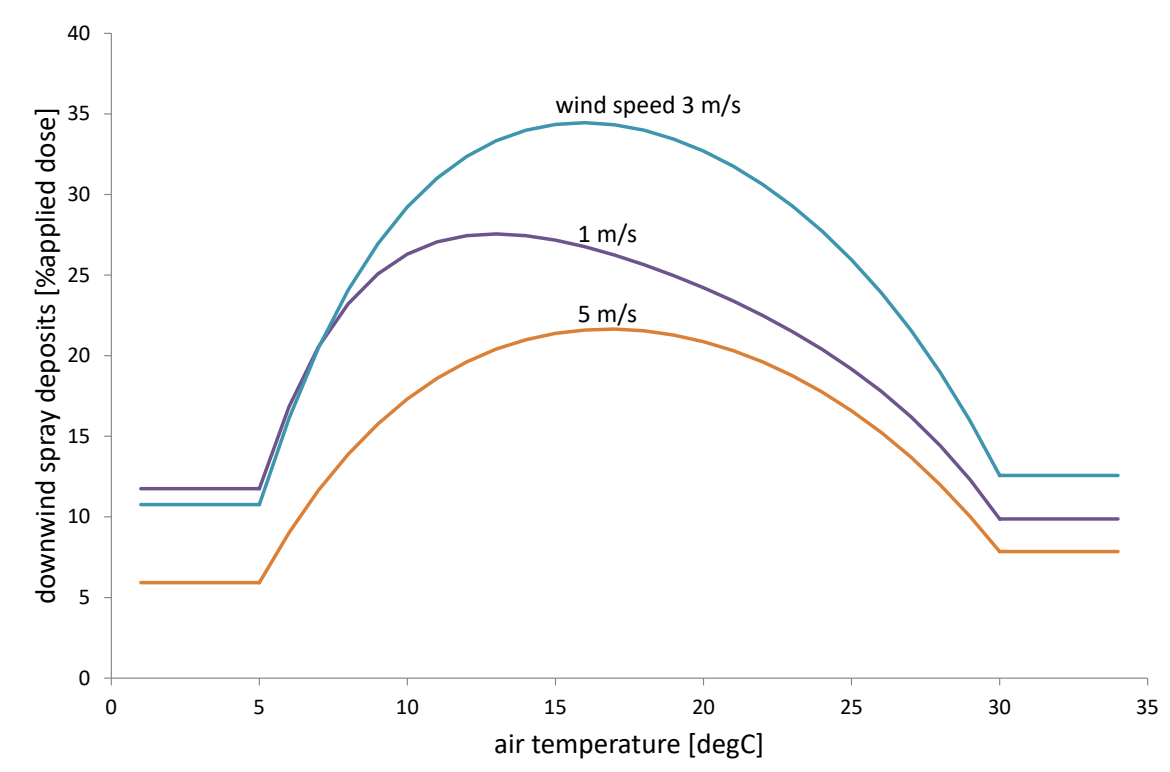

Figure 36 Downwind spray deposits at $4-6 m$ downwind from the last tree row, as a function of air temperature, for three wind speeds. ( $\mathrm{BBCH} 70$, conventional spray application).

\subsection{Effect of canopy density on downwind deposits}

An important feature of the current model is the continuous dependence on growth stage rather than using distinct models for a limited number of fixed growth stages. This is shown in Figure 37, where spray deposits at a typical water body surface $(4-6 \mathrm{~m})$ are given as a function of $\mathrm{BBCH}$, for three wind speeds, cross wind direction. In summer and autumn when the trees are in full leaf (BBCH 75 - 95), the orchard can intercept much more spray and the downwind deposits of spray drift are relatively low. There is some effect of wind speed, basically reflecting what was already found in Section 4.2. Using the unique relationship between $\mathrm{BBCH}$ and DOY, as shown in Figure 17 (Section 3.1.5), the curves of Figure 37 could have been shown as a function of DOY also.

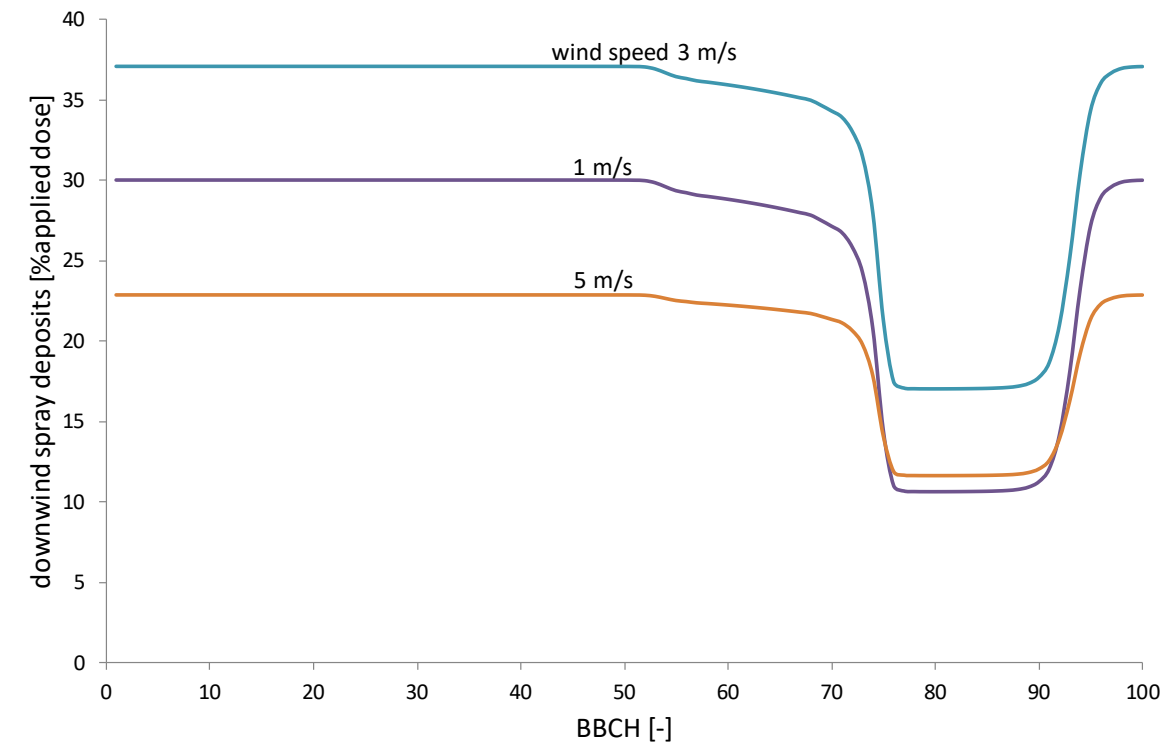

Figure 37 Downwind spray deposits at $4-6 m$ downwind from the last tree row, as a function of growth stage $(B B C H)$, for three wind speeds. (temperature $15^{\circ} \mathrm{C}$; high fan speed; cross wind). 


\section{Discussion}

The SPEXUS spray drift model developed and described in this report depends on a wide range of experimental drift deposits. Still, a significant variance remains (Figure 19). A large set of parameters had to be optimized (Annex 9). In such occasion, usually parameters are not fully independent: the effect of a change in one parameter may be compensated more or less by an appropriate change in another parameter. So how can we be sure that the final optimum is the best solution? Actually, we cannot. Each numerical search method for minimizing sum-of-squares can be depicted as taking sample solutions in a n-dimensional surface and estimating the height at that location in the landscape. The optimum found represents at least a local valley in that landscape, though many valleys may exist. It cannot be known for sure that the valley found is the lowest of all. An often used method is repeating the optimization process for different sets of initial values of the factors, that is, starting at a different point in the imaginary landscape. If these sets lead to the same local optimum, the probability increases that it is the global optimum. The problem with changing the initial values, however, is that certain methods converge too slow or may not converge at all. On the other hand, for many factors a 'physically acceptable' range can be defined, narrowing down the range of initial values, as well as offering a check on acceptability of the resulting optimum. With the present spray drift model, various sets of initial values were tried, all leading to the same optimization results.

In Section 3.1.3 the effective fetch was computed disregarding edge effects. Two types of edge effects can be considered, indicated in Figure 16 by the lines $A B$ and $C D$. Both types of edge effect cause a reduction in spray deposits. Assuming the layout of Figure 16, at the north side of the orchard, line $C D$ implies a reduced fetch while introducing a complementary 'no-spray' zone. Whether this zone is cropfree or not depends on the land use at the area north of the orchard. More important though, point D is located outside the reach of the edge-of-field length of the adjacent water body at the east side. This means that spray drift along the line CD does not contribute to deposits on that (part of the) water body. The second type of edge effect is drawn at the south side in Figure 16, indicated by line $A B$. Again, a reduced fetch needs to be considered. A no-spray zone is not present here. The line $A B$ crosses the edge-of-field water body at the east side, so possible deposits have to be accounted for. Neglecting these edge effects is acceptable during the process of curve-fitting of experimental data, since in the experiments the wind angle $\theta$ was relatively small. However, when using the spray drift model for simulation studies the wind may have an arbitrary direction and the edge effect of type 'AB' may be significant, particularly when the wind angle $\theta$ is large (i.e. near $\pm 90^{\circ}$ ). But with such large wind angles, the effective distance from orchard to water body surface increases significantly, thus reducing drift deposits even if no edge effect would occur. Apparently, the additional effect of the 'AB' type of edge effect tends to lower deposits that may be low already. A further consideration concerns the total amount of drifting spray. Whereas edge effect ' $A B^{\prime}$ ' leads to lower deposits locally, this is compensated by the spray deposits caused by edge effect ' $C D$ ', although these deposits occur on the ditch following the actual edge-of-field ditch for the orchard treated. Therefore, these types of edge effects were not further developed.

Figure 19 shows the correlation between measured and computed downwind deposits. The corresponding correlation coefficient (0.86; Section 3.2.3) may be acceptable but it is significantly lower than its upper limit given by the pairwise correlation (0.98; Section 2.3). Figure 19 clearly shows that there is significant scatter of the data when comparing computed deposits and measured deposits. In the measurements, paired deposits were very similar (Figure 10), yet deposits in repeated field trials occasionally differed significantly, as shown in Figure 22. Note that the model reflects dependencies on averaged ambient conditions. This implies that local and momentary changes in ambient conditions such as wind speed and wind direction due to local turbulence cannot be accounted for and may (and will) cause stochastic variations in the spray deposits. This is supported by Figure 21 which shows an almost normal frequency distribution of the logarithm of ratios of measured and modelled deposits, indicating that it is likely that the differences are stochastic indeed. Clearly, such stochastic variations in deposits cannot be explained by averaged meteorological data. Still, the model 
will predict the averaged deposits of repeated experiments more accurately. However, the scatter in the experimental data prevents the model from being significantly improved (e.g. giving a higher correlation coefficient), unless the scatter can be accounted for by some variable not yet considered. The scatter of data might have been reduced by first taking averages of each pair, rather than using the paired deposits independently as in the present approach. However, since the pairwise correlation was very high, this would not have reduced scatter much.

The 'shadow effect' for spray deposits just outside the orchard (see Figure 22) was not accounted for in the model given by Eq.(3). In practice, however, edge-of-field water bodies next to fruit orchards are never closer to the last tree row than the minimal crop-free zone of $3 \mathrm{~m}$ which allows the fruit grower to drive his sprayer there. It might have been better to exclude such nearby deposits from the experimental database in order to improve the model for downwind distances from $3 \mathrm{~m}$ and beyond. On the other hand, nearby deposits are relevant in evaluation of exposure of non-target plants and arthropods to spray drift deposits.

The canopy density factor, Eq.(14), was derived in Annex 4. Other mathematical sub-models (both simpler and more complex than the one presented here) have been tried, but the present one appeared to give best results while displaying a plausible dependence on DOY. The canopy density factor requires five curve-fitting constants which is a significant part of the total number of constants to be optimised. This acknowledges the importance of the canopy density in the SPEXUS model. As explained in Section 3.1.5, having five parameters can be considered a minimum to control the shape of the $\beta$ function conveniently.

In Section 2.3 paired spray deposits were investigated. The relative differences between paired deposits may be used for estimating the standard error in measured spray deposits. In Section 3.2.1 the standard error in deposits was estimated analytically. Figure 12 in Section 2.3 shows that the experimental decrease of RMS of RD with increasing deposits is slower than the analytical approach would suggest. RD is based on only two deposits (Eq.(1)) and may therefore represent CV not too well. Due to its definition RD is limited to the range -1 through +1 and therefore its RMS value is limited as well. On the other hand, the analytical approach is based on the implicit assumption that a measured deposit is linearly related to the number of drops deposited on a collector. That is, the drop size distribution is assumed to be the same at all downwind locations and in all situations. Clearly, it is likely that smaller deposits (e.g. farther downwind) consist of relatively small drops, while larger deposits may also contain a few larger drops. As a result, weighting measured deposits by their inverse square-root (Eq.(22)) might lead to a bias towards larger deposits.

Usually it is assumed that downwind spray deposits increase with increasing wind speed. While this appears to be true for arable crops, in orchard spraying the experimental data appear to show a less simple relation (e.g. Figure 4). Evidence in literature for such effects of wind speed on downwind spray deposits in orchard spraying were hard to find. One clear exception was the paper of Fox et al. (1993); they found no significant effect of wind speed on downwind deposits at distances less than $30 \mathrm{~m}$ from the orchard. At the edge of the orchard, a considerable part of the drifting spray plume is found at heights above the orchard trees. Only a limited part of the spray passes through the canopy of the trees. Therefore, at higher wind speeds the spray plume may travel a larger distance before depositing on the ground. Besides, droplets remaining airborne for a longer period will become smaller due to evaporation of the solvent. This reduces the settling velocity of the spray cloud further.

The effect of air temperature on spray deposits seems strange, at first glance. Higher temperatures tend to increase evaporation, thereby decreasing the drop size in the spray plume. This will tend to increase downwind deposits, although clouds consisting of very small droplets will deposit only slowly. Secondly, higher ambient temperatures usually imply a significantly increased vertical spreading of the cloud due to buoyancy, thus diluting the spray cloud. This, too, will decrease spray deposition at relatively short downwind distances. At relatively low temperatures, evaporation is low and drop sizes in the spray cloud will decrease only slowly. Thus, a relatively large part of the spray cloud will be intercepted by the orchard before reaching the field edge. Consequently, in this case downwind spray deposits are expected to be low. So a change of temperature may have different effects on spray deposits simultaneously, which makes a clear interpretation difficult. Nevertheless, the strong 
temperature effects on spray deposits at low $\left(5^{\circ} \mathrm{C}\right)$ and high $\left(30^{\circ} \mathrm{C}\right)$ temperatures as illustrated in Figure 36 seem rather overstated. Possibly, further experiments may clarify this.

The examples seem to indicate that deposits of spray drift are highest for environmental conditions corresponding to median wind speed $(3 \mathrm{~m} / \mathrm{s})$ and median temperature $\left(15^{\circ} \mathrm{C}\right)$ (Figure 32 and Figure 36, respectively). There is no a priori cause for this and therefore it is assumed to be coincidental. Besides, wind speed and temperature related to highest deposits are mutually dependent and depend on the downwind distance of interest as well (see e.g. Figure 33 and Figure 34). Unfortunately, though, these average Dutch weather conditions appear to represent worst-case conditions for downwind spray deposits next to fruit orchards.

Table 1 shows the experimental ranges of the parameters for which the SPEXUS model was developed. In a strict sense the model can only be used for situations within the ranges of these parameters. It can be considered a challenge to investigate experimentally the possible validity of the model for parameters outside these ranges.

One might argue that since the day-of-year is selected as a parameter for the model, $\mathrm{BBCH}$ can be avoided and the relation between $\mathrm{BBCH}$ and $\mathrm{DOY}$ is of no importance in the model. Although this is essentially true, canopy density still relates primarily to $\mathrm{BBCH}$. Also, in practice spray treatments are usually authorised for specific $\mathrm{BBCH}$ intervals only. This implies that using the BBCH-to-DOY relationship is relevant. Possible future adaptions of the SPEXUS model to other crops or other climate zones could be implemented more easily when the appropriate $\mathrm{BBCH}$-to-DOY relations can be used. 


\section{Conclusion}

A new approach to model and assess the deposits of spray drift from orchard spraying was presented. The results indicate that the SPEXUS model can predict downwind deposits as a continuous function of average wind speed, average wind direction, air temperature and canopy density. However, local small-scale turbulence is not accounted for. The continuous relationship to canopy density is new and it certainly is a step forward in developing realistic models for spray drift in orchard spraying.

In a next step, the model should be validated against new experimental data not used in its development. Experimental verification under specific conditions (such as low and high wind speeds and temperatures) would be welcome and may help to strengthen the model.

The SPEXUS model can be used on its own, but it has been implemented in a realistic risk assessment model for aquatic organisms exposed to pesticides applied in fruit orchards for all edge-of-field water bodies in the Netherlands (Holterman et al. 2018).

The model has been developed for orchards of apple trees in the Netherlands. In principle, the model can be adjusted for other fruit crops and other climate zones by using an appropriate BBCH-to-DOY relationship. 


\section{References}

$\mathrm{BBCH}, 2001$. Growth stages of mono- and dicotyledonous plants. Ed: U. Meier, 2nd ed. Federal Biological Research Centre for Agriculture and Forestry, Braunschweig Germany.

Bertsekas, D.P., 1999. Nonlinear programming., 2nd ed. Athena Scientific, Belmont, Massachusetts USA.

Fox, R.D., Reichard, D.L., Brazee, R.D., Krause, C.R., Hall, F.R., 1993. Downwind residues from spraying a semi-dwarf apple orchard. Transactions of the American Society of Agricultural Engineers 36 (2), 333-340.

Groot, T.T., Holterman, H.J., Van De Zande, J.C., 2012. A drift-calculation tool based on spray drift field measurements in field crops. In: Proceedings International Advances in Pesticide Application, Aspects of Applied Biology (114): pp. 215-223.

Holterman, H.J., 2000. Statistical aspects of sampling agricultural sprays. In: Proceedings 16th Annual Conference on Liquid Atomization and Spray Systems (ILASS), Darmstadt, 11-13 September 2005, 11-13.

Holterman, H.J., Van De Zande, J.C., Huijsmans, J.F.M., Wenneker, M., 2017. An empirical model based on phenological growth stage for predicting pesticide spray drift in pome fruit orchards. Biosystems Engineering 154, 46-61.

Holterman, H.J., Zande, J.C.V.D., Massop, H.T.L., Wipfler, E.L., Boesten, J.J.T.I., Huijsmans, J.F.M., 2018. Development of a probabilistic model for risk assessment of spray drift deposition onto surface waters for fruit orchards in the Netherlands. Wageningen University and Research, WPR Report 565 (in prep.).

Hooke, R., Jeeves, T.A., 1961. "Direct search" solution of numerical and statistical problems. Journal of the Association for Computing Machinery 8 (2), 212-229.

Jansen, M.J., Thissen, J., Withagen, J.C., 2005. Usage manual uncertainty and sensitivity analysis in a genstat environment. Biometris report 11 (05).

Michielsen, J.M.G.P., Wenneker, M., Van De Zande, J.C., Heijne, B., 2007. Contribution of individual tree row sprayings to airborne drift spraying an apple orchard. In: Proceedings 8th Workshop on Spray Application Techniques in Fruit Growing, Barcelona, June 2005, 37-46.

Monteith, J.L., Unsworth, M.H., 1990. Principles of environmental physics, 2nd ed. E. Arnold, London UK.

Piñeiro, G., Perelman, S., Guerschman, J.P., Paruelo, J.M., 2008. How to evaluate models: Observed vs. Predicted or predicted vs. Observed? Ecological Modelling 216 (3), 316-322.

Press, W.H., Teukolsky, S.A., Vetterling, W.T., Flannery, B.P., 2007. Numerical recipes 3rd edition: The art of scientific computing. Cambridge University Press.

Stallinga, H., Wenneker, M., Van De Zande, J., Michielsen, J., Van Velde, P., Nieuwenhuizen, A., Luckerhoff, L., 2013. Drift en driftreductie van de innovatieve drierijige emissiearme fruitteeltspuit van KWH. Plant Research International Wageningen UR, Business Unit Agrosystems. 
Van De Zande, J.C., Holterman, H.J., Huijsmans, J.F.M., 2012. Spray drift for the assessment of exposure of aquatic organisms to plant protection products in the Netherlands : Part 1: Field crops and downward spraying. Plant Research International Wageningen UR, Business Unit Agrosystems, Wageningen.

Van De Zande, J.C., Holterman, H.J., Huijsmans, J.F.M., Wenneker, M., 2017. Spray drift for the assessment of exposure of aquatic organisms to plant protection products in the Netherlands. Part 2: Sideways and upward sprayed fruit and tree crops. Wageningen University and Research, WPR Report 564, pp. 78

Van De Zande, J.C., Porskamp, H.A.J., Michielsen, J.M.G.P., Holterman, H.J., Huijsmans, J.F.M., 2000. Classification of spray applications for driftability to protect surface water. In: Proceedings Pesticide Application, Guildford UK, 17-18 January 2000, Aspects of Applied Biology (57): pp. 57-65.

Wenneker, M., Michielsen, J.M.G.P., Heijne, B., Van De Zande, J.C., 2007. Contribution of individual tree row sprayings to total spray drift deposition next to an apple orchard. In: Proceedings 8th Workshop on Spray Application Techniques in Fruit Growing, Barcelona, June 2005, 57-64. 


\section{List of symbols}

\begin{tabular}{|c|c|c|}
\hline Symbol & Description & Unit \\
\hline $\mathrm{BBCH}$ & Scale index for phenological growth stages & - \\
\hline$\Delta \mathrm{B}$ & Incremental length of deposition area & $\mathrm{m}$ \\
\hline D & Applied dose of pesticides & $\mathrm{g} \mathrm{m}^{-2}$ \\
\hline Drow & Distance between rows of trees & $\mathrm{m}$ \\
\hline DOY & Day of year & - \\
\hline DRTnn & Drift reduction class with at least $n n \%$ drift reduction & - \\
\hline $\mathrm{F}_{\mathrm{dir}}$ & Adjustment factor for wind direction & - \\
\hline$F_{f}$ & Adjustment factor for fans speed of the sprayer & - \\
\hline $\mathrm{F}_{\mathrm{T}}$ & Adjustment factor for temperature & - \\
\hline $\mathrm{F}_{\mathrm{N}}$ & Adjustment factor for the number of treated rows & - \\
\hline $\mathrm{F}_{\mathrm{W}}$ & Adjustment factor for wind speed & - \\
\hline L & Width of orchard & $\mathrm{m}$ \\
\hline$L_{\text {eff }}$ & Effective 'fetch' of orchard & $\mathrm{m}$ \\
\hline $\mathrm{N}$ & Number of treated rows of trees & - \\
\hline $\mathrm{N}_{\mathrm{d}}$ & Number of droplets & - \\
\hline RD & Relative pairwise difference & - \\
\hline $\mathrm{RH}$ & Relative humidity & $\%$ \\
\hline RMS & Root of mean squared differences & - \\
\hline $\mathrm{R}_{\mathrm{F}}$ & Drift reduction factor for trees in full leaf & - \\
\hline $\mathrm{R}_{\mathrm{D}}$ & Drift reduction factor for dormant trees & - \\
\hline $\mathrm{R}_{\text {act }}$ & Drift reduction factor for actual situation (interpolated) & - \\
\hline $\mathrm{S}$ & Sum of squares & - \\
\hline$\Delta S$ & Surface area of deposition & $\mathrm{m}^{2}$ \\
\hline $\mathrm{T}$ & Ambient temperature & ${ }^{\circ} \mathrm{C}$ \\
\hline $\mathrm{V}$ & Average volume of one drop & $\mu \mathrm{m}^{3}$ \\
\hline Y & Average deposits on finite area & $\mathrm{g} \mathrm{m}^{-2}$ \\
\hline$a, b, m$ & Constants describing factor $\mathrm{c}$ & - \\
\hline$a_{0} \ldots a_{4}$ & Constants in canopy density factor & - \\
\hline$a_{11}, a_{12}$ & Constants in $\mathrm{F}_{\mathrm{W}}$ & $\mathrm{s} \mathrm{m}^{-1}$ \\
\hline$a_{21}, a_{22}$ & Constants in $\mathrm{F}_{\mathrm{W}}$ & $\mathrm{s}^{2} \mathrm{~m}^{-2}$ \\
\hline$b_{11}, b_{12}$ & Constants in $\mathrm{F}_{\mathrm{T}}$ & ${ }^{\circ} \mathrm{C}^{-1}$ \\
\hline$b_{21}, b_{22}$ & Constants in $\mathrm{F}_{\mathrm{T}}$ & ${ }^{\circ} \mathrm{C}^{-2}$ \\
\hline c & Constant & - \\
\hline$f_{i}$ & Computed deposits & $\mathrm{mg} \mathrm{m}^{-2}$ \\
\hline$g_{i}$ & Weights in sum of squares & - \\
\hline $\mathrm{k}_{\mathrm{fan}}$ & Fan speed index $(0=$ low speed, $1=$ high speed $)$ & - \\
\hline$\Delta \mathrm{m}$ & Mass deposited & $\mathrm{g}$ \\
\hline $\mathrm{n}$ & Number of data points & - \\
\hline $\mathrm{n}_{\mathrm{par}}$ & Number of parameters & - \\
\hline $\mathrm{p}_{\mathrm{ijD}}$ & Constants in $\mathrm{F}_{\mathrm{N}}$ & - \\
\hline $\mathrm{q}_{1}$ & Constant & $\mathrm{mg} \mathrm{m}^{-2}$ \\
\hline$q_{2}$ & Constant & $\mathrm{m}-\mathrm{c}$ \\
\hline$r_{i j}$ & Constants in $\mathrm{F}_{\mathrm{N}}$ & - \\
\hline s & Distance in direction of wind & $\mathrm{m}$ \\
\hline $\mathrm{u}_{\mathrm{ij}}$ & Constants in $\mathrm{F}_{\mathrm{N}}$ & - \\
\hline w & Wind speed (typically, at $4 \mathrm{~m}$ height) & $\mathrm{m} \mathrm{s}^{-1}$ \\
\hline $\mathrm{x}$ & Distance from the last tree row to sampling point & $\mathrm{m}$ \\
\hline y & Spray deposits & $\mathrm{mg} \mathrm{m}^{-2}$ \\
\hline$y_{i}$ & Measured deposits & $\mathrm{mg} \mathrm{m}^{-2}$ \\
\hline z & Fraction of year, DOY/365 & - \\
\hline$\Phi$ & Ratio of $\mathrm{CV}_{\mathrm{y}}$ and $\mathrm{CV}_{\mathrm{N}}$ & - \\
\hline$\beta$ & Canopy density factor & - \\
\hline$\beta_{\mathrm{m}}$ & Maximum value of canopy density factor & - \\
\hline$\lambda$ & Marquardt parameter in LM iterative process & - \\
\hline$\sigma$ & Standard deviation in normal distribution & - \\
\hline$\theta$ & Wind direction & $\circ$ \\
\hline
\end{tabular}




\section{Annex $1 \quad$ Single-row drift experiments}

In a series of experiments in 2002, individual rows of apple trees were sprayed and the downwind deposition of spray drift was measured (Michielsen et al. 2007, Wenneker et al. 2007). In this way the contribution of spraying each row of trees to total spray drift was investigated. Spray applications were carried out using a Munckhof cross-flow sprayer with common settings in Dutch fruit growing (e.g. Albuz ATR lilac hollow cone nozzles at $700 \mathrm{kPa}$ spray pressure, spraying volume $175-200 \mathrm{~L} / \mathrm{ha}$ ). The experiments were carried out both in early (dormant) and in late (full canopy) growth stage of the trees.

Figure A1.1 gives an overview of the experimental layout. Path numbers for spraying range from 1 (driving path just outside the orchard) up top 11 (between $10^{\text {th }}$ and $11^{\text {th }}$ row of trees). The green arrows indicate the direction of spray application. In paths 2 to 11 the spray was applied to both sides (i.e. spraying one side of the trees in both rows adjacent to the path). In path 1 spray was applied only in the upwind direction (i.e. toward the first row of trees).

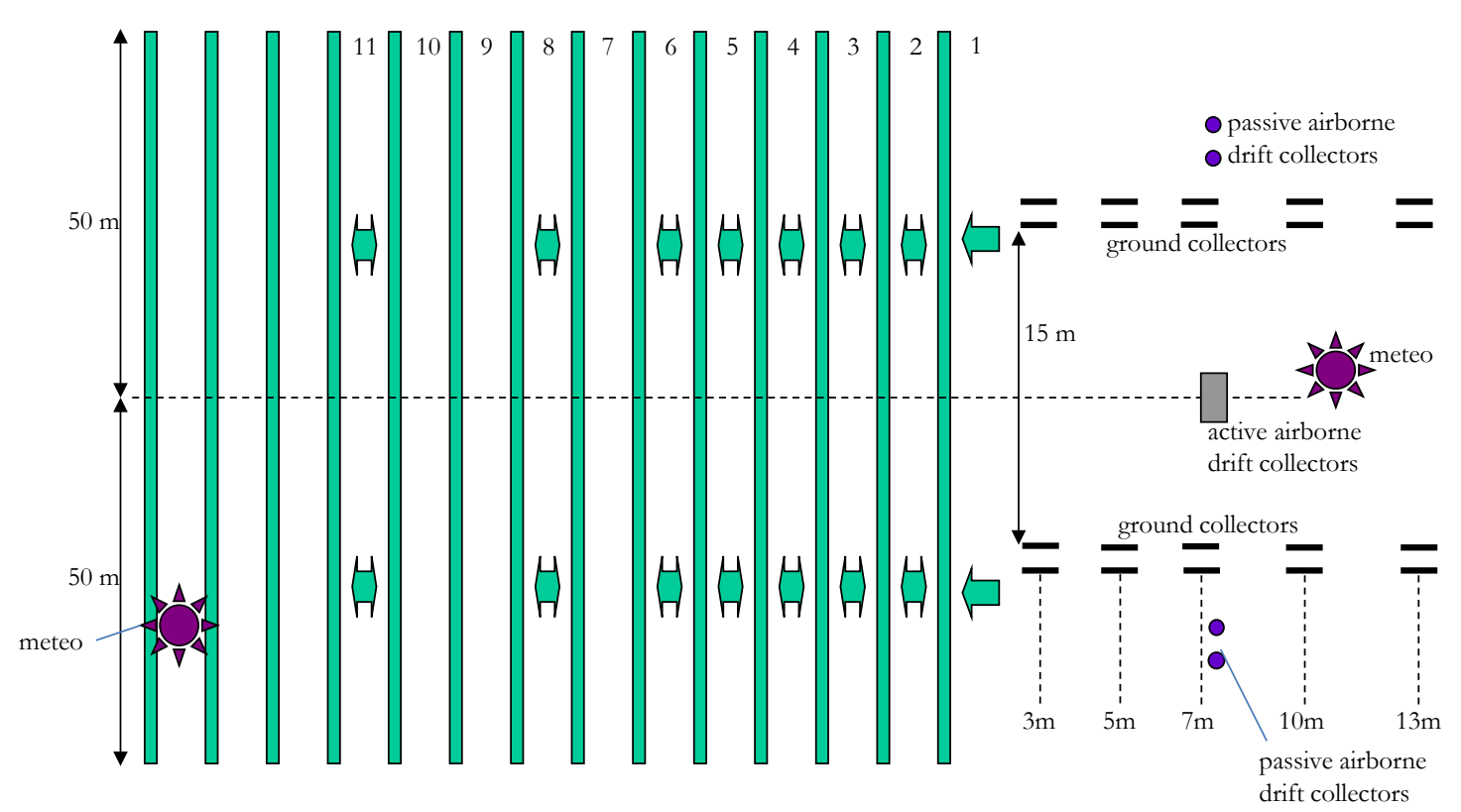

Figure A1.1 Layout of orchard for downwind spray drift measurements with single-row applications. Airborne spray drift was measured as well, but these data were not used in the model development in this report. (Wenneker et al. 2007).

Table A1.1 gives the downwind spray deposits (\% applied dose) at various downwind distances for each of the single-row spray applications, for dormant trees. Note that the application in path 2 results in higher downwind deposits than that in path 1. Clearly, this is the consequence of applying in two directions in path 2, one of which is directed downwind, although a row of (bare) trees is in between. This was common practice in the year the experiment was conducted. Currently, the two-way application in path 2 is not allowed anymore when using drift reducing techniques.

To determine the cumulative deposits for an increasing number of rows treated, downwind deposits of spray drift from untreated rows (i.e. paths 7, 9 and 10) are required as well. Downwind deposits for these paths were estimated by linear interpolation. Table A1.2 shows the cumulated drift deposits as a function of the number of treated rows $(N)$. Note that after treatment in path 1 only 0.5 row is 
treated. Similarly, after treatments in path 1 and 2 the number of treated rows is 1.5 , etc. The data in this table are also shown graphically in Figure 6 (Section 2.1).

Similarly, the experimental data for trees in leaves are given in Table A1.3 (measured deposits) and Table A1.4 (computed cumulative deposits; see also Figure 7, Section 2.1).

Table A1.1 Measured downwind ground deposits of spray drift in single-row experiments in an orchard with dormant apple trees.

\begin{tabular}{|c|c|c|c|c|c|c|c|c|}
\hline Path index: & $1^{1}$ & 2 & 3 & 4 & 5 & 6 & 8 & 11 \\
\hline Downwind distance & \multirow{2}{*}{\multicolumn{8}{|c|}{$\begin{array}{l}\text { Downwind deposits } \\
\text { [\%applied dose] }\end{array}$}} \\
\hline$[\mathrm{m}]$ & & & & & & & & \\
\hline 5 & 4.73 & 8.60 & 5.13 & 2.89 & 1.84 & 0.83 & 0.35 & 0.16 \\
\hline 7 & 3.14 & 6.68 & 3.61 & 2.26 & 1.63 & 0.77 & 0.28 & 0.16 \\
\hline 13 & 1.16 & 2.89 & 1.42 & 0.84 & 0.82 & 0.50 & 0.21 & 0.14 \\
\hline
\end{tabular}

1 Path 1 sprayed in upwind direction only.

Table A1.2 Cumulative downwind ground deposits of spray drift as a function of the number of treated rows $(N)$ in an orchard with dormant apple trees. Contributions of paths 7, 9 and 10 is estimated by interpolation.

\begin{tabular}{|c|c|c|c|c|c|c|c|c|c|c|c|}
\hline N: & 0.5 & 1.5 & 2.5 & 3.5 & 4.5 & 5.5 & 6.5 & 7.5 & 8.5 & 9.5 & 10.5 \\
\hline Downwind distance & \multicolumn{11}{|c|}{ Cumulative downwind deposits } \\
\hline [m] & \multicolumn{11}{|c|}{$[\%$ applied dose $]$} \\
\hline 3 & 9.56 & 21.62 & 29.28 & 33.45 & 35.67 & 36.83 & 37.64 & 38.11 & 38.48 & 38.74 & 38.90 \\
\hline 5 & 4.73 & 13.33 & 18.46 & 21.35 & 23.19 & 24.02 & 24.61 & 24.96 & 25.25 & 25.47 & 25.63 \\
\hline 7 & 3.14 & 9.82 & 13.43 & 15.69 & 17.32 & 18.09 & 18.62 & 18.90 & 19.14 & 19.34 & 19.50 \\
\hline 10 & 1.52 & 4.96 & 6.85 & 8.09 & 9.12 & 9.68 & 10.07 & 10.29 & 10.49 & 10.67 & 10.83 \\
\hline 13 & 1.16 & 4.05 & 5.47 & 6.31 & 7.13 & 7.63 & 7.98 & 8.19 & 8.38 & 8.54 & 8.68 \\
\hline
\end{tabular}

Table A1.3 Measured downwind ground deposits of spray drift in single-row experiments in an orchard with apple trees in full leaf.

\begin{tabular}{|c|c|c|c|c|c|c|c|c|}
\hline Path index: & $1^{1}$ & 2 & 3 & 4 & 5 & 6 & 8 & 11 \\
\hline $\begin{array}{c}\text { Downwind distance } \\
{[\mathrm{m}]}\end{array}$ & \multicolumn{8}{|c|}{$\begin{array}{l}\text { Downwind deposits } \\
\text { [\%applied dose] }\end{array}$} \\
\hline 3 & 4.82 & 8.41 & 2.33 & 1.01 & 0.39 & 0.24 & 0.12 & 0.04 \\
\hline 5 & 2.28 & 5.32 & 1.32 & 0.86 & 0.42 & 0.24 & 0.16 & 0.05 \\
\hline 7 & 1.18 & 3.16 & 0.87 & 0.63 & 0.37 & 0.29 & 0.14 & 0.06 \\
\hline 10 & 0.57 & 1.78 & 0.53 & 0.39 & 0.23 & 0.16 & 0.11 & 0.03 \\
\hline 13 & 0.41 & 1.23 & 0.31 & 0.33 & 0.15 & 0.08 & 0.06 & 0.03 \\
\hline
\end{tabular}

\footnotetext{
1 Path 1 sprayed in upwind direction only.
} 
Table A1.4 Cumulative downwind ground deposits of spray drift as a function of the number of treated rows $(N)$ in an orchard with apple trees in full leaf. Contributions of paths 7, 9 and 10 is estimated by interpolation.

\begin{tabular}{|c|c|c|c|c|c|c|c|c|c|c|c|}
\hline N: & 0.5 & 1.5 & 2.5 & 3.5 & 4.5 & 5.5 & 6.5 & 7.5 & 8.5 & 9.5 & 10.5 \\
\hline Downwind distance & \multicolumn{11}{|c|}{ Cumulative downwind deposits } \\
\hline$[\mathrm{m}]$ & \multicolumn{11}{|c|}{ [\%applied dose] } \\
\hline 3 & 4.82 & 13.23 & 15.56 & 16.57 & 16.96 & 17.20 & 17.38 & 17.50 & 17.59 & 17.66 & 17.70 \\
\hline 5 & 2.28 & 7.60 & 8.92 & 9.78 & 10.20 & 10.44 & 10.64 & 10.80 & 10.92 & 11.01 & 11.06 \\
\hline 7 & 1.18 & 4.34 & 5.21 & 5.84 & 6.21 & 6.50 & 6.72 & 6.86 & 6.98 & 7.07 & 7.13 \\
\hline 10 & 0.57 & 2.35 & 2.88 & 3.27 & 3.50 & 3.66 & 3.79 & 3.90 & 3.98 & 4.04 & 4.07 \\
\hline 13 & 0.41 & 1.64 & 1.95 & 2.28 & 2.43 & 2.51 & 2.58 & 2.64 & 2.69 & 2.73 & 2.76 \\
\hline
\end{tabular}

For each $\mathrm{N}$, the cumulative drift curves (i.e. individual columns in Table A1.2 and Table A1.4) were fitted using the following equation (equal to Eq.(3)):

$$
Y=a e^{-b x^{c}}
$$

where $\mathrm{c}$ was a constant; putting $\mathrm{c}=0.6$ appeared to give best results. Parameters $\mathrm{a}$ and $\mathrm{b}$ are implicit functions of the number of rows $N$. Different sets of parameters $a$ and $b$ were obtained for dormant trees (indexed D) and trees in full leaf (indexed L), see Table A1.5.

Table A1.5 Parameters a and b from fits of cumulative downwind ground deposits, for dormant trees and trees in full leaf.

\begin{tabular}{ccccccccccccc}
$\mathrm{N}$ & 0.5 & 1.5 & 2.5 & 3.5 & 4.5 & 5.5 & 6.5 & 7.5 & 8.5 & 9.5 & 10.5 \\
$\mathrm{a}_{\mathrm{D}}$ & 52.97 & 76.62 & 102.46 & 114.28 & 116.18 & 117.26 & 118.08 & 118.65 & 118.86 & 118.69 & 118.16 \\
\hline $\mathrm{b}_{\mathrm{D}}$ & 0.8922 & 0.6564 & 0.6481 & 0.6351 & 0.6101 & 0.5989 & 0.5916 & 0.5879 & 0.5840 & 0.5799 & 0.5756 \\
\hline $\mathrm{a}_{\mathrm{L}}$ & 37.26 & 65.86 & 75.68 & 74.98 & 73.30 & 72.07 & 71.09 & 70.27 & 69.62 & 69.15 & 68.85 \\
\hline $\mathrm{b}_{\mathrm{L}}$ & 1.0596 & 0.8296 & 0.8184 & 0.7808 & 0.7566 & 0.7406 & 0.7279 & 0.7182 & 0.7105 & 0.7049 & 0.7014 \\
\hline
\end{tabular}

The above values of $\mathrm{a}$ and $\mathrm{b}$ were fitted as a function of $\mathrm{N}$ using the following equation:

$$
\begin{aligned}
& a(N)=p_{10}\left(1-p_{11} e^{-p_{12} N}\right) \\
& b(N)=p_{20}\left(1+p_{21} e^{-p_{22} N}\right)
\end{aligned}
$$

where $p_{10} . . p_{22}$ are positive constants; their resulting values are given in Table A1.6; see also Figure $\mathrm{A} 1.2$ and Figure $\mathrm{A} 1.3$. For $\mathrm{N} \rightarrow \infty$ parameters $\mathrm{a}$ and $\mathrm{b}$ approach $\mathrm{p}_{10}$ and $\mathrm{p}_{20}$, respectively. These latter parameters depend on external factors such as orchard geometry, weather conditions and sprayer settings. Besides, values of $\mathrm{p}_{10}$ and $\mathrm{p}_{20}$ for trees in leaves differ from those for dormant trees, so the factors $\mathrm{p}_{\mathrm{ij}}$ are functions of canopy density $\beta$. 


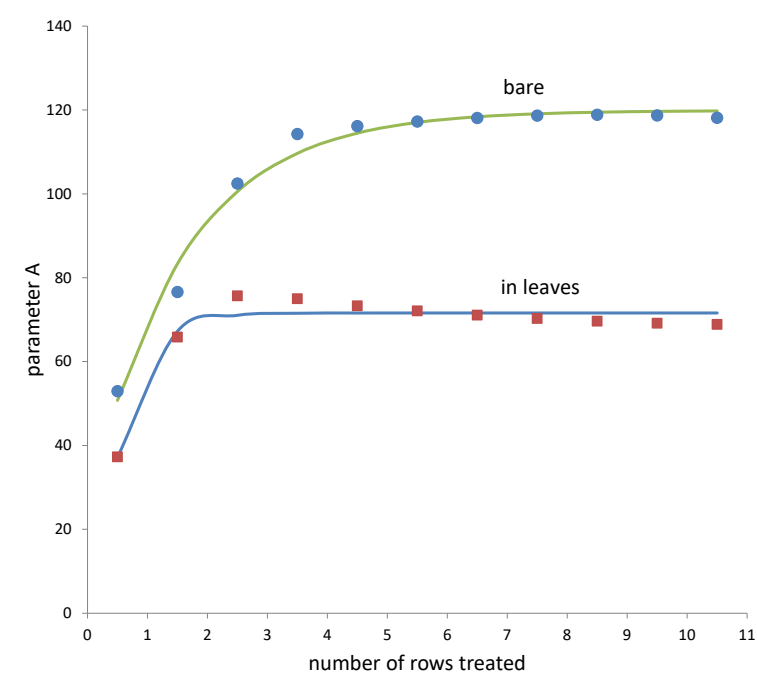

Figure A1.2 Parameter a(N) and curve-fit, as a function of the number of rows treated. Dots: derived from experiments; lines: curve-fits.

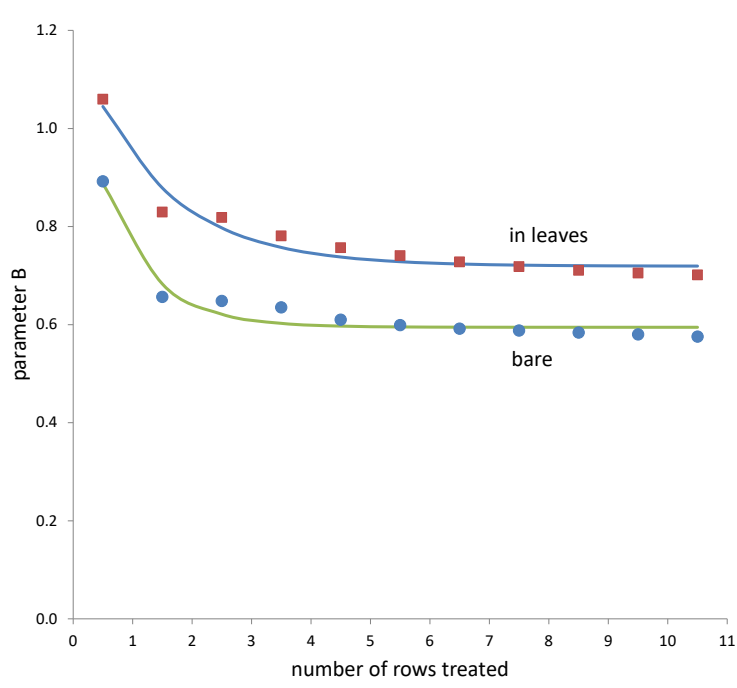

Figure A1.3 Parameter $b(N)$ and curve-fit, as a function of the number of rows treated. Dots: derived from experiments; lines: curve-fits.

All single-row experiments were carried out in the same orchard with approximately cross-wind conditions. Obviously, wind speeds and temperatures varied; experiments with dormant trees were done in March and April, experiments with trees in leaves in June and October. Sprayer fan speed was low with dormant trees and high with trees in leaves. Although the effect of varying wind speeds on spray deposits downwind from orchards appeared to be rather limited, the effect of varying air temperatures may be significant. Yet, for simplicity it is assumed that the observed differences in downwind deposits in the single-row experiments are caused only by differences in canopy density (crop growth stage) and sprayer fan speed (high or low). Consequences are argued in the Discussion, Section 5 . When the values of $\mathrm{p}_{10 \mathrm{D}}$ through $\mathrm{p}_{22 \mathrm{D}}$ for dormant trees are considered as references, Eqs.(1.2) and (1.3) can be written as:

$$
\begin{aligned}
& a(N)=p_{10 D} r_{10} f_{f S}\left(1-p_{11 D} r_{11} e^{-p_{12 D} r_{12} N}\right) \\
& b(N)=p_{20 D} r_{20} f_{f S}\left(1+p_{21 D} r_{21} e^{-p_{22 D} r_{22} N}\right)
\end{aligned}
$$

where the parameters $r_{i j}$ are scaling factors (defined by $r_{i j}(\beta)=p_{i j}(\beta) / p_{i j D}$ ) that only depend on canopy density; by definition, all $r_{i j}$ equal 1 for bare trees. The factor $f_{f s}$ accounts for sprayer fan speed; by definition $f_{f s}=1$ when fan speed is low, while it turns out that $f_{f s}<1$ when fan speed is high (see Annex 2). The values of the parameters $r_{i j}$ in the above equations are shown in Table A1.6, in the row indicated as 'ratios $\mathrm{p}_{\mathrm{ijL}} / \mathrm{p}_{\mathrm{ijD}}$ '. In the single-row experiments with dormant trees the fan speed was low, while with trees in leaves the fan speed was high. Consequently, from these experiments the values for $r_{10}, r_{20}$ and $f_{f s}$ cannot be derived separately, only in their combination as used in the above equations. Annex 2 describes the estimation of $f_{\mathrm{fs}}(\approx 0.52)$ using a limited set of experiments at the same growth stage yet with different fan speeds. However, using an estimate of $\mathrm{f}_{\mathrm{fs}} \approx 0.85$ appeared to give better results while optimizing the spray drift model.

Note that $\mathrm{a}$ and $\mathrm{b}$ approach $\mathrm{p}_{10 \mathrm{D}}$ and $\mathrm{p}_{20 \mathrm{D}}$, respectively, for a sufficient large orchard $(\mathrm{N} \rightarrow \infty)$ with dormant trees (and, consequently, the sprayer fan speed set to low). Thus, Eqs.(1.4) and (1.5) can be interpreted as modifications for limited orchard size, various growth stages and the use of the high fan speed. The modification part for orchard size and canopy density is represented by $F_{N 1}\left(=a /\left(p_{10 D} f_{f s}\right)\right)$ and $F_{\mathrm{N} 2}\left(=b /\left(p_{20 D} f_{f s}\right)\right)$ :

$$
\begin{aligned}
& F_{N 1}=r_{10}\left(1-p_{11 D} r_{11} e^{-p_{12 D} r_{12} N}\right) \\
& F_{N 2}=r_{20}\left(1+p_{21 D} r_{21} e^{-p_{22 D} r_{22} N}\right)
\end{aligned}
$$


Table A1.6 Parameters $p_{10} . . p_{22}$ and their derivatives from fits of primary parameters $a$ and $b$, for dormant trees and trees in leaves. Preliminary values acting as initials in model optimisation process.

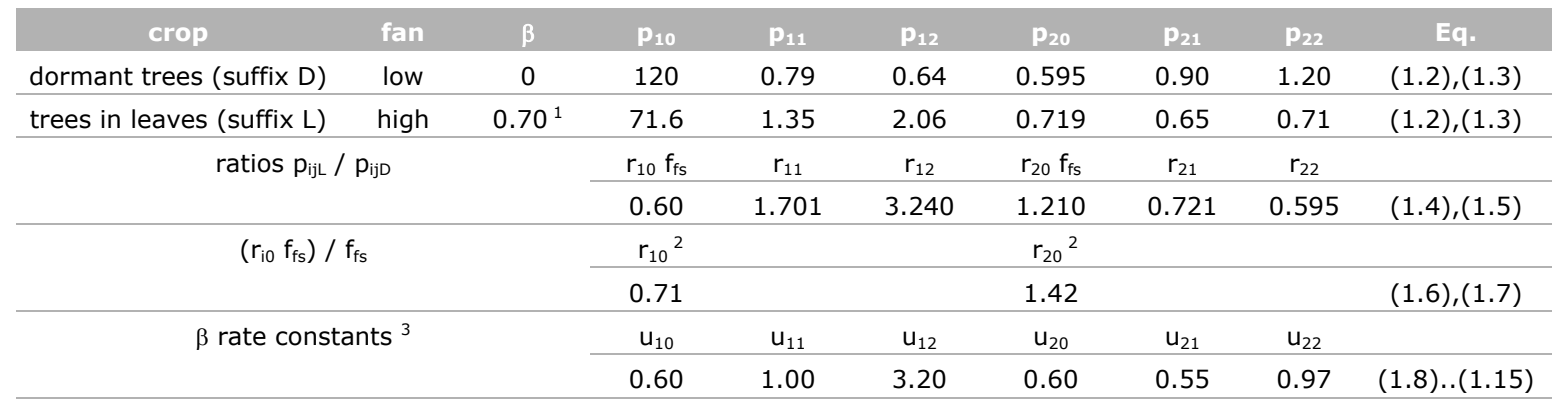

\footnotetext{
1 Assumed reference value $\beta_{\text {ref. }}$

2 Estimated value, assuming $\mathrm{f}_{\mathrm{fs}}=0.85$ (value obtained from preliminary curve-fitting procedures).

3 Estimated rate constant, assuming $\beta_{\text {ref }}=0.70$ (value obtained from preliminary curve-fitting procedures).
}

Note that in general the canopy density factor $(\beta)$ is not limited to a few discrete values. Therefore, the values of the scaling factors $r_{i j}$ should all equal 1 for $\beta=0$ (dormant trees) and change gradually when $\beta$ increases, in such a way that the values given in Table A1. 6 are obtained for $\beta=\beta_{\text {ref }}(=0.70$,

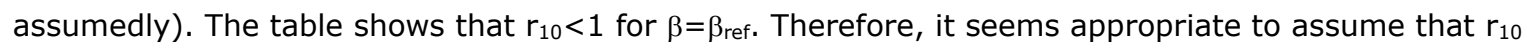
is a decreasing yet positive function of $\beta$. Empirically, the following reciprocal linear relation has this 'decreasing-yet-positive' property (assuming the rate constant $\mathrm{u}_{10}>0$ ):

$$
r_{10}=\frac{1}{1+u_{10} \cdot \beta}
$$

Now the rate constant $u_{10}$ can be determined, provided that the corresponding value of $\beta_{\text {ref }}$ is known:

$$
u_{10}=\frac{1}{\beta_{\text {ref }}} \cdot\left(\frac{1}{r_{10, \text { ref }}}-1\right)
$$

Example: if $\mathrm{f}_{\mathrm{fs}}=0.85$ and $\mathrm{r}_{10} \cdot \mathrm{f}_{\mathrm{fs}}=0.60$ (Table A1.6) then $\mathrm{r}_{10, \text { ref }}=0.71$ and finally $\mathrm{u}_{10}=0.60$, when $\beta_{\text {ref }}=0.70$.

Similarly, Table A1.6 shows that $r_{20}>1$ for $\beta=\beta_{\text {ref. }}$ Thus, in its simplest form $r_{20}$ is a linearly increasing function of $\beta$ :

$$
r_{20}=1+u_{20} \cdot \beta
$$

Again, constant $\mathrm{u}_{20}$ can be estimated from the curve-fit results of the single-row experiments:

$$
u_{20}=\frac{1}{\beta_{\text {ref }}} \cdot\left(r_{20, r e f}-1\right)
$$

Example: if $f_{f s}=0.85$ and $r_{20} \cdot f_{f s}=1.21$ (Table A1.6) then $r_{20, \text { ref }}=1.42$ and finally $u_{20}=0.60$, when $\beta_{\text {ref }}=0.70$.

Table A1.6 indicates that scaling factors $r_{21}$ and $r_{22}$, like $r_{10}$, appear to be decreasing-yet-positive functions of $\beta$. Thus, these can be described by equations similar to Eq.(1.8):

$$
\begin{aligned}
& r_{21}=\frac{1}{1+u_{21} \cdot \beta} \\
& r_{22}=\frac{1}{1+u_{22} \cdot \beta}
\end{aligned}
$$


where the rate constants $\mathrm{u}_{21}$ and $\mathrm{u}_{22}$ can be estimated in a way similar to that for $\mathrm{u}_{10}$. On the other hand, the factors $r_{11}$ and $r_{12}$ are increasing functions of $\beta$, like $r_{20}$, and thus can be assumed to follow the pattern of Eq.(1.10):

$$
\begin{aligned}
& r_{11}=1+u_{11} \cdot \beta \\
& r_{12}=1+u_{12} \cdot \beta
\end{aligned}
$$

Again, the rate constants $\mathrm{u}_{11}$ and $\mathrm{u}_{12}$ can be estimated similar to $\mathrm{u}_{20}$. The derived rate constants $\mathrm{u}_{\mathrm{ij}}$ are shown in the bottom row of Table A1.6.

To summarize, the effects of canopy density and orchard size on spray drift deposits are modelled by $F_{\mathrm{N} 1}$ and $F_{\mathrm{N} 2}$ as given in Eqs.(1.6) and (1.7), where the rate factors $r_{\mathrm{ij}}$ are modelled by Eqs.(1.8) through (1.15). The computed values of the constants in Table A1.6 were used as initial values in the optimization process of the spray drift model. Each of these parameters was allowed a small adjustment to improve the model. However, only a relative change of not more than $5 \%$ was allowed. The final values used in the SPEXUS spray drift model are shown in Table A1.7.

\begin{tabular}{|c|c|c|c|c|}
\hline & \multicolumn{2}{|c|}{$\mathrm{F}_{\mathrm{N} 1}$} & \multicolumn{2}{|c|}{$F_{\mathrm{N} 2}$} \\
\hline $\begin{array}{c}\text { p-constants (dormant } \\
\text { trees) }\end{array}$ & $\mathrm{p}_{11 \mathrm{D}}$ & 0.8295 & $\mathrm{p}_{21 \mathrm{D}}$ & 0.9450 \\
\hline \multirow[t]{2}{*}{$\beta$ rate constants } & $\mathrm{u}_{10}$ & 0.6054 & $\mathrm{u}_{20}$ & 0.5034 \\
\hline & $\mathrm{u}_{11}$ & 0.8799 & $\mathrm{u}_{21}$ & 0.6571 \\
\hline
\end{tabular}

Table A1.7 Final parameters to be used in $F_{N 1}$ and $F_{N 2}$ in the SPEXUS spray drift model. 


\section{Annex 2 Estimating the fan speed factor}

Usually, spraying orchards with bare trees requires the sprayer's fan speed set to 'low', while with trees in leaves the fan speed is set to 'high'. This means that effects of canopy density and fan speed setting always are combined and cannot be derived separately. However, in several field trials with trees in leaves (BBCH between 70 and 80 ) the fan speed was set to low by mistake. Fortunately, these experiments now offer the opportunity to extract the effect of fan speed by comparison to experiments of similar $\mathrm{BBCH}(70-80)$ but high fan speed. In fact, two sets of experiments are available which essentially differ in fan speed setting only. For each of these experiment, drift deposits y were fitted as a function of distance $x$ by:

$$
y=A e^{-B x}
$$

Averages and standard deviations of $A$ and $B$ were computed for both sets of experiments; $n_{\exp }$ gives the number of experiments for both sets; see Table A2.1. Although the variation in the set with low fan speed is considerable, a t-test reveals that both $A$ and $B$ are significantly different for the two sets.

Table A2.1 Averages and standard deviations for parameter $A$ and $B$ in sets of experiments with low and high fan speed. $\mathrm{BBCH}$ range $70-80$.

\begin{tabular}{|c|c|c|c|c|c|}
\hline Fan speed & $\mathbf{n}_{\text {exp }}$ & $\begin{array}{c}\text { Avg_A } \\
\text { [\%dose] }\end{array}$ & $\begin{array}{c}\text { STD_A } \\
\text { [\%dose] }\end{array}$ & $\begin{array}{c}\text { Avg_B } \\
{\left[\mathrm{m}^{-1}\right]}\end{array}$ & $\begin{array}{l}\text { STD_B } \\
{\left[\mathrm{m}^{-1}\right]}\end{array}$ \\
\hline low & 14 & 42 & 21 & 0.33 & 0.11 \\
\hline ratio high/low & & 0.52 & & 0.53 & \\
\hline
\end{tabular}

The ratios of average values show that in the case of a high fan speed both A and B are roughly halved with respect to their values at low fan speed. In fact, this ratio corresponds with the previously defined fan speed factor $\mathrm{f}_{\mathrm{fs}}$, so $\mathrm{f}_{\mathrm{fs}} \approx 0.52$.

Clearly, the standard deviations in A and B are relatively large, so the fan speed factor being approximately 0.5 probably is merely a rough indication. Besides, the model represented by Eq.(2.1), as used in this comparison, differs slightly from the basic model given by Eq.(3). To summarize, the main conclusions are (a) the fan speed factor is $<1$, and (b) this factor is about the same for both $A$ and $\mathrm{B}$. Therefore in the development of the basic model a fan speed factor is implemented with these two general features. 


\section{Annex $3 \quad \mathrm{BBCH}$ and day-of-year for apple trees}

In a large number of experiments in apple trees in the Netherlands, the relation between the phenological growth stage used for pome and stone fruit fruit (BBCH 2001) and day-of-year (DOY) was determined. In simulations a continuous mathematical description is more convenient. Therefore the observed data were fitted with an empirical equation. The DOYs show three relatively fast changes where $\mathrm{BBCH}$ changes only little. The rate of change $\mathrm{dDOY} / \mathrm{dBBCH}$ is relatively high at those locations, while it is low in between. This rate of change was modelled using the following equation:

$$
d D / d B=\frac{p_{1}}{\left(1+q_{1}\left(B-B_{1}\right)^{2}\right)}+\frac{p_{2}}{\left(1+q_{2}\left(B-B_{2}\right)^{2}\right)}+\frac{p_{3}}{\left(1+q_{3}\left(B-B_{3}\right)^{2}\right)}
$$

Where $D=D O Y$ and $B=B B C H$. Parameters $p_{1} \ldots p_{3}, q_{1} \ldots q_{3}$ and $B_{1} \ldots B_{3}$ are constants obtained from curvefitting. Integrating of $\mathrm{dD} / \mathrm{dB}$ gives $\mathrm{DOY}$ as function of $\mathrm{BBCH}$ :

$$
D(B)=f_{0}+\int_{0}^{B}\left(\frac{d D}{d B} \cdot d B\right)
$$

Parameter $\mathrm{f}_{0}$ is an additional constant giving the DOY at January 1 . The final result is shown in Figure A3.1. The parameters are listed in Table A3.1.

Table A3.1 Parameters for empirical relation between DOY and BBCH; for apple trees in the Netherlands.

\begin{tabular}{cccccc}
$\mathrm{f}_{0}:$ & 52 & $\mathrm{p}_{2}:$ & 30 & $\mathrm{p}_{3}:$ & 10 \\
\hline $\mathrm{p}_{1}:$ & 13 & $\mathrm{q}_{2}:$ & 0.5 & $\mathrm{q}_{3}:$ & 0.05 \\
\hline $\mathrm{q}_{1}:$ & 0.5 & $\mathrm{~B}_{2}:$ & 75 & $\mathrm{~B}_{3}:$ & 92 \\
\hline $\mathrm{B}_{1}:$ & 52 & & 75
\end{tabular}

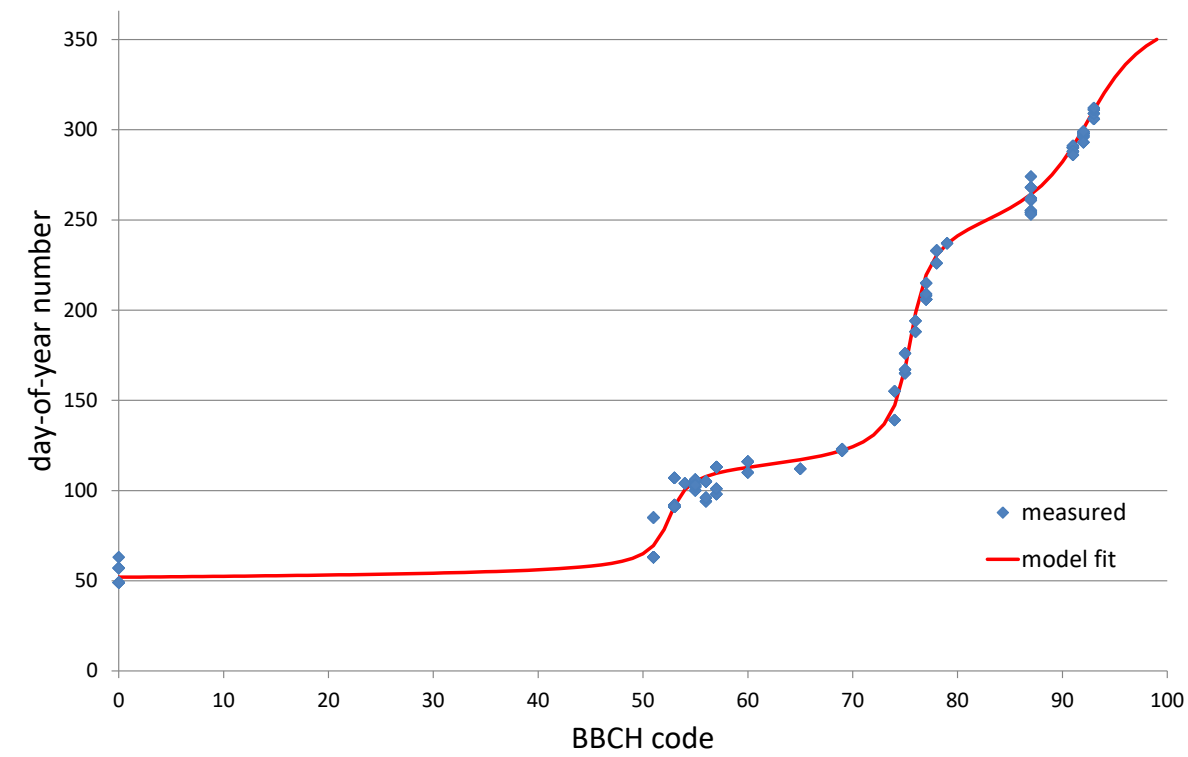

Figure A3.1 Observed BBCH values at various days-of-year (dots); solid line represents fitted curve of DOY as a function of $B B C H$. 
For speeding up simulations, it is convenient to use a table of DOY vs BBCH rather than carrying out the computation of Eq.(3.2) each time a DOY needs to be determined. Table A3.2 shows DOY vs $\mathrm{BBCH}$, as computed using the above empirical equation. $\mathrm{BBCH}$ is a phenological stage between 0 and 100 and not all $\mathrm{BBCH}$ codes may have explicit meanings (Annex 10). The table gives average DOYs for all $\mathrm{BBCH}$ s between 0 and 100 , including $\mathrm{BBCH}$ not used in practice.

Table A3.2 DOY as a function of BBCH, computed using the empirical equation (3.2).

\begin{tabular}{|c|c|c|c|c|c|c|c|c|c|}
\hline ВBCH & DOY & $\mathrm{BBCH}$ & DOY & $\mathrm{BBCH}$ & DOY & BBCH & DOY & $\mathrm{BBCH}$ & DOY \\
\hline 0 & 52 & & & & & & & & \\
\hline 1 & 52 & 21 & 53 & 41 & 56 & 61 & 113 & 81 & 244 \\
\hline 3 & 52 & 23 & 53 & 43 & 57 & 63 & 115 & 83 & 250 \\
\hline 4 & 52 & 24 & 53 & 44 & 57 & 64 & 116 & 84 & 253 \\
\hline 6 & 52 & 26 & 53 & 46 & 58 & 66 & 118 & 86 & 260 \\
\hline 7 & 52 & 27 & 53 & 47 & 59 & 67 & 119 & 87 & 264 \\
\hline 8 & 52 & 28 & 53 & 48 & 60 & 68 & 120 & 88 & 269 \\
\hline 9 & 52 & 29 & 54 & 49 & 62 & 69 & 122 & 89 & 275 \\
\hline 13 & 52 & 33 & 54 & 53 & 91 & 73 & 136 & 93 & 310 \\
\hline 14 & 52 & 34 & 54 & 54 & 100 & 74 & 147 & 94 & 320 \\
\hline 15 & 52 & 35 & 54 & 55 & 105 & 75 & 168 & 95 & 329 \\
\hline 16 & 52 & 36 & 55 & 56 & 107 & 76 & 198 & 96 & 336 \\
\hline 17 & 52 & 37 & 55 & 57 & 109 & 77 & 219 & 97 & 341 \\
\hline 18 & 53 & 38 & 55 & 58 & 110 & 78 & 230 & 98 & 346 \\
\hline 19 & 53 & 39 & 55 & 59 & 111 & 79 & 236 & 99 & 350 \\
\hline 20 & 53 & 40 & 56 & 60 & 112 & 80 & 241 & 100 & 353 \\
\hline
\end{tabular}




\section{Annex 4 Canopy density factor}

The tree canopy acts as a filter that may catch part of the passing spray cloud. The canopy density factor is introduced to quantify the effect of canopy on several parameters involved in the spray drift model. The canopy density factor $\beta$ is cyclic function of the day-of-year with a period of 1 year. Therefore it may be convenient to start with an intrinsically cyclic function like a sinusoid. Defining the fraction of year $z=D O Y / 365$, the following equation represents a first trial for $\beta$ :

$$
\beta=a_{0} \sin ^{2} \pi z
$$

With this function $\beta=0$ for $z=0$ and $z=1$ (i.e. at January 1 and December 31), and it is 'smooth' when going from one year to the next (i.e. the derivative $d \beta / d z=0$ at $z=0$ ). At $z=0.5$ (about July 1) $\beta$ has is maximum value $a_{0}$; see Figure A4.1.

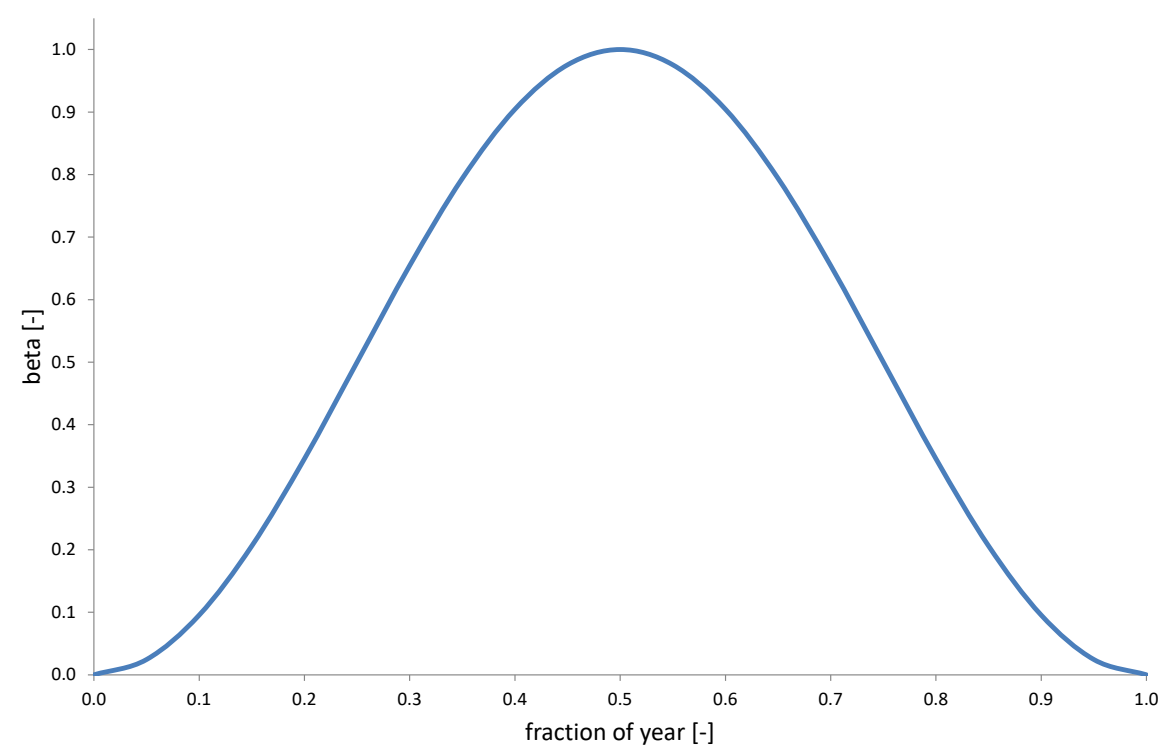

Figure A4.1 Canopy density factor, first approach, as a function of fraction of year $(z) ; a_{0}=1$.

However, a skewed function of $z$ with its maximum at $z>0.5$ would be more natural. Therefore $z$ is replaced by a function $u(z)$ with boundary conditions $u(0)=0$ and $u(1)=1$, to make sure the modified $\beta$ function keeps its above-mentioned performance at $z=0$ and $z=1$. A $3^{\text {rd }}$ grade polynomial in $z$ appears to work out quite well. With the conditions given above, this polynomial takes the following general form:

$$
u(z)=z \cdot\left(1+a_{1}(z-1)+a_{2}\left(z^{2}-1\right)\right)
$$

Furthermore, practical use requires that $u(z)$ is a monotonically increasing function, i.e. its derivative must be $\geq 0$ for all $z$ between 0 and 1 . This restricts the possible range of values of parameters $a_{1}$ and $a_{2}$. While $a_{2}$ appears to be restricted to the range $-2 \cdot .4$, the values of $a_{1}$ depend on those of $a_{2}$ and therefore are more complicated:

$$
\begin{array}{ll}
\text { if }-2 \leq a_{2} \leq 1: & -1-2 a_{2} \leq a_{1} \leq 1-a_{2} \\
\text { if } \quad 1<a_{2} \leq 4: & -\frac{3}{2} a_{2}-\frac{1}{2} \sqrt{3 a_{2}\left(4-a_{2}\right)} \leq a_{1} \leq-\frac{3}{2} a_{2}+\frac{1}{2} \sqrt{3 a_{2}\left(4-a_{2}\right)}
\end{array}
$$


For combinations of values of $a_{1}$ and $a_{2}$ outside these ranges, $u(z)<0$ or $u(z)>1$ or $d u / d z<0$ for at least some values of $z$ at the range $0 \cdot \cdot 1$.

The top of the $\beta$ function can be flattened by passing its sinusoid part into an exponential function of the form $y=1-e^{-x}$. For small values of $x(>0), y \sim x$, so the exponential modification has almost no effect. For large $x$, though, the function approaches $y=1$, thus reducing the effect of $x$ considerably. Replacing $x$ by $\left(a_{0} \sin \pi u\right)^{m}$ and scaling the result by a factor $a_{3}$, the final result looks like:

$$
\beta=a_{3}\left(1-e^{-\left(a_{0} \sin \pi u\right)^{m}}\right)
$$

Figure IV-2 gives an example of the looks of this $\beta$ as a function of the fraction of year $z$, after optimization based on spray drift experiments. The optimized constants are: $a_{0}=1.39, a_{1}=1.46$, $\mathrm{a}_{2}=-0.46, \mathrm{a}_{3}=0.97, \mathrm{~m}=5.22$.

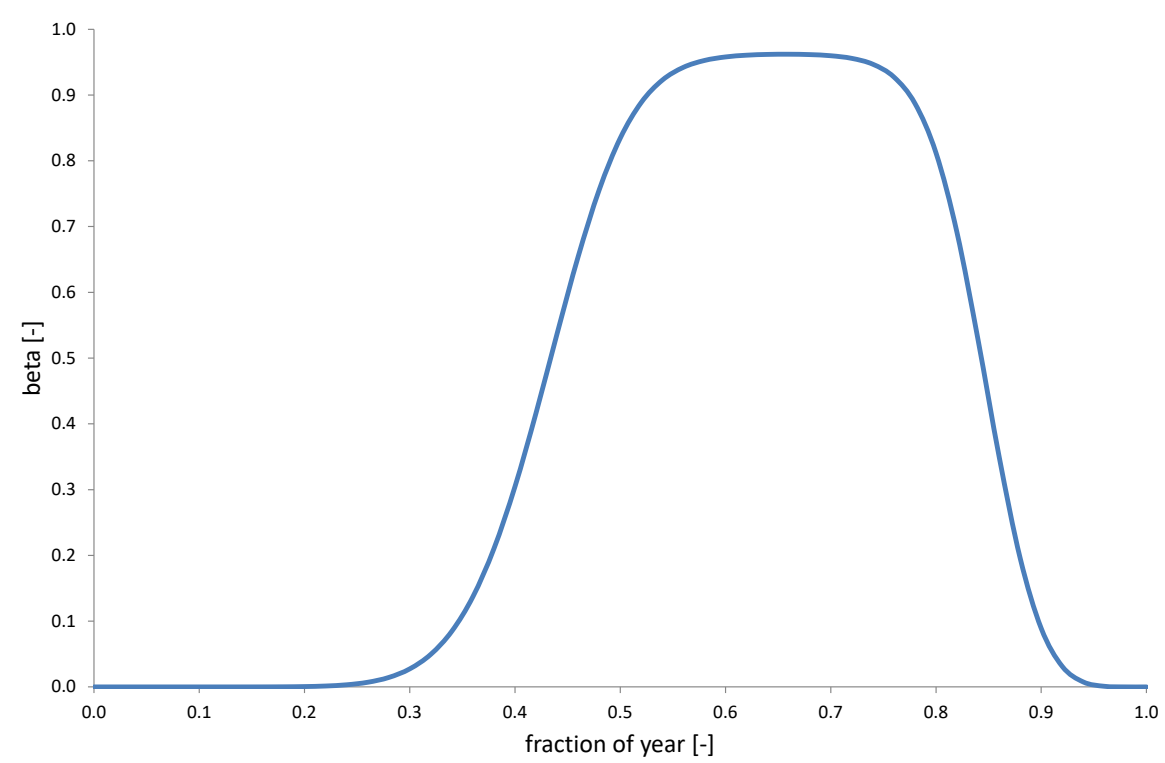

Figure A4.2 Canopy density factor, final approach, as a function of fraction of year (z), optimized for spray drift experiments. 


\section{Annex 5 Alternative interpretation of canopy density effects}

Typically, when the canopy density increases, downwind spray deposits decrease. In fact, a change of canopy density may affect both $\mathrm{q}_{1}$ and $\mathrm{q}_{2}$ in Eq.(3). For simplicity (and to provide the possibility to solve it analytically), let us assume that $c=1$ :

$$
Y=q_{1} e^{-q_{2} x}
$$

Assume the part of the spray cloud which deposits at distance $x$ originates from the sprayer in row $n_{1}$, that is, from an inward distance $x_{1}=n_{1} D_{\text {row. }}$ It has to travel distance $x_{1} F_{\text {dir }}$ in the direction of wind flow to reach the edge of the orchard. In a simplified assumption, an increase in canopy density may correspond to an increase in effective distance $x_{1}$ by a factor $1+\gamma$ (where $\gamma=0$ for bare trees and $\gamma>0$ for trees in leaves). The parameter $\gamma$ can be referred to as a 'fetch enhancement' factor. Travelled distance outside the orchard is $x \cdot F_{\text {dir }}$. Thus, the total distance to account for is $\left(x+(1+\gamma) x_{1}\right) \cdot F_{\text {dir }}$. Then, the contribution to drift deposits for this imaginary cloud element is given by:

$$
d Y=v_{1} e^{-v_{2}\left(x+x_{1}(1+\gamma)\right) F_{d i r} \cdot d x_{1}}
$$

where $v_{1}$ and $v_{2}$ are constants. The orchard has length $L=N D_{\text {row }}$, so the total deposits at location $x$ are given by the integral of $d Y$ over $x_{1}$, reaching from 0 to $L$ :

$$
Y(x)=\frac{v_{1}}{v_{2} F_{d i r}(1+\gamma)} \cdot e^{-v_{2} x F_{d i r}} \cdot\left(1-e^{-v_{2}(1+\gamma) F_{\text {dir }} D_{\text {row }} N}\right)
$$

Comparing this equation to Eq.(5.1) shows the following relationships:

$$
\begin{aligned}
& q_{1}=\frac{v_{1}}{v_{2} F_{d i r}(1+\gamma)} \cdot\left(1-e^{-v_{2}(1+\gamma) F_{d i r} D_{\text {row }} N}\right) \\
& q_{2}=v_{2} F_{d i r}
\end{aligned}
$$

Firstly, Eq.(5.4) corresponds to Eq.(9), provided that $p_{11 B} \cdot r_{11}=1, p_{12 B} r_{12}=v_{2}(1+\gamma) D_{\text {row }}$ and $r_{10} \sim v_{1} /\left(v_{2} F_{\text {dir }}(1+\gamma)\right)$. Apparently, Eq. (9) is a meaningful equation for $F_{N 1}$, as far its dependence on $N$ is concerned. However, when introducing the $\beta$ relationships of $r_{i j}$ (Eqs. (1.8), (1.14), (1.15)) the correspondence between the two approaches shows some differences:

$$
\begin{aligned}
& p_{11 B}\left(1+u_{11} \cdot \beta\right)=1 \\
& p_{12 B}\left(1+u_{12} \cdot \beta\right)=v_{2}(1+\gamma) D_{\text {row }} \\
& \frac{1}{1+u_{10} \cdot \beta} \sim \frac{1}{1+\gamma}
\end{aligned}
$$

While the first of these equations cannot be satisfied for varying canopy density, the second and third indicate roughly that $\beta$ is proportional to $\gamma$. This implies that the canopy density factor $\beta$ may be interpreted as a rough measure of the fetch enhancement factor $\gamma$.

The wind direction factor $\mathrm{F}_{\mathrm{dir}}$ in the denominator of Eq.(5.4) would reduce $\mathrm{q}_{1}$ for angles unequal to zero, which seems strange from a physical point of view. Additionally, Eq.(5.5) states that $\mathrm{q}_{2}$ depends only on wind direction, while it is independent of both orchard size (through $\mathrm{N}$ ) and canopy density (through $\gamma$ ). This, too, seems strange from a physical point of view. It is caused by the implicit 
assumption in Eq.(5.2) that, although the spray cloud dilutes while travelling a distance $\mathrm{x}_{1}$ through the orchard, its drop size spectrum remains the same (reflected by the parameters $\mathrm{v}_{1}$ and $\mathrm{v}_{2}$ that are assumed to be constant).

An improved approach would require a parameter $c<1$ (i.e. using Eq.(3) rather than Eq.(5.1)) and parameters $v_{1}$ and $v_{2}$ being functions of $x_{1}$. Unfortunately, such an approach could not be solved analytically. Then, a comparison to the empirical approach of Section 3.1.4 would be impossible.

Therefore, the main conclusion is that the above physical approach supports the empirical approach of Section 3.1.4 since (a) both approaches have a similar exponential relationship between $\mathrm{F}_{\mathrm{N} 1}$ and $\mathrm{N}$ (Eqs.(9) and (5.4)), and (b) the empirical factor $\beta$ (for canopy density) appears to be linked to the physical parameter $\gamma$ (for fetch enhancement due to canopy effects). 


\section{Annex 6 The Levenberg-Marquardt method}

Assume a set of $n$ measurements gives results $y_{i}$, for $i=1 . . n$. This set of measurements is fitted using the model $\mathrm{f}$ which is a function of $\mathrm{m}$ external parameters $\alpha_{1}$ through $\alpha_{\mathrm{m}}$. The performance of the model fit is quantified by the weighted sum of squares of observed differences:

$$
S=\sum_{i=1}^{n} w_{i}^{2}\left(y_{i}-f_{i}\left(\alpha_{1} \ldots \alpha_{m}\right)\right)^{2}
$$

where $w_{i}$ is a weight factor. The best-fitting set of parameters $\alpha_{1} \ldots \alpha_{m}$ gives the lowest sum of squares $\mathrm{S}$. This means, in that case the derivatives $\mathrm{dS} / \mathrm{d} \alpha_{\mathrm{j}}$ must be 0 for all $\mathrm{j}$ :

$$
2 \sum_{i=1}^{n} w_{i}^{2}\left(y_{i}-f_{i, o p t}\right) \cdot \frac{\partial f_{i}}{\partial \alpha_{j}}=0 \quad ; \forall j(=1 . . m)
$$

where $f_{i, o p t}$ is the estimate of $y_{i}$ corresponding to the optimum set of parameters. Near this optimum, $f_{i, o p t}$ can be approximated by the first order Taylor expansion of $f_{i}\left(\alpha_{j}\right)$ for the actual set of parameters:

$$
f_{i, o p t}=f_{i}\left(\alpha_{1} \ldots \alpha_{m}\right)+\sum_{k=1}^{m} \frac{\partial f_{i}}{\partial \alpha_{k}} d \alpha_{k}
$$

Now the optimization problem is converted into finding the solution for the set $d \alpha_{k}$ (for $k=1 . . m$ ), such that Eq.(6.2) is satisfied. Using the last equation, Eq.(6.2) turns into:

$$
\sum_{i=1}^{n} w_{i}^{2}\left(y_{i}-f_{i}\left(\alpha_{1} \ldots \alpha_{m}\right)-\sum_{k=1}^{m} \frac{\partial f_{i}}{\partial \alpha_{k}} d \alpha_{k}\right) \cdot \frac{\partial f_{i}}{\partial \alpha_{j}}=0 \quad ; \forall j
$$

Defining the residual deposit $r_{i}=y_{i}-f_{i}$, the above equation transfers into:

$$
\sum_{k=1}^{m} d \alpha_{k}\left(\sum_{i=1}^{n} w_{i}^{2} \frac{\partial f_{i}}{\partial \alpha_{j}} \cdot \frac{\partial f_{i}}{\partial \alpha_{k}}\right)=\sum_{i=1}^{n}\left(w_{i}^{2} r_{i} \cdot \frac{\partial f_{i}}{\partial \alpha_{j}}\right) \quad ; \forall j
$$

In matrix notation:

$$
\overline{\bar{M}} \cdot \bar{\alpha}=\overline{\bar{J}} \cdot \overline{\bar{W}} \cdot \bar{r}
$$

Where $\bar{r}$ is a vector with elements $r_{1} \ldots r_{n} ; \bar{\alpha}$ is the displacement vector to be determined, with elements $\mathrm{d} \alpha_{1} \ldots \mathrm{d} \alpha_{\mathrm{m}} . \overline{\bar{W}}$ is a square $\mathrm{n} \times \mathrm{n}$ matrix which is zero except for the diagonal elements $\mathrm{w}_{\mathrm{i}, \mathrm{i}}=\mathrm{w}_{\mathrm{i}}{ }^{2} . \overline{\bar{J}}$ is a $m \times n$ matrix whose elements are the derivatives of $f_{i}$ with respect to the parameters $a_{j}$ :

$$
J_{i, j}=\frac{\partial f_{i}}{\partial \alpha_{j}}
$$

Finally, $\overline{\bar{M}}$ is a square $\mathrm{m} \times \mathrm{m}$ matrix with elements

$$
M_{j, k}=\sum_{i=1}^{n} w_{i}^{2} \frac{\partial f_{i}}{\partial \alpha_{j}} \cdot \frac{\partial f_{i}}{\partial \alpha_{k}}
$$

In fact, $\overline{\bar{M}}$ equals:

$$
\overline{\bar{M}}=\overline{\bar{J}} \cdot \overline{\bar{W}} \cdot \overline{\bar{J}}^{T}
$$


Using the matrix notation, the solution vector $\bar{\alpha}$ is given by (replacing $\bar{R}=\overline{\bar{J}} \cdot \overline{\bar{W}} \cdot \bar{r}$ for simplicity):

$$
\bar{\alpha}=\overline{\bar{M}}^{-1} \cdot \overline{\bar{J}} \cdot \overline{\bar{W}} \cdot \bar{r}=\left(\overline{\bar{J}} \cdot \overline{\bar{W}} \cdot \overline{\bar{J}}^{T}\right)^{-1} \cdot \bar{R}
$$

which requires the matrix $M$ to be inverted. This method is known as the Gauss-Newton method (Bertsekas 1999). After determining the displacement vector $\bar{\alpha}$ the model solutions are improved; usually the method has to be repeated various times to reach an optimal solution.

The Levenberg-Marquardt (LM) method (Press et al. 2007) is a modification of the Gauss-Newton method to improve iteration stability by damping the successive steps:

$$
(\overline{\bar{M}}+\lambda \operatorname{diag}(\overline{\bar{M}})) \cdot \bar{\alpha}=\overline{\bar{R}}
$$

Where $\operatorname{diag}(\overline{\bar{M}})$ is a square matrix which is zero except for the diagonal elements of $\overline{\bar{M}}$. The positive factor $\lambda$ is called the Levenberg-Marquardt factor. For small $\lambda$ the system approaches the GaussNewton method, for large $\lambda$ the LM method corresponds to the 'gradient descent' method (Bertsekas 1999). Typically, iterations start with a small value of $\lambda$ and improvements are relatively large (i.e. the sum of squares $S$ decreases rapidly). Gradually, progress will slow down and iterations may become unstable. Then an increase in $\lambda$ can improve performance. In the end, when $\lambda$ becomes very large and no progress is observed, the LM iteration method is stopped. 


\section{Annex 7 The Pattern-Search method}

Assume a set of $n$ measurements gives results $y_{i}$, for $i=1 . . n$. This set of measurements is fitted using the model $f$ which is a function of $m$ external parameters $a_{1}$ through $a_{m}$. The performance of the model fit is quantified by the weighted sum of squares of observed differences (Eq.(6.1) in Annex 6). The 'pattern search' method (PS) (Hooke and Jeeves 1961) is a simple technique that will always lead to a result, though convergence may be rather slow. Each of the $\mathrm{m}$ factors to be optimized is changed twice by adding and subtracting a small value, while all other factors remain as they are. Figure A7.1 shows a schematic representation of this process for two parameters $\left(a_{1}\right.$ and $\left.a_{2}\right)$. The current situation (A) is changed to positions 1 through 4 , representing a small change in either $a_{1}$ or $a_{2}$. For each position the sum-of-squares is determined and compared to that for the current situation. If one of these four situations has a lower sum-of-squares, then this case represents a better curve-fit and it will be used as the 'current' position in the next iteration step. If position A remains the best option, then the step sizes for $a_{1}$ and $a_{2}$ are halved and the process is repeated. These processes are repeated until the step sizes changing $a_{1}$ and $a_{2}$ are sufficiently small (compared to a predefined value). Thus, after a finite number of steps, this process leads to a local optimum of the factors.

The points A and 1 through 4 form a kind of star; therefore this PS method is called 'star-wise', contrary to a 'block-wise' approach where points 5 through 8 (representing situations were both $a_{1}$ and $a_{2}$ are changed) are investigated as well. The block-wise approach converges faster than the star-wise approach (when considering the number of iteration steps needed), yet requires more computation time. Typically, with $\mathrm{m}$ parameters the star-wise approach required $2 m+1$ situations to be evaluated (including the current position), whereas the block-wise approach requires $3^{\mathrm{m}}$ situations to evaluate. Clearly, when $\mathrm{m}$ is relatively large, the number of computations in block-wise approach increases significantly. The next paragraph indicates that often the star-wise approach is computationally favourable.

Assume one of the corners (say point 5) is the current optimum in the block-wise approach. This point can be reached in one step consisting of $3^{\mathrm{m}}$ computations. In the star-wise approach, point 5 can only be reached by first finding point 1 (say) as local optimum, shifting $A$ to point 1 and then repeated the search to find point 5 (which is a point of type 2 in the shifted layout). In general, with m parameters, reaching the corner of a block in the start-wise approach takes $m$ steps of $2 m+1$ computations, so it requires a total of $2 m^{2}+m$ computations. So for $m \geq 3$ the block-wise approach requires more computations to reach the corner than the star-wise approach, which makes the star-wise approach the favourable method. Note that a keeping track of positions in a sophisticated way may reduce computations. For instance, if situation 1 is better than the situation $A$, then situation 1 is the new central position (the new ' $A$ '), while the old ' $A$ ' is the new ' 3 ' and would not require the sum-of-squares to be computed again. Such a computational reduction is applicable both to star-wise and block-wise methods. It appears to be very elaborate to analytically compare the number of computations required in a series of block-wise steps and a corresponding series of star-wise steps, but again it turns out that for $\mathrm{m} \geq 3$ the star-wise approach is the more computational effective.

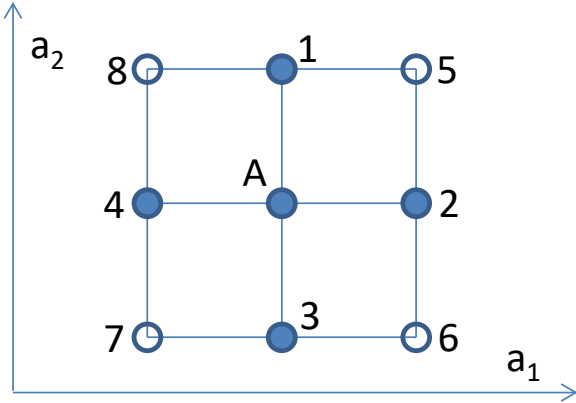

Figure A7.1 Schematic representation of Pattern Search method with star-wise and block-wise approach in a system of two parameters $(m=2)$. 


\section{Annex 8 Wind speed stratification}

For a useful database of experimental settings and results, all data should be stratified. For instance, for all experiments wind speeds should be given at the same height. Since occasionally wind speeds were measured at different heights, these data need modification to estimate their corresponding inorchard values at a height of $4 \mathrm{~m}$ above ground level.

Assuming a logarithmic wind speed profile with height, in principle only one measurement is required to estimate wind speeds at each arbitrary height. The logarithmic wind speed profile takes the following conventional form (Monteith and Unsworth 1990):

$$
w(z)=\frac{u_{*}}{k} \ln \left(\frac{z-d_{0}}{z_{0}}\right)
$$

where $w(z)$ is average wind speed at height $z, u_{*}$ is the friction velocity, $k$ is Von Karman's constant, $\mathrm{d}_{0}$ is the zero-plane displacement height, and $z_{0}$ is roughness length. The last two depend on the height of the crop, or in this case the tree height. Conventionally, displacement height and roughness length are assumed proportional with tree height:

$$
\begin{aligned}
& d_{0}=\alpha_{d} h_{0} \\
& z_{0}=\alpha_{z} h_{0}
\end{aligned}
$$

Where $h_{0}$ is average height of the trees in the orchard. Typically, $\alpha_{d}=0.7$ and $\alpha_{z}=0.1$.

If tree height is known and wind speed $w_{1}$ is measured at some height $z_{1}$, then wind speed $w_{2}$ at a required height $z_{2}$ can be estimated from the equations above:

$$
\frac{w_{2}}{w_{1}}=\frac{\frac{u_{*}}{k} \ln \left(\frac{z_{2}-d_{0}}{z_{0}}\right)}{\frac{u_{*}}{k} \ln \left(\frac{z_{1}-d_{0}}{z_{0}}\right)}
$$

This equation can be simplified easily, resulting in:

$$
w_{2}=w_{1} \cdot \frac{\ln \left(z_{2} / h_{0}-\alpha_{d}\right)-\ln \left(\alpha_{z}\right)}{\ln \left(z_{1} / h_{0}-\alpha_{d}\right)-\ln \left(\alpha_{z}\right)}
$$

The spray drift model for fruit orchards is based on wind speed values at $z_{1}=4 \mathrm{~m}$ height while in meteorology wind speeds are measured at $z_{2}=10 \mathrm{~m}$. Average tree height is assumed $h_{0}=2.25 \mathrm{~m}$ (see also Section 2.1). With these heights, the ratio of wind speeds at $10 \mathrm{~m}$ and $4 \mathrm{~m}$ is $\mathrm{w}_{2} / \mathrm{w}_{1}=1.524$ or inversely $\mathrm{w}_{1} / \mathrm{w}_{2}=0.656$. If in good agricultural practice sprays are not applied at wind speeds above $5 \mathrm{~m} / \mathrm{s}$ measured at $4 \mathrm{~m}$ height, then the corresponding wind speed limit at $10 \mathrm{~m}$ height is $7.6 \mathrm{~m} / \mathrm{s}$. However, this approach disregards the fact that weather stations are usually located in a field of cut grass. Wind speeds at $10 \mathrm{~m}$ height may not be the same in a field of cut grass or in a fruit tree orchard, although differences are probably small. 


\section{Annex 9 List of model constants}

The SPEXUS model contains a lot of constants whose values were determined in the curve-fitting process. Table A9.1 shows these constants, their values and their connection to quantities in various equations. The parameters connected to orchard size are derived in Annex 1. A summary of resulting constants in given in Table A9.2.

Table A9.1 Factors optimized and their final values.

\begin{tabular}{|c|c|c|c|c|}
\hline Submodel & Factor & Sub-factor & Value & Eqs. \\
\hline \multirow[t]{4}{*}{ Main factors } & $\mathrm{q}_{1}$ & $\mathrm{q}_{10}$ & 0.9952634 & \multirow[t]{2}{*}{$(3),(4)$} \\
\hline & $\mathrm{q}_{2}$ & $\mathrm{q}_{20}$ & 0.3498658 & \\
\hline & \multirow[t]{2}{*}{ c } & $\mathrm{a}$ & 0.5042081 & \multirow[t]{2}{*}{$(3),(13)$} \\
\hline & & $\mathrm{m}$ & 0.6334076 & \\
\hline \multirow[t]{4}{*}{ Wind speed factor } & \multirow[t]{2}{*}{$\mathrm{F}_{\mathrm{w} 1}$} & $a_{11}$ & 0.2543382 & \multirow[t]{4}{*}{$(4),(5)$} \\
\hline & & $a_{21}$ & 0.0449953 & \\
\hline & \multirow[t]{2}{*}{$\mathrm{F}_{\mathrm{w} 2}$} & $a_{12}$ & 0.2439259 & \\
\hline & & $a_{22}$ & -0.0281577 & \\
\hline \multirow[t]{5}{*}{ Canopy density factor } & \multirow[t]{5}{*}{$\beta$} & $a_{0}$ & 1.3863454 & \multirow[t]{5}{*}{$(14),(15)$} \\
\hline & & $a_{1}$ & 1.4627357 & \\
\hline & & $a_{2}$ & -0.4627521 & \\
\hline & & $a_{3}$ & 0.9660170 & \\
\hline & & $a_{4}$ & 5.2203472 & \\
\hline \multirow[t]{4}{*}{ Temperature factor } & \multirow[t]{2}{*}{$\mathrm{F}_{\mathrm{T} 1}$} & $b_{11}$ & 0.0305028 & \multirow[t]{4}{*}{$(4),(6)$} \\
\hline & & $b_{21}$ & -0.0048358 & \\
\hline & \multirow[t]{2}{*}{$\mathrm{F}_{\mathrm{T} 2}$} & $b_{12}$ & 0.0347715 & \\
\hline & & $b_{22}$ & -0.0022583 & \\
\hline Sprayer fan speed & $F_{f}$ & $f_{f s}$ & 0.7212178 & $(4),(16)$ \\
\hline
\end{tabular}

Table A9.2 Final parameters to be used in $F_{N 1}$ and $F_{N 2}$ in the spray drift model (see Annex 1 ).

\begin{tabular}{|c|c|c|c|c|}
\hline & \multicolumn{2}{|c|}{$\mathrm{F}_{\mathrm{N} 1}$} & \multicolumn{2}{|c|}{$\mathrm{F}_{\mathrm{N} 2}$} \\
\hline & parameter & value & parameter & value \\
\hline \multirow{2}{*}{$\begin{array}{c}\text { p-constants } \\
\text { (dormant trees) }\end{array}$} & $\mathrm{p}_{11 \mathrm{D}}$ & 0.8295 & $\mathrm{p}_{21 \mathrm{D}}$ & 0.9450 \\
\hline & $\mathrm{p}_{12 \mathrm{D}}$ & 0.5985 & $\mathrm{p}_{22 \mathrm{D}}$ & 1.2000 \\
\hline \multirow[t]{3}{*}{$\beta$ rate constants } & $\mathrm{u}_{10}$ & 0.6054 & $\mathrm{u}_{20}$ & 0.5034 \\
\hline & $\mathrm{u}_{11}$ & 0.8799 & $\mathrm{u}_{21}$ & 0.6571 \\
\hline & $\mathrm{u}_{12}$ & 3.4314 & $\mathrm{u}_{22}$ & 1.0988 \\
\hline
\end{tabular}




\section{Annex $10 \mathrm{BBCH}$ codes for pome fruit}

The following table identifies $\mathrm{BBCH}$ codes to growth stages for pome fruit; apple (Malus domestica Borkh.) and pear (Pyrus communis L.) (BBCH 2001).

Table A10.1 Factors optimized and their final values.

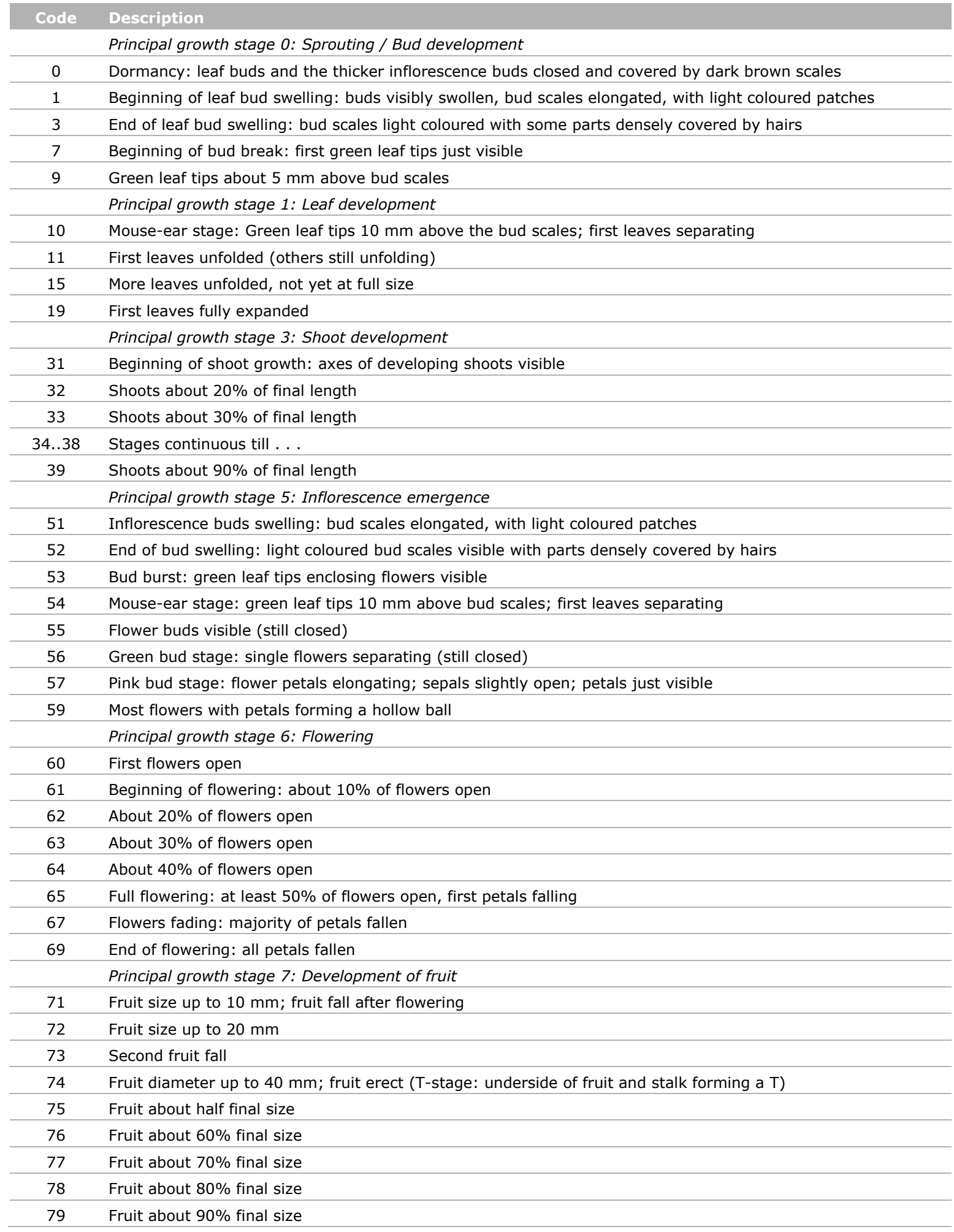




\section{Code Description}

Principal growth stage 8: Maturity of fruit and seed

81 Beginning of ripening: first appearance of cultivar-specific colour

85 Advanced ripening: increase in intensity of cultivar-specific colour

$87 \quad$ Fruit ripe for picking

89 Fruit ripe for consumption: fruit have typical taste and firmness

Principal growth stage 9: Senescence, beginning of dormancy

91 Shoot growth completed; terminal bud developed; foliage still fully green

92 Leaves begin to discolour

93 Beginning of leaf fall

$9550 \%$ of leaves discoloured

97 All leaves fallen

99 Harvested product 
Corresponding address for this report:

P.O. Box 16

6700 AA Wageningen

The Netherlands

T +31 (0)317480700

www.wur.eu/plant-research

Report WPR-566
The mission of Wageningen University and Research is "To explore the potential of nature to improve the quality of life". Under the banner Wageningen University \& Research, Wageningen University and the specialised research institutes of the Wageningen Research Foundation have joined forces in contributing to finding solutions to important questions in the domain of healthy food and living environment. With its roughly 30 branches, 5,000 employees and 10,000 students, Wageningen University \& Research is one of the leading organisations in its domain. The unique Wageningen approach lies in its integrated approach to issues and the collaboration between different disciplines. 



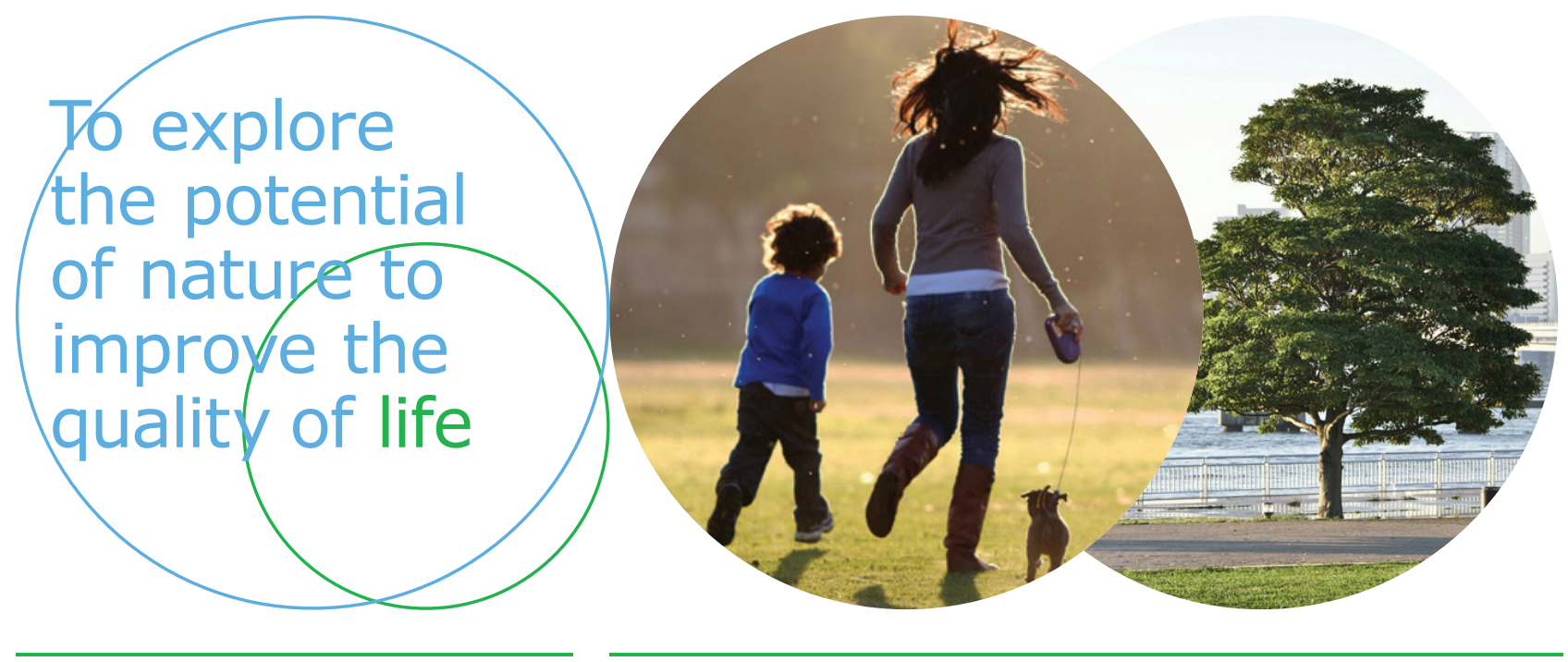

Corresponding address for this report:

P.O. Box 16

6700 AA Wageningen

The Netherlands

T +31 (0)317480700

www.wur.eu/plant-research

Report 566
The mission of Wageningen University and Research is "To explore the potential of nature to improve the quality of life". Under the banner Wageningen University \& Research, Wageningen University and the specialised research institutes of the Wageningen Research Foundation have joined forces in contributing to inding solutions to important questions in the domain of healthy food and living environment. With its roughly 30 branches, 5,000 employees and 10,000 students, Wageningen University \& Research is one of the leading organisations in its domain. The unique Wageningen approach lies in its integrated approach to issues and the collaboration between different disciplines. 